Portland State University

PDXScholar

Fall 1-16-2018

\title{
Stress Analysis of Embedded Devices Under Thermal Cycling
}

Sadhana Radhakrishnan

Portland State University

Follow this and additional works at: https://pdxscholar.library.pdx.edu/open_access_etds

Part of the Mechanical Engineering Commons

Let us know how access to this document benefits you.

\section{Recommended Citation}

Radhakrishnan, Sadhana, "Stress Analysis of Embedded Devices Under Thermal Cycling" (2018). Dissertations and Theses. Paper 4075.

https://doi.org/10.15760/etd.5959

This Thesis is brought to you for free and open access. It has been accepted for inclusion in Dissertations and Theses by an authorized administrator of PDXScholar. Please contact us if we can make this document more accessible: pdxscholar@pdx.edu. 
Stress Analysis of Embedded Devices under Thermal Cycling

\title{
by
}

Sadhana Radhakrishnan A thesis submitted in partial fulfillment of the
requirements for the degree of

\author{
Master of Science \\ in \\ Mechanical Engineering
}

Thesis Committee:

Sung Yi, Chair

Faryar Etesami

Chien Wern

\section{Portland State University}

2017 
(C) 2017 Sadhana Radhakrishnan 


\begin{abstract}
Embedded active and passive devices has been increasingly used by in order to integrate more functions inside the same or smaller size device and to meet the need for better electrical performance of the component assemblies.

Solder joints have been used in the electronic industry as both structural and electrical interconnections between electronic packages and printed circuit boards (PCB). When solder joints are under thermal cyclic loading, mismatch in coefficients of thermal expansion (CTE) between the printed circuit boards and the solder balls creates thermal strains and stresses on the joints, which may finally result in cracking. Consequently, the mechanical interconnection is lost, leading to electrical failures which in turn causes malfunction of the circuit or whole system.
\end{abstract}

When a die is embedded into a substrate, Young's modulus of the die is larger than one of the core of the substrate and the CTEs of the die is smaller than those of the substrate. As a result, mismatch in coefficients of thermal expansions (CTE) between the substrate with the embedded device and the solder balls may increase.

In the present study, finite element method (FEM) is employed to find out the stress and strain distribution of ball grid array(BGA) solders under thermal cycling. The ANAND model for viscoplasticity is employed for this purpose. 


\section{Acknowledgements}

I would like to thank my thesis advisor Dr.Sung Yi for his guidance and support throughout the course of this thesis. I would also like to thank my thesis committee members Dr. Dave Turcic, Dr. Faryar Etesami and Dr. Chien Wern for the valuable inputs and suggestions.

I am also thankful to Dr.Seunghyun Cho for his timely help and support provided during the initial stages of my research. I am also grateful to Songlong Wu and Chinh Wu for their help. Last but not the least, I am extremely thankful to my husband Rajesh and parents for constantly motivating me and encouraging me to always do my 


\section{Table of Contents}

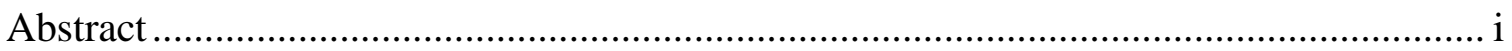

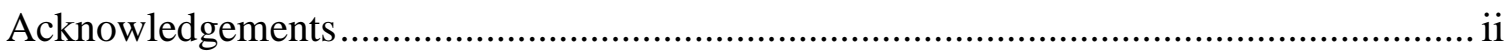

List of Tables................................................................................................. iv

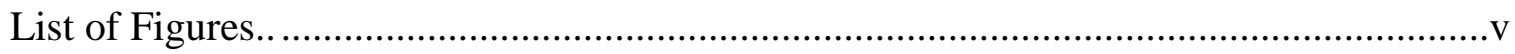

Chapter 1. Introduction ................................................................................... 1

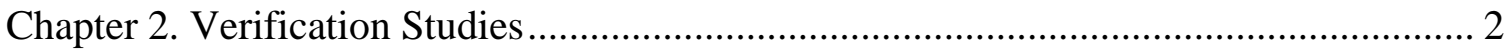

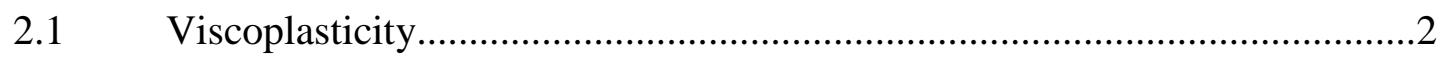

Chapter 3. Grid Array Packages under Thermal Cycling ............................................ 4

3.1 Finite Element Model ................................................................................... 4

3.1.1. Geometries and Mechanical Properties .............................................

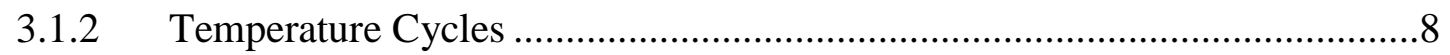

3.1.3 Finite Element Modelling ...................................................................

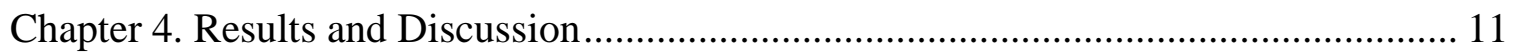

4.1 Single die model with varying thickness .....................................................11

4.2 Results of two dies in the Molding Compound: ...............................................24

4.3 Results of one die in molding compound and one die in substrate: ....................37

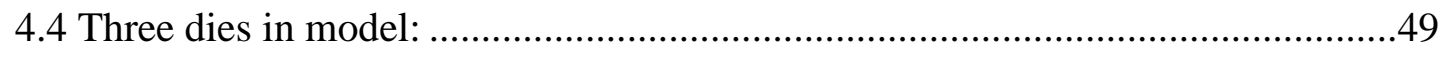

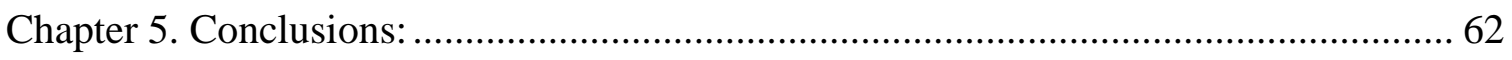

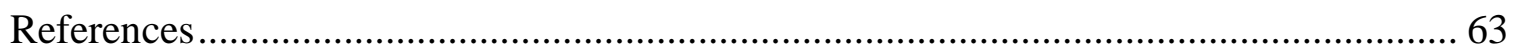




\section{List of Tables}

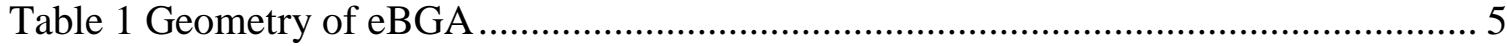

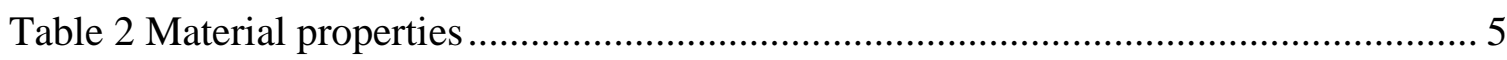

Table 3 ANAND model parameters ........................................................................... 7 


\section{List of Figures}

Figure 1 FEM model for verification studies...................................................... 2

Figure 2 Creep strain and shear strain viscoplastic results ........................................ 3

Figure 3 Embedded device geometry used for analysis.......................................... 4

Figure 4 Temperature profile used for simulation .................................................. 9

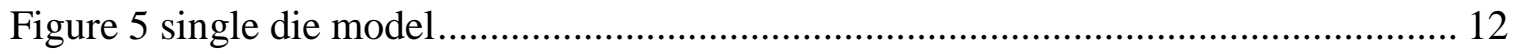

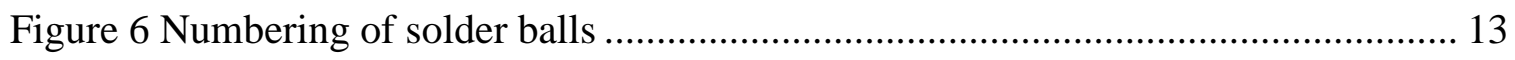

Figure 7 Variation of von Mises stress (Smises) during thermal cycling - .12 mm

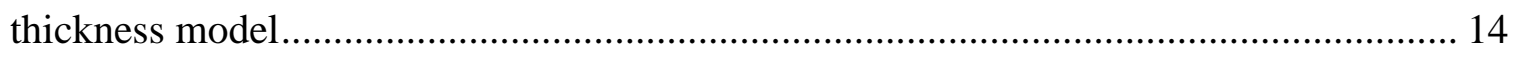

Figure 8 Variation of von mises stress diagonal solder model $-.12 \mathrm{~mm}$ model.............. 15

Figure 9 Variation of creep strain (CEEQ) during thermal cycling - .12 mm thickness

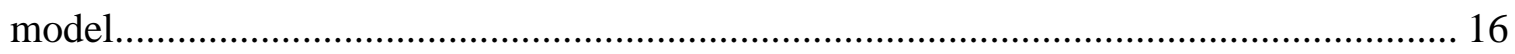

Figure 10 Variation of von Mises stress (Smises) during thermal cycling - .15 mm

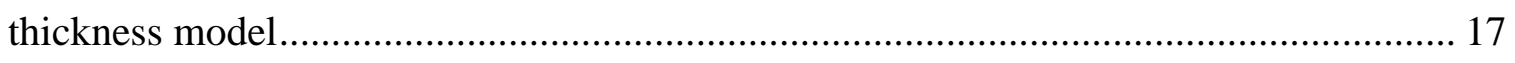

Figure 11 Variation of von mises stress diagonal solder model - .15 mm model............ 18

Figure 12 Variation of creep strain (CEEQ) during thermal cycling - .15 mm thickness

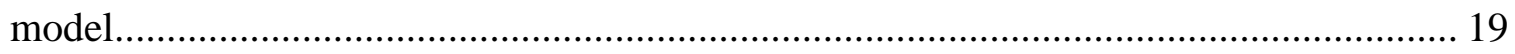

Figure 13 Variation of von Mises stress (Smises) during thermal cycling - .18 mm

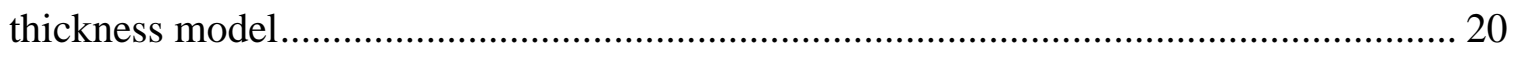

Figure 14 Variation of von mises stress diagonal solder model - .18 mm model............. 21 
Figure 15 Variation of creep strain (CEEQ) during thermal cycling - $.18 \mathrm{~mm}$ thickness

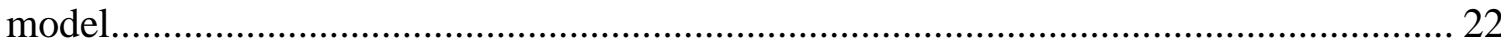

Figure 16 von mises stress comparison - single die with varying thickness .................. 23

Figure 17 creep strain comparison - single die with varying thickness ........................ 24

Figure 18 Two dies in molding compound model ................................................. 25

Figure 19 Variation of von Mises stress (Smises) during thermal cycling - .12 mm

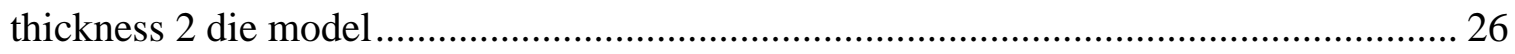

Figure 20 Variation von mises stress in the diagonal solder balls- .12 mm thickness ..... 27 Figure 21 Variation of creep strain (CEEQ) during thermal cycling - .12 mm thickness 2

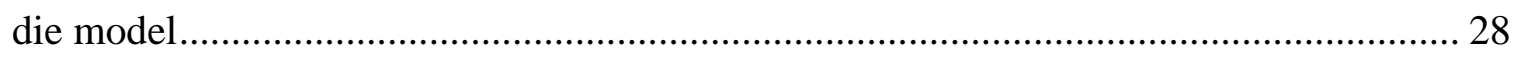

Figure 22 Variation of von Mises stress (Smises) during thermal cycling - .15 mm

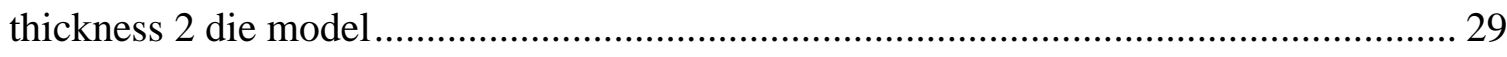

Figure 23 Variation of von Mises stress in the diagonal solder balls - .15 mm thickness 30 Figure 24 Variation of creep strain (CEEQ) during thermal cycling - .15 mm thickness 2

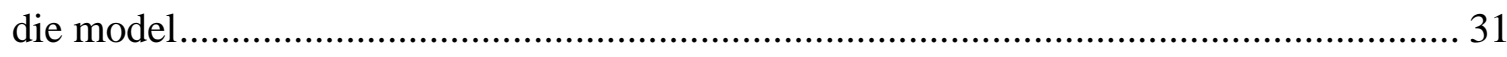

Figure 25 Variation of von Mises stress (Smises) during thermal cycling - .18 mm

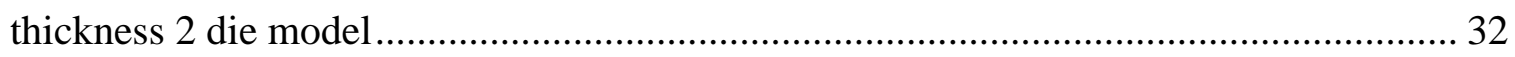

Figure 26 Variation of von Mises stress in the diagonal solder balls - .18 mm thickness33 Figure 27 Variation of creep strain (CEEQ) during thermal cycling - .18 mm thickness 2

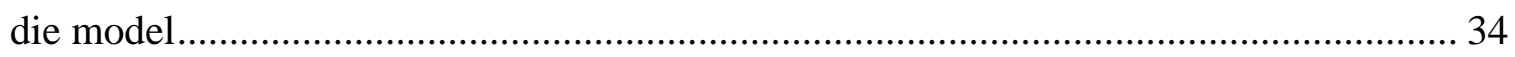

Figure 28 Bar plot comparison of von mises stress for the 2 die model........................ 35

Figure 29 Bar plot comparison of von mises stress for the 1 and 2 die model ................. 36

Figure 30 Two die molding compound - one die in MC and one die in substrate........... 37 
Figure 31 Variation of von Mises stress (Smises) during thermal cycling - .05 mm

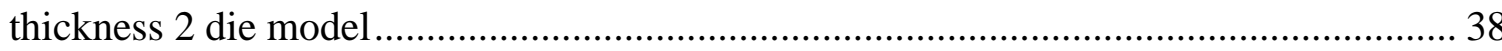

Figure 32 Variation of von Mises stress in the diagonal solder balls - .05 mm thickness 2 die model. 39 Figure 33 Variation of creep strain (CEEQ) during thermal cycling - .05 mm thickness 2 die model. 40 Figure 34 Variation of von Mises stress (Smises) during thermal cycling - .075 mm thickness 2 die model 41 Figure 35 Variation of von Mises stress in the diagonal solder balls - $.075 \mathrm{~mm}$ thickness 2 die model. 42 Figure 36 Variation of creep strain (CEEQ) during thermal cycling - .075 mm thickness 2 die model. 43

Figure 37 Variation of von Mises stress (Smises) during thermal cycling - .1 mm thickness 2 die model 44 Figure 38 Variation of von Mises stress in the diagonal solder balls - .01 mm thickness 2 die model. 45 Figure 39 Variation of creep strain (CEEQ) during thermal cycling - .1 mm thickness 2

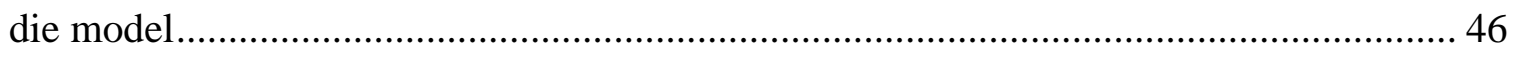
Figure 40 Bar plot comparison of von mises stress for the 2 die (substrate) model........ 47 Figure 41 Bar plot comparison of creep strain for the 2 die (substrate) model ............... 48 Figure 42 Two dies in molding compound and one die in substrate model 49 Figure 43 Variation of von Mises stress (Smises) during thermal cycling - .05 mm thickness 3 die model 50 
Figure 44 Variation of von Mises stress in the diagonal solder balls - .05 mm thickness 3

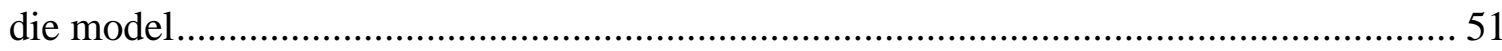

Figure 45 Variation of creep strain (CEEQ) during thermal cycling - .05 mm thickness 3

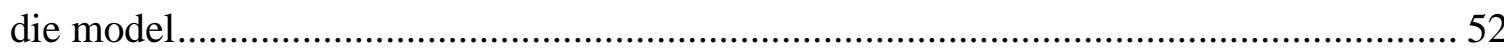

Figure 46 Variation of von Mises stress (Smises) during thermal cycling - .075 mm

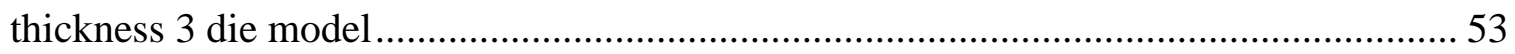

Figure 47 Variation of von Mises stress in the diagonal solder balls - .075 $\mathrm{mm}$ thickness

Figure 48 Variation of creep strain (CEEQ) during thermal cycling - .075 mm thickness 3

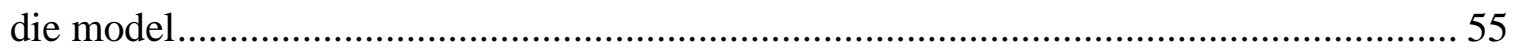

Figure 49 Variation of von Mises stress (Smises) during thermal cycling - .1 mm

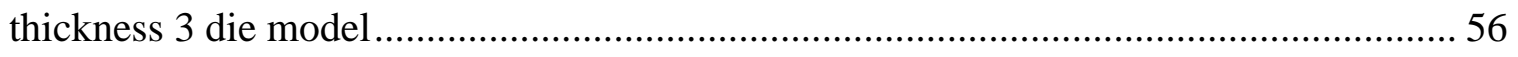

Figure 50 Variation of von Mises stress in the diagonal solder balls - .1 mm thickness 2

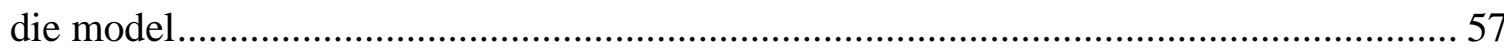

Figure 51 Variation of creep strain (CEEQ) during thermal cycling - .1 mm thickness 3

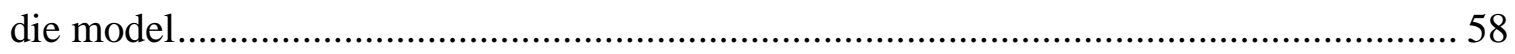

Figure 52 Bar plot comparison of von mises for the 3 die model............................... 59

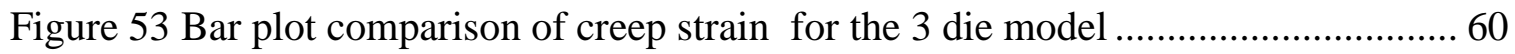

Figure 54 Bar plot comparison of creep strain for the 3 die model ............................ 61 


\section{Chapter 1. Introduction}

Solder joints provide structural and electrical interconnections between electronic packages and printed circuit boards (PCB). Due to mismatch in coefficients of thermal expansion (CTE) between the printed circuit boards and the solder balls, when the IC packages are subjected to thermal cycling thermal strains and stresses occur at the joints , which may finally result in cracking (Zhong and Yi, 1998; Zhong and Yi, 1999; Zhong et al., 2002). Due to this the mechanical interconnection is lost, leading to electrical failures which in turn causes malfunction of the circuit. Such failure mechanism is called thermal fatigue which plays a major role in electronic package reliability prediction. Therefore it is very important to predict thermal fatigue in order to assess the product reliability as it saves time and cost product development and optimization.

In the present study, the stress in solder joints of chip scale packages (CSP) with embedded dies under thermal cycling conditions is evaluated using the finite element method. The viscoplastic hyperbolic sine ANAND model for solders is employed for this analysis. 


\section{Chapter 2. Verification Studies}

Verification studies for viscoplasticty using ANAND creep model is done to check the accuracy of the result obtained by using the ABAQUS hyperbolic sine model

\subsection{Viscoplasticity}

A cubical structure with a dimension of $1 \times 1 \times 1(\mathrm{~m})$ is considered. A surface traction of $1000 \mathrm{~Pa}$ is applied on the top surface in the $\mathrm{x}$-direction. The top surface has all the degrees of freedom restricted except the x-direction whereas the bottom surface is completely fixed.
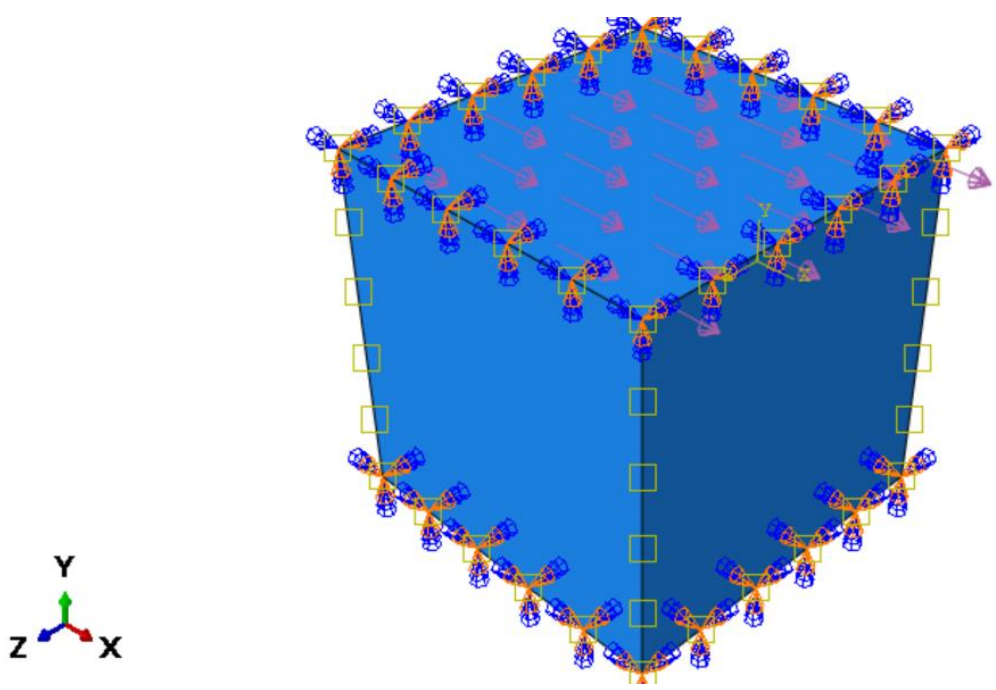

Figure 1 FEM model for verification studies.

Shear strain in this case is given by

$$
\gamma_{12}=\bar{\gamma}=\tau / G
$$


Where $\tau=$ surface tracction on the top surface and $G=$

Shear modulus of elasticity.

The analytical result for the shear strain is $7.05268 \mathrm{e}-05$ with $\mathrm{G}=14179 \mathrm{Mpa}$. The finite element result of shear strain (E12) obtained using the hyperbolic sine model for CREEP is approximately $7.2 \mathrm{e}-05$. The analytical results agree quite well to finite element one with the hyperbolic sine ANAND model.

Equivalent creep strain rate is given by the hyperbolic sine version of the ANAND model as

$$
\begin{aligned}
\dot{\gamma} & =A(\sinh (\beta \tau))^{n} * e^{\left(-\frac{Q}{R T}\right)}=3484 *(\sinh (0.15 * 1))^{5} * e^{\left(-\frac{75624}{8.314 * 293}\right)} \\
& =1.49456 \mathrm{E}-12 \mathrm{~s}-1 \text { at } 100 \mathrm{~s}
\end{aligned}
$$
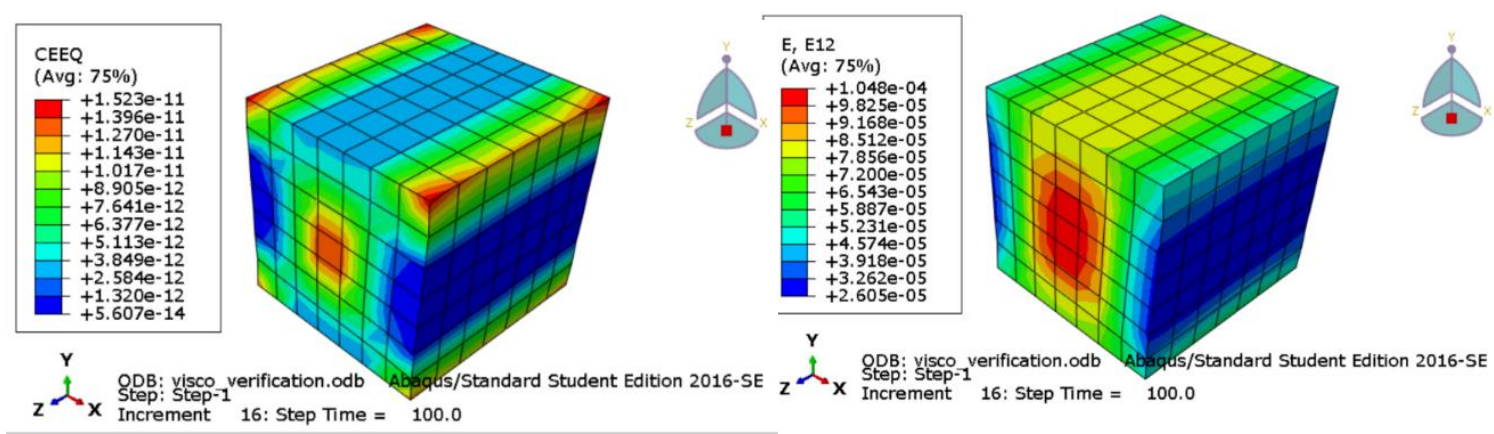

Figure 2 Creep strain and shear strain viscoplastic results 


\section{Chapter 3. Grid Array Packages under Thermal Cycling}

The viscoplastic behaviors of solders are considered for the eBGA with an embedded chip to study the deformation and stresses during thermal cycle loading. The finite element formulation based on the viscoplastic constitutive relationship presented in the previous chapter is employed to analyze thermo-mechanical behaviors of solders.

\subsection{Finite Element Model}

\subsubsection{Geometries and Mechanical Properties}

The geometry considered for this study is the eBGA as shown below.

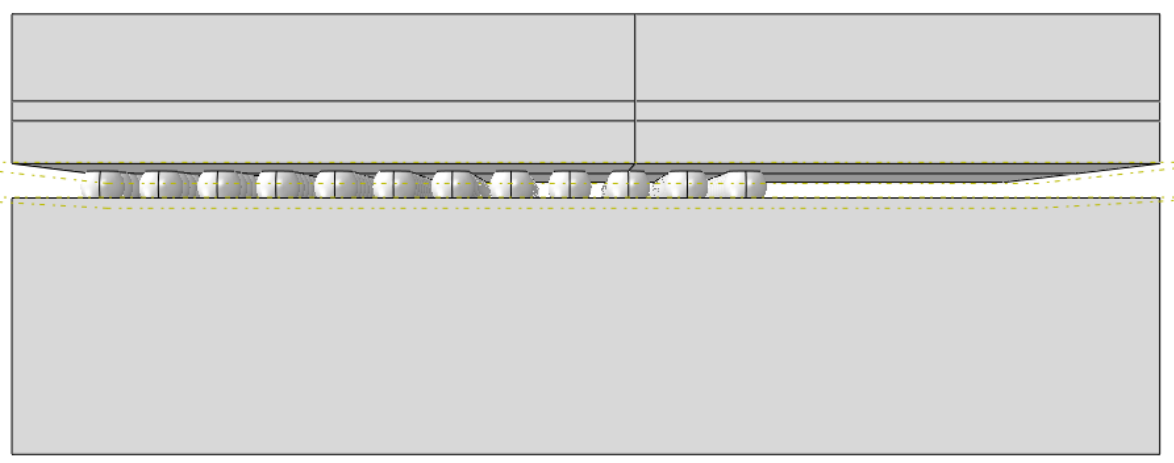

Figure 3 Embedded device geometry used for analysis

One fourth of the model is constructed due to geometric symmetry about the vertical axis.

An 8-node linear brick element with reduced integration (C3D8R in ABAQUS) is used.

The geometry and material properties of the eBGA used for the present study are given in Tables 1 and 2, respectively. Substrate and PCB are elastic and orthotropic because of their laminar structures. The mechanical properties in the $\mathrm{x}$ and $\mathrm{z}$-directions are identical, 
but are different from those in the y-direction. The remaining materials are assumed to be elastic and isotropic (Morris et al., 2002; Yi et al., 2005).

Table 1 Geometry of eBGA

\begin{tabular}{|c|c|c|c|c|}
\hline Single die & Thickness & Length & Width & \\
\hline $\begin{array}{l}\text { Molding } \\
\text { Compound }\end{array}$ & $0.65 \mathrm{~mm}$ & $7 \mathrm{~mm}$ & $7 \mathrm{~mm}$ & \\
\hline Die & $0.12 \mathrm{~mm}$ & $3.8 \mathrm{~mm}$ & $3.8 \mathrm{~mm}$ & \\
\hline $\begin{array}{c}\text { Layers } \\
\text { (Substrate) }\end{array}$ & $0.26 \mathrm{~mm}$ & $7 \mathrm{~mm}$ & $7 \mathrm{~mm}$ & \\
\hline Sold balls & $0.21 \mathrm{~mm}$ & $0.3 \mathrm{~mm}$ & $0.3 \mathrm{~mm}$ & $\begin{array}{c}\text { Pitch }=0.4 \\
\mathrm{~mm}\end{array}$ \\
\hline PCB & $1.56 \mathrm{~mm}$ & $7 \mathrm{~mm}$ & $7 \mathrm{~mm}$ & \\
\hline
\end{tabular}

Table 2 Material properties

\begin{tabular}{|c|c|c|c|c|}
\hline Material & $\begin{array}{l}\text { Young's } \\
\underline{\text { modulus }} \\
(\mathrm{MPa})\end{array}$ & $\begin{array}{c}\text { Poisson's } \\
\text { ratio }\end{array}$ & $\begin{array}{c}\text { CTE } \\
(\mathrm{ppm} / \mathrm{K})\end{array}$ & $\begin{array}{l}\text { Additional } \\
\text { information }\end{array}$ \\
\hline $\begin{array}{c}\text { Mold } \\
\text { compound }\end{array}$ & 15000 & 0.3 & 16.0 & \\
\hline Substrate & $\begin{array}{c}x, z=26000 \\
y=78600\end{array}$ & $\begin{array}{c}\mathrm{xz}=0.11 \\
\mathrm{xy}, \\
\mathrm{zy}=0.3\end{array}$ & $\begin{array}{c}x, z=15 \\
y=57\end{array}$ & $\begin{array}{c}\mathrm{Gxy}=8250 \\
(\mathrm{MPa}) \\
\mathrm{Gyz}=8250(\mathrm{MPa})\end{array}$ \\
\hline
\end{tabular}




\begin{tabular}{|c|c|c|c|c|}
\hline & & & & $\begin{array}{c}\mathrm{G} \\
\mathrm{xz}=11712(\mathrm{MPa})\end{array}$ \\
\hline \multirow{3}{*}{$\begin{array}{c}\text { Solder ball } \\
\text { Sn3Ag0.5C } \\
\mathrm{u} \\
\text { (SAC305) }\end{array}$} & 50439 & \multirow{3}{*}{0.36} & $2.42 \mathrm{E}-5$ & $218 \mathrm{~K}$ \\
\hline & 41419 & & $2.56 \mathrm{E}-5$ & $300 \mathrm{~K}$ \\
\hline & 30639 & & $2.79 \mathrm{E}-5$ & $398 \mathrm{~K}$ \\
\hline PCB & $\begin{aligned} x, z & =18000 \\
y & =7380\end{aligned}$ & $\begin{array}{c}x z=0.11 \\
x y,\end{array}$ & $\begin{array}{c}x, z=14.5 \\
y=67.2\end{array}$ & $\begin{array}{c}\mathrm{Gxy}=5535(\mathrm{MPa} \\
)\end{array}$ \\
\hline \multirow{6}{*}{ Silicon Die } & 1.305E5 & $\begin{array}{l}7 \mathrm{v}-\cap 30 \\
0.2785\end{array}$ & $2.78343 \mathrm{E}-6$ & $\begin{array}{c}\text { Gviz-5525(M(Ma) } \\
200 \mathrm{~K}\end{array}$ \\
\hline & & & $3.0004 \mathrm{E}-6$ & $250 \mathrm{~K}$ \\
\hline & & & $3.14811 \mathrm{E}-6$ & $293 \mathrm{~K}$ \\
\hline & $1.298 \mathrm{E} 5$ & 0.2782 & $3.16888 \mathrm{E}-6$ & $300 \mathrm{~K}$ \\
\hline & & & $3.30238 \mathrm{E}-6$ & $350 \mathrm{~K}$ \\
\hline & $1.298 \mathrm{E} 5$ & 0.278 & $3.40867 \mathrm{E}-6$ & $400 \mathrm{~K}$ \\
\hline Die attach & 1800 & 0.3 & $80 \mathrm{E}-6$ & \\
\hline
\end{tabular}

In electronic packaging literature, many researchers have been proposing varying combinations of creep constitutive models discussed above. For this study the Anand model was used.

The Anand model was proposed by Anand and Brown et al. given by

$$
\dot{\gamma}=A(\sinh (\xi * \sigma / s))^{1 / n} * e^{\left(-\frac{Q}{R T}\right)}
$$

where $\xi$ in is the inelastic strain rate, $\mathrm{n}$ is a multiplier of stress, $\sigma$ is the applied stress, $\mathrm{s}$ is a single scalar as an internal variable to represent the averaged isotropic resistance to plastic flow, and $m$ is the strain rate sensitivity of stress. For the steady-state creep approximation, 
Anand model is simplified to the hyperbolic-sine creep form resulting in the following steady-state creep equation:

as

$$
\dot{\gamma}=A(\sinh (\beta \tau))^{n} * e^{\left(-\frac{Q}{R T}\right)}
$$

For the rest of the visocplastic analysis the hyperbolic sine creep model in ABAQUS has been used with the parameters below taken from Mohammad Motalab et.al, Determination of Anand constants for SAC Solders using Stress-Strain or Creep Data, 13th IEEE ITHERM Conference, may 2012

Table 3 ANAND model parameters

\begin{tabular}{|c|c|c|}
\hline Parameter & SAC305 & (creep) \\
\hline Pre-exponential factor & A (s-1) & 3,484 \\
\hline Activation energy/Boltzmann's constant & Q/R $\left({ }^{\circ} \mathrm{K}\right)$ & 9096 \\
\hline Multiplier of stress & $\xi$ & 4 \\
\hline Strain rate sensitivity of stress & $\mathrm{m}$ & 0.2 \\
\hline Deformation resistance saturation coefficient & $\mathrm{s}(\mathrm{Mpa})$ & 26.4 \\
\hline Strain rate sensitivity of saturation & $\mathrm{n}$ & 0.01 \\
\hline Hardening constant & $\mathrm{h} 0(\mathrm{Mpa})$ & 144,000 \\
\hline Strain rate sensitivity of hardening & $\mathrm{a}$ & 1.9 \\
\hline Deformation resistance & $\mathrm{s} 0(\mathrm{Mpa})$ & 18.07 \\
\hline
\end{tabular}




\subsubsection{Temperature Cycles}

The temperature profile has an important effect on solder joint deformation since solder behavior is rate-dependent and the creep is a time-dependent strain. The temperature profile of thermal cycling has a strong influence on solder deformation. Fast temperature ramp rate increases the strain and stress as solder behavior is rate-dependent. The dwell time is also another factor because it allows creep to develop. Therefore, the choice of temperature profile affects the reliability of solder balls significantly.

The temperature profile of thermal cycling chosen in the present study consists of Tinitial $=25^{\circ} \mathrm{C}(298 \mathrm{~K})$, Thigh $=125^{\circ} \mathrm{C}(398 \mathrm{~K})$, Tlow $=-40^{\circ} \mathrm{C}(233 \mathrm{~K})$, dwell time $=10 \mathrm{mins}$, and $\operatorname{ramp} \operatorname{rate}\left(10^{\circ} \mathrm{C} / \mathrm{min}\right)$.

A common standard used by the electronic packaging industry is JEDEC. With standards, comparisons can be made between test results performed by different parties. Temperature profile used in this present study corresponds to 'Condition G' from the JEDEC standard which is commonly used by industry to conduct solder joint reliability studies. Temperature profile is plotted in figure 4. 


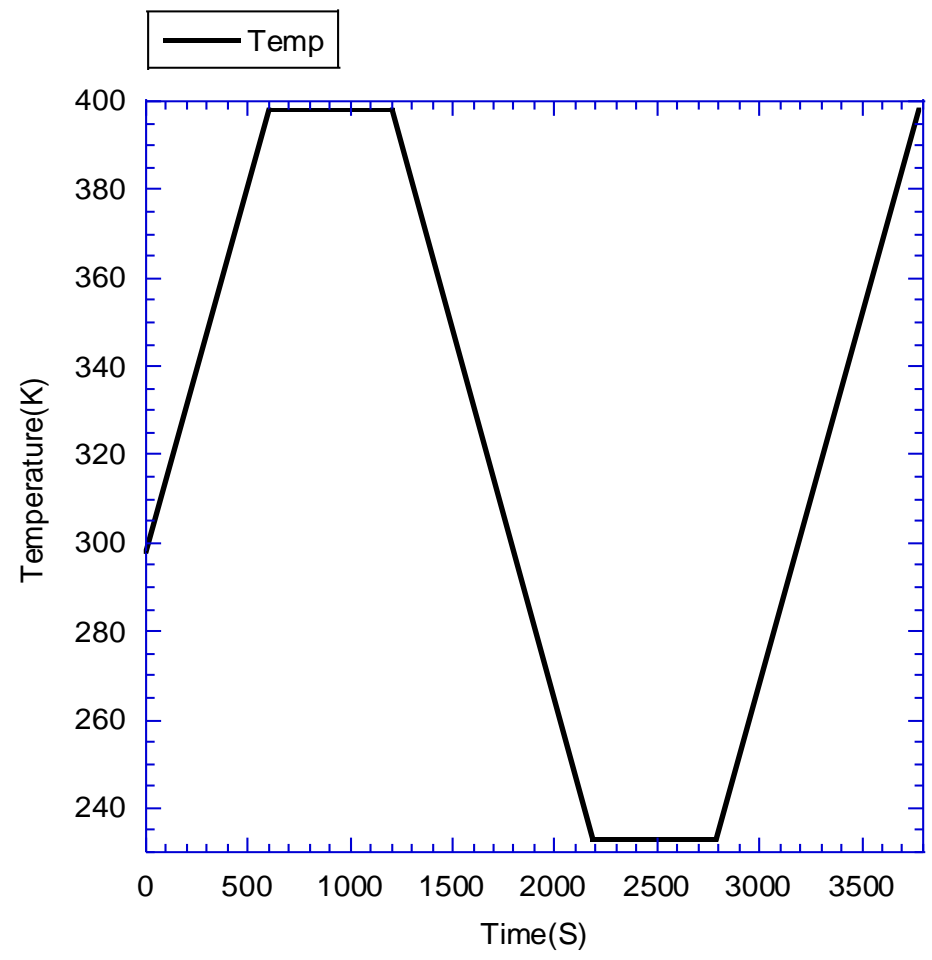

Figure 4 Temperature profile used for simulation

\subsubsection{Finite Element Modelling}

The coordinate system $(1,2,3)$ is interchangeably used with the coordinate system $(\mathrm{x}, \mathrm{y}$, $\mathrm{z}$ ), and the 3 axis ( $\mathrm{z}$ axis) is out-of-plane. The boundary conditions are set as fixed $(\mathrm{U} 1=\mathrm{U} 2=\mathrm{U} 3=0)$ at the left bottom point of $\mathrm{PCB}$ and symmetry about the $\mathrm{x}$-axis $(\mathrm{U} 1=\mathrm{UR} 2=\mathrm{UR} 3=0)$ and the $\mathrm{z}$-aixs $(\mathrm{U} 3=\mathrm{UR} 1=\mathrm{UR} 2=0)$. The stress-free state is considered at Tinitial $=25^{\circ} \mathrm{C}(298 \mathrm{~K})$. 
Quarter of the model is constructed due to geometric symmetry about the $\mathrm{x}$ and $\mathrm{z}$ axis.

Linear elastic and viscoplastic behaviors of solders are considered. 


\section{Chapter 4. Results and Discussion}

The maximum von mises stress in each solder ball to figure out which one has the highest value, this will be the first solder ball that has thermal fatigue.In this study we will figure out how the thickness of the die and multiple dies will affect the max vonMises in solder ball.

\subsection{Single die model with varying thickness}

A simplified BGA (Ball Grid Array) format packaging model of the original model was used. This model consists of four parts: MC (moulding compound), die, substrate, solder ball and PCB. The die is embedded in the MC part. Figure 5 shows the side view of the model. 

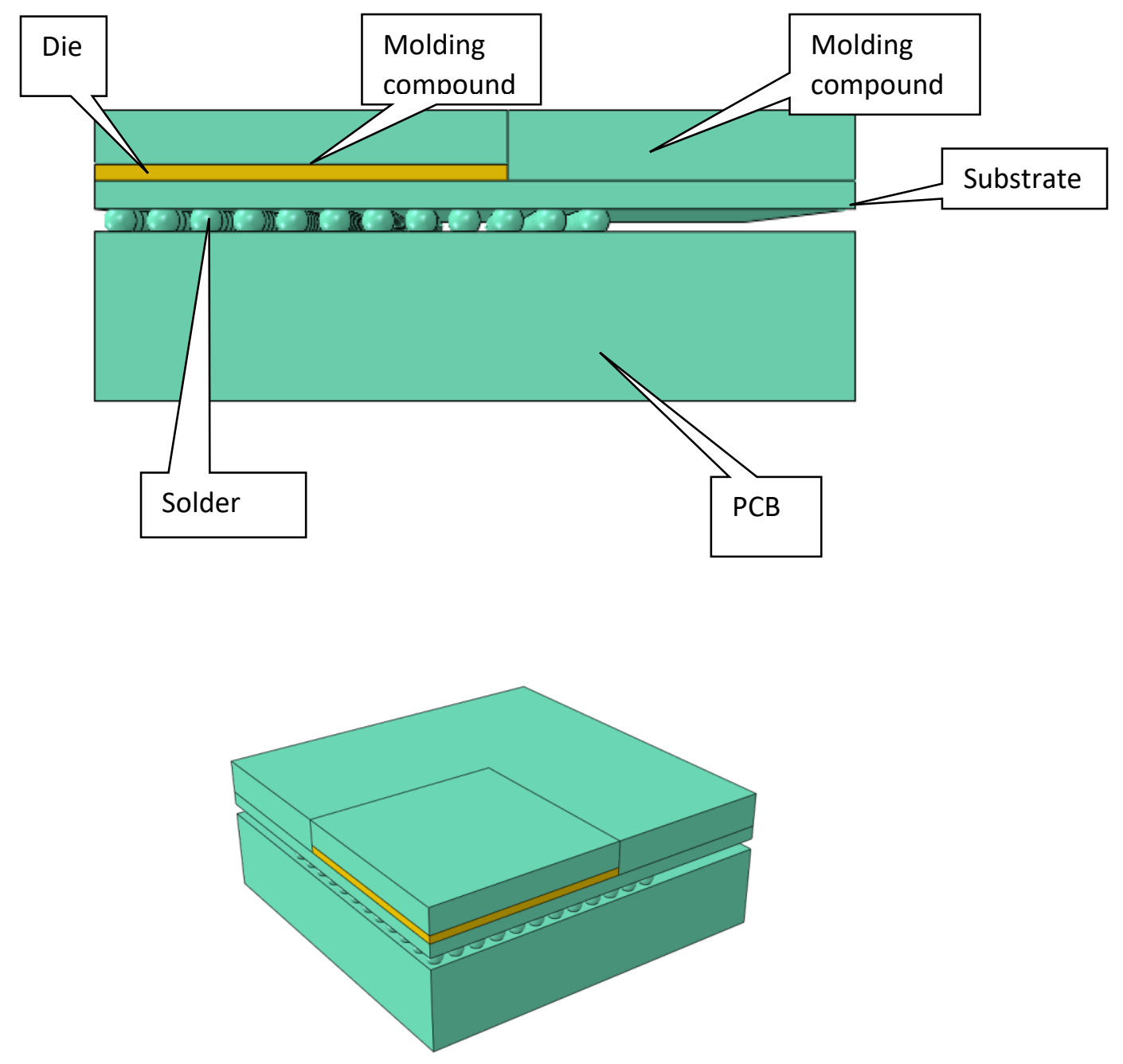

Figure 5 single die model 
In order to recognize the ball easier, we gave them a number like the following figure.

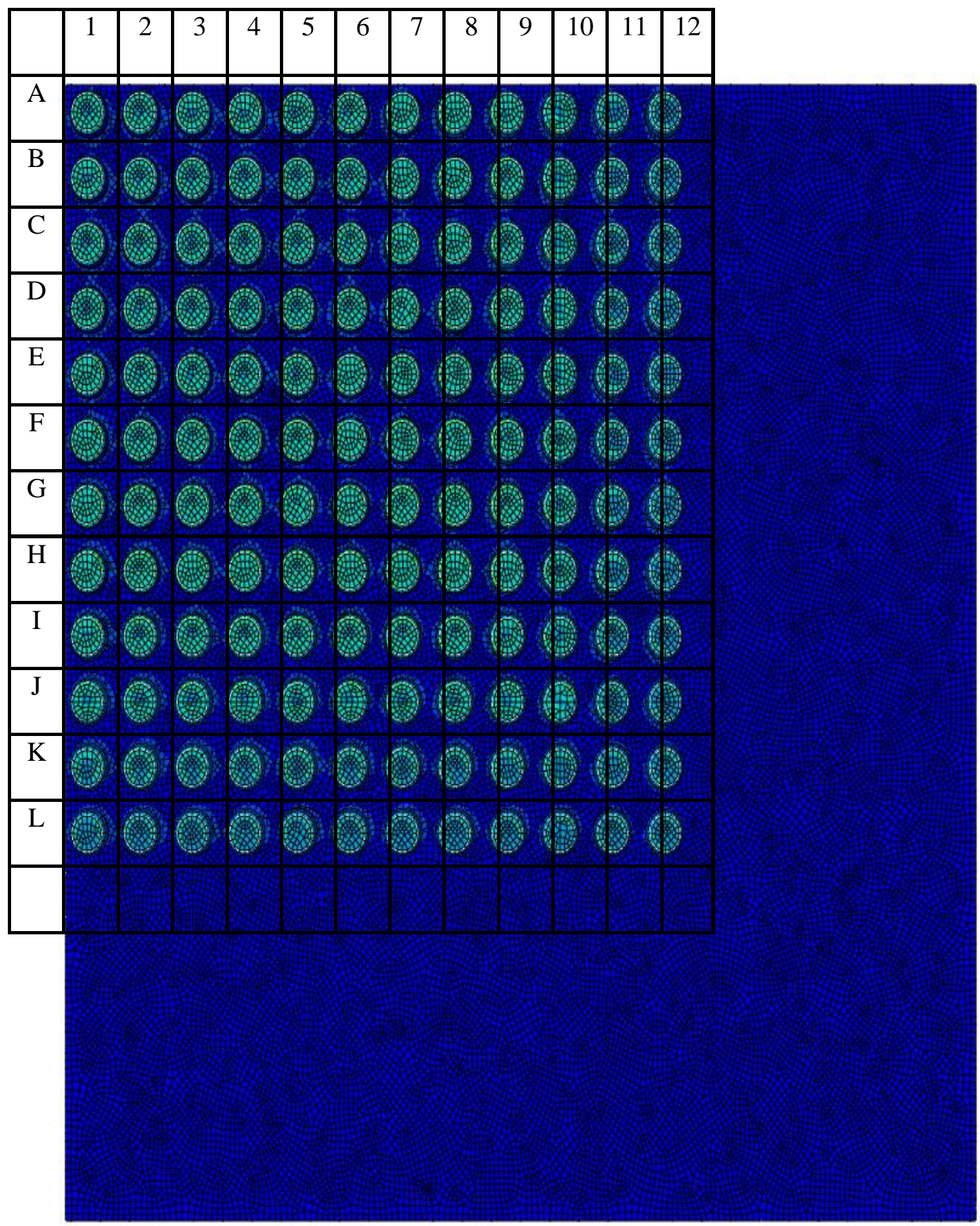

Figure 6 Numbering of solder balls 
First set of simulations were done for the 1 die model, in which there is only one 0.12 thickness die embedded in MC part. Then we get the max vonMiese in each solder ball and compare them.

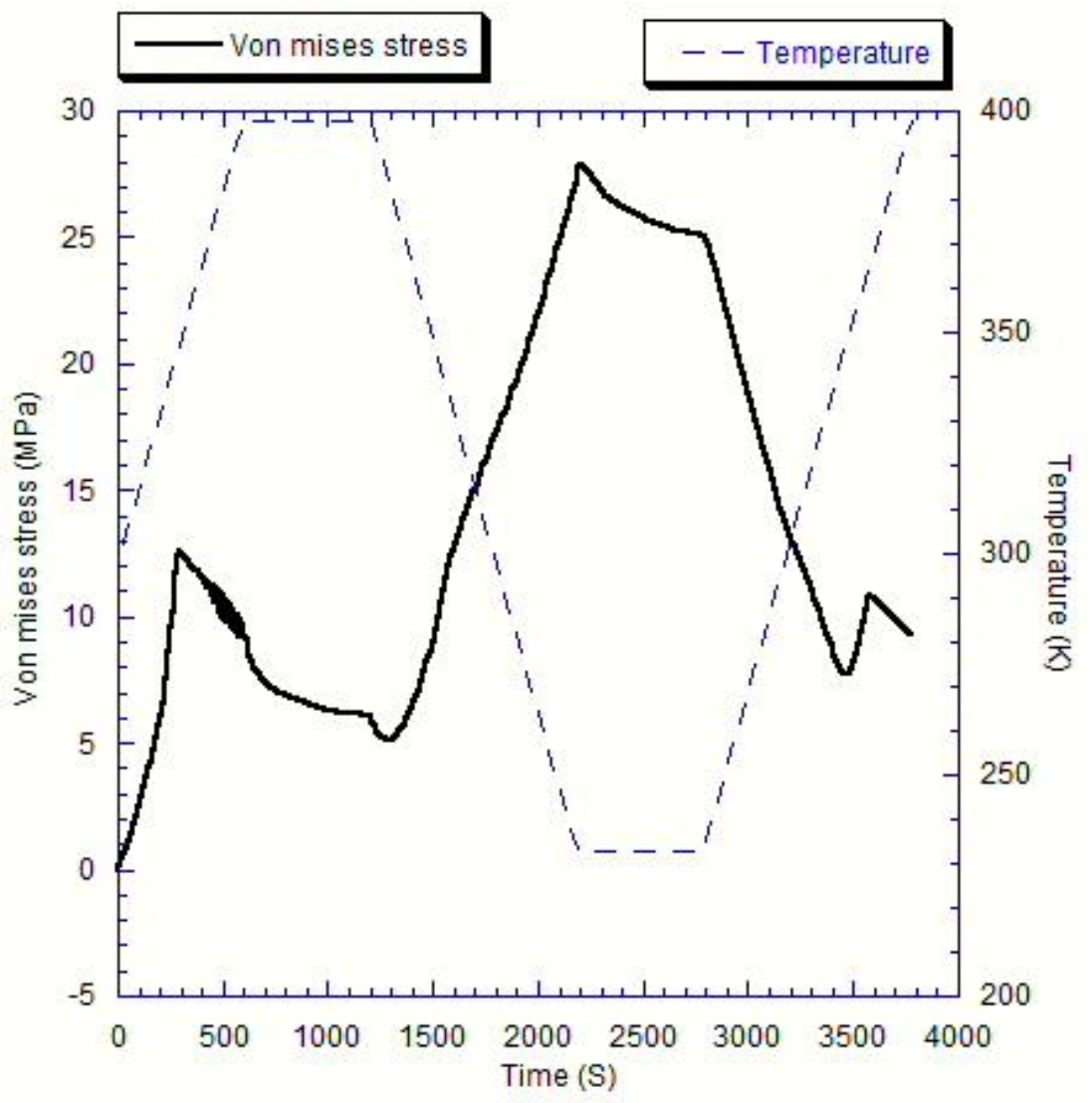

Figure 7 Variation of von Mises stress (Smises) during thermal cycling - .12 mm thickness model

During the temperature ramp up, the magnitudes of stresses decrease due to reduction of Young's modulus of the solder. The von Mises stress (Smises) in the right corner of the 10th solder ball decrease from $24.880 \mathrm{MPa}$ to $12.732 \mathrm{MPa}$ when temperature increases from $233 \mathrm{~K}$ to $340 \mathrm{~K}$, but it increases from $12.732 \mathrm{MPa}$ to $11.92 \mathrm{MPa}$ for when temperature increases further from $340 \mathrm{~K}$ to $398 \mathrm{~K}$. During the cool or hot dwell period, the magnitudes 
of stresses decrease as stress relaxation occurs. The von Mises stress (Smises) decreases from $12.578 \mathrm{MPa}$ to $6.102 \mathrm{MPa}$ during the hot dwell period $(398 \mathrm{~K})$.

During the temperature ramp down, the magnitudes of stresses increase due to increase of Young's modulus of the solder. The von Mises stress (Smises) in the right corner of the 10th solder ball increases from $6.102 \mathrm{MPa}$ to $27.805 \mathrm{MPa}$, which is maximum, when temperature decreases from $398 \mathrm{~K}$ to $233 \mathrm{~K}$. During the cold dwell, cycle, the magnitudes of stresses decrease because of stress relaxation

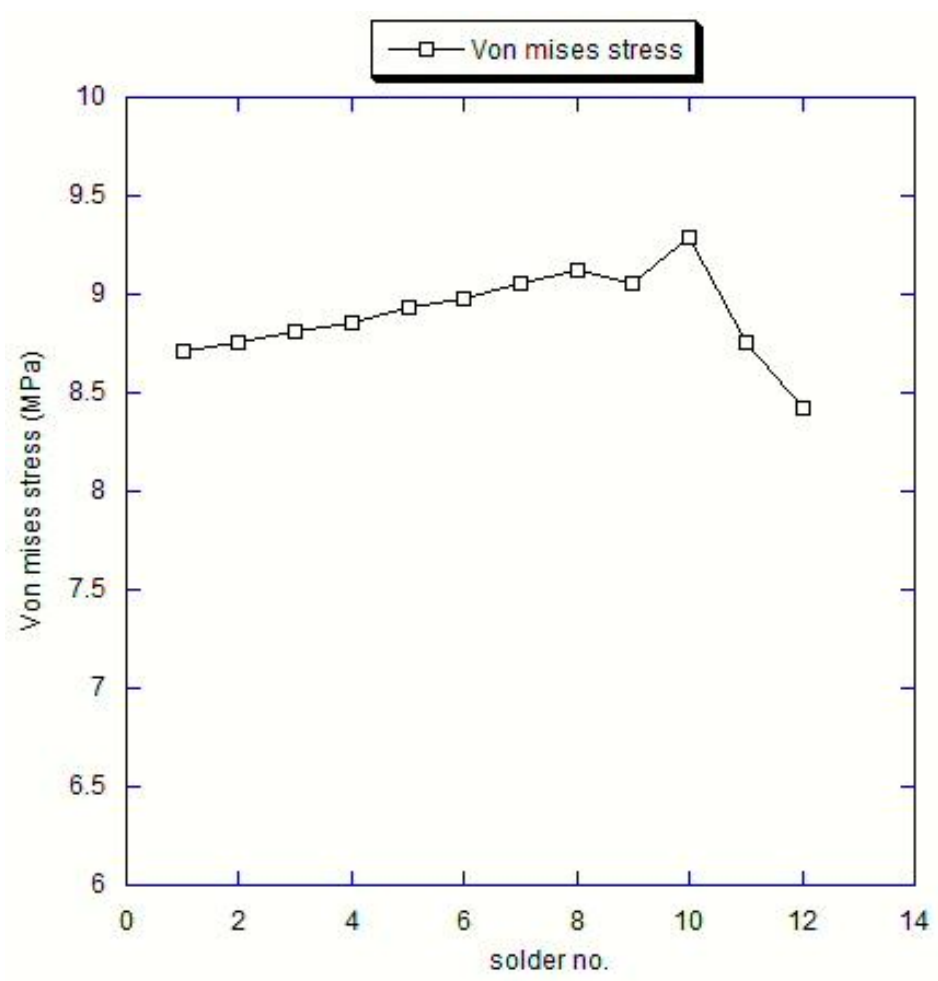

\begin{tabular}{|c|c|}
\hline Solder no. & $\begin{array}{l}\text { Von mises } \\
\text { stress (MPa) }\end{array}$ \\
\hline 1 & 8.712 \\
\hline 2 & 8.753 \\
\hline 3 & 8.808 \\
\hline 4 & 8.855 \\
\hline 5 & 8.933 \\
\hline 6 & 8.982 \\
\hline 7 & 9.056 \\
\hline 8 & 9.127 \\
\hline 9 & 9.053 \\
\hline 10 & 9.286 \\
\hline 11 & 8.755 \\
\hline 12 & 8.422 \\
\hline
\end{tabular}

Figure 8 Variation of von mises stress diagonal solder model - .12 mm model 


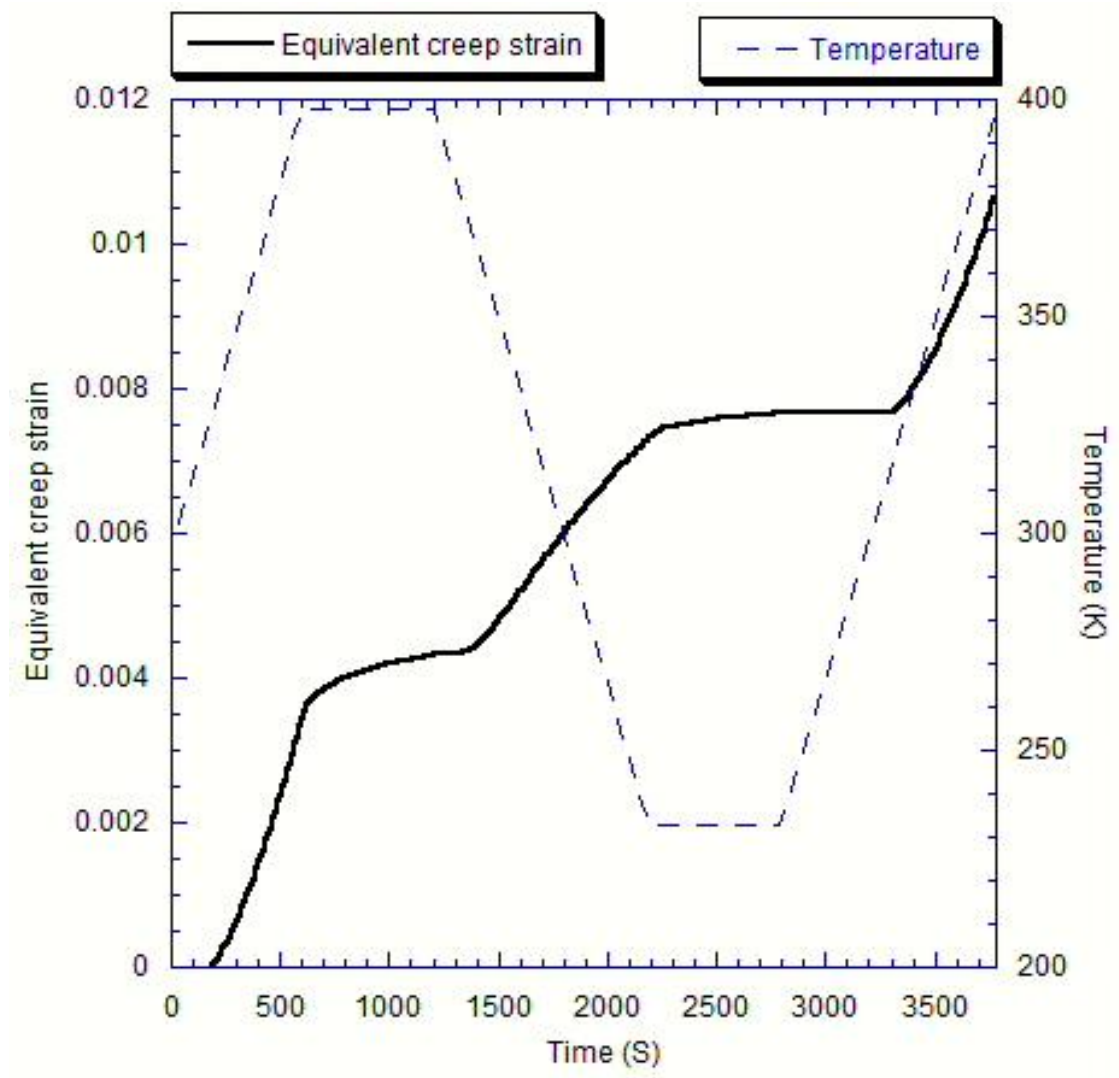

Figure 9 Variation of creep strain (CEEQ) during thermal cycling - .12 mm thickness model

As for the creep strain, it remains almost constant during the both the dwell times and increases during temperature ramp up and ramp down. 


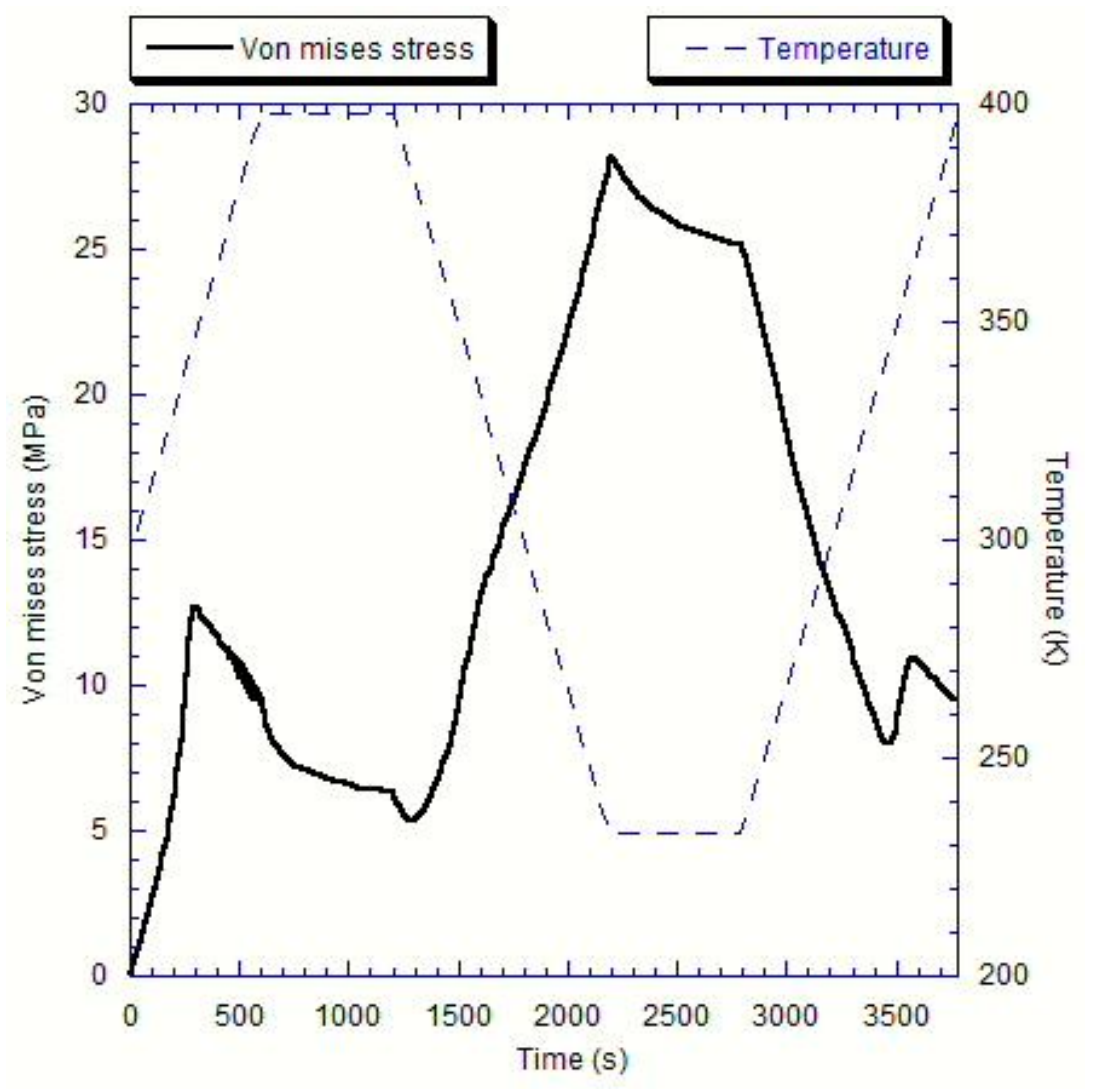

Figure 10 Variation of von Mises stress (Smises) during thermal cycling - $.15 \mathrm{~mm}$ thickness model 


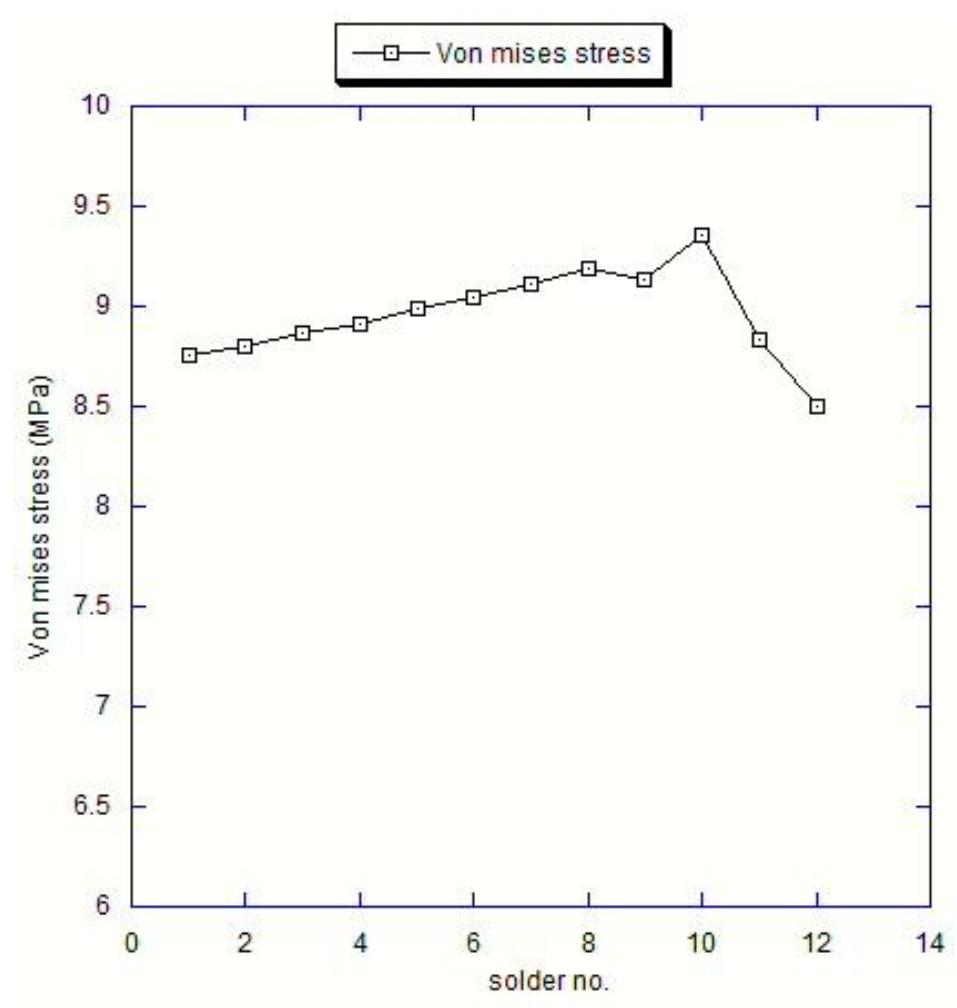

\begin{tabular}{|c|l|}
\hline $\begin{array}{c}\text { Solder } \\
\text { no. }\end{array}$ & \multicolumn{1}{|c|}{ son mises } \\
\hline 1 & 8.751 \\
\hline 2 & 8.798 \\
\hline 3 & 8.862 \\
\hline 4 & 8.913 \\
\hline 5 & 8.992 \\
\hline 6 & 9.044 \\
\hline 7 & 9.115 \\
\hline 8 & 9.184 \\
\hline 9 & 9.133 \\
\hline 10 & $\mathbf{9 . 3 5 3}$ \\
\hline 11 & 8.837 \\
\hline 12 & 8.502 \\
\hline 15 & \\
\hline
\end{tabular}

Figure 11 Variation of von mises stress diagonal solder model - .15 mm model

For the above case with a die thickness of $.15 \mathrm{~mm}$, the behavior is very similar with a slight increase in stress values. 


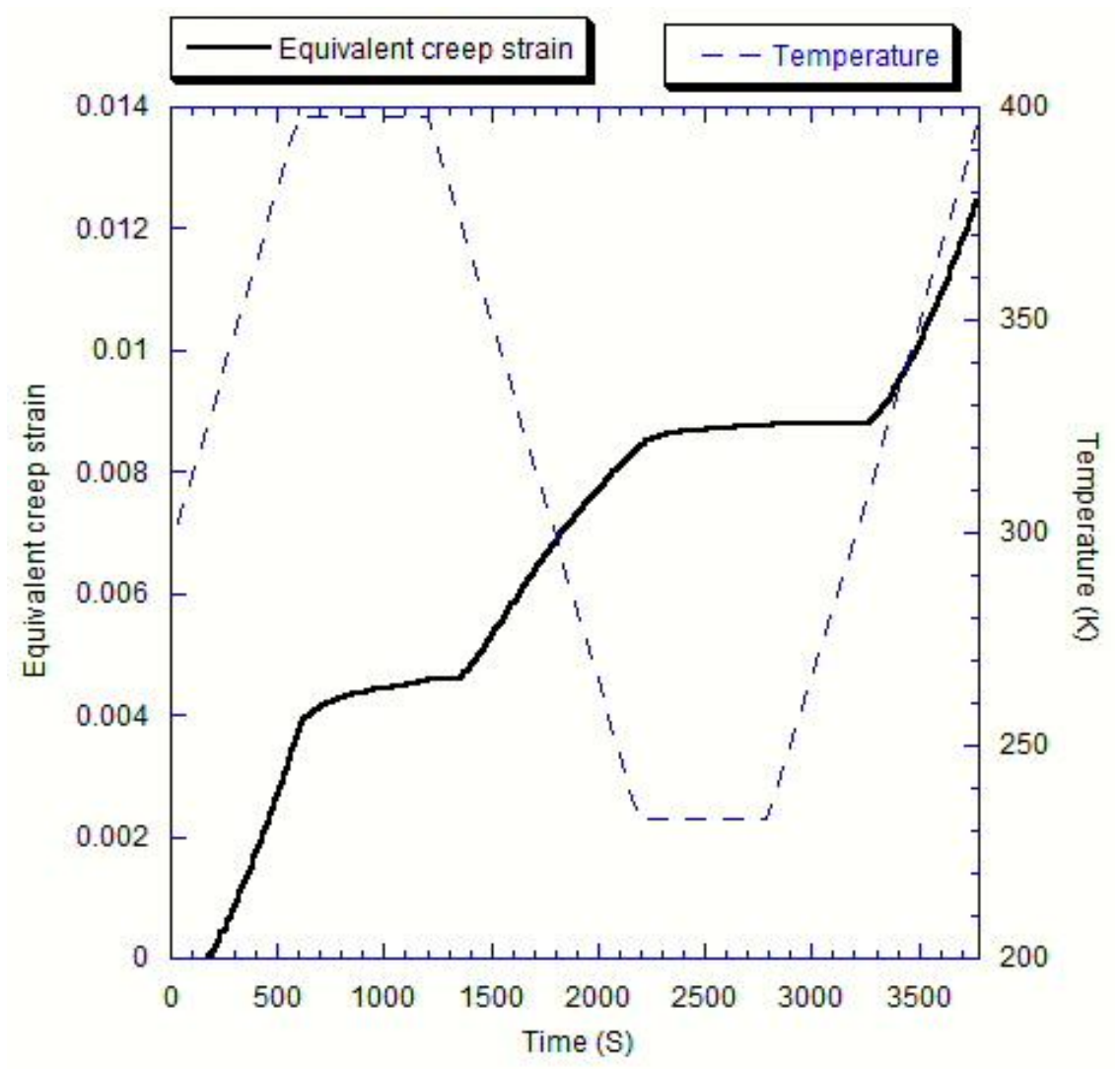

Figure 12 Variation of creep strain (CEEQ) during thermal cycling - .15 mm thickness model 


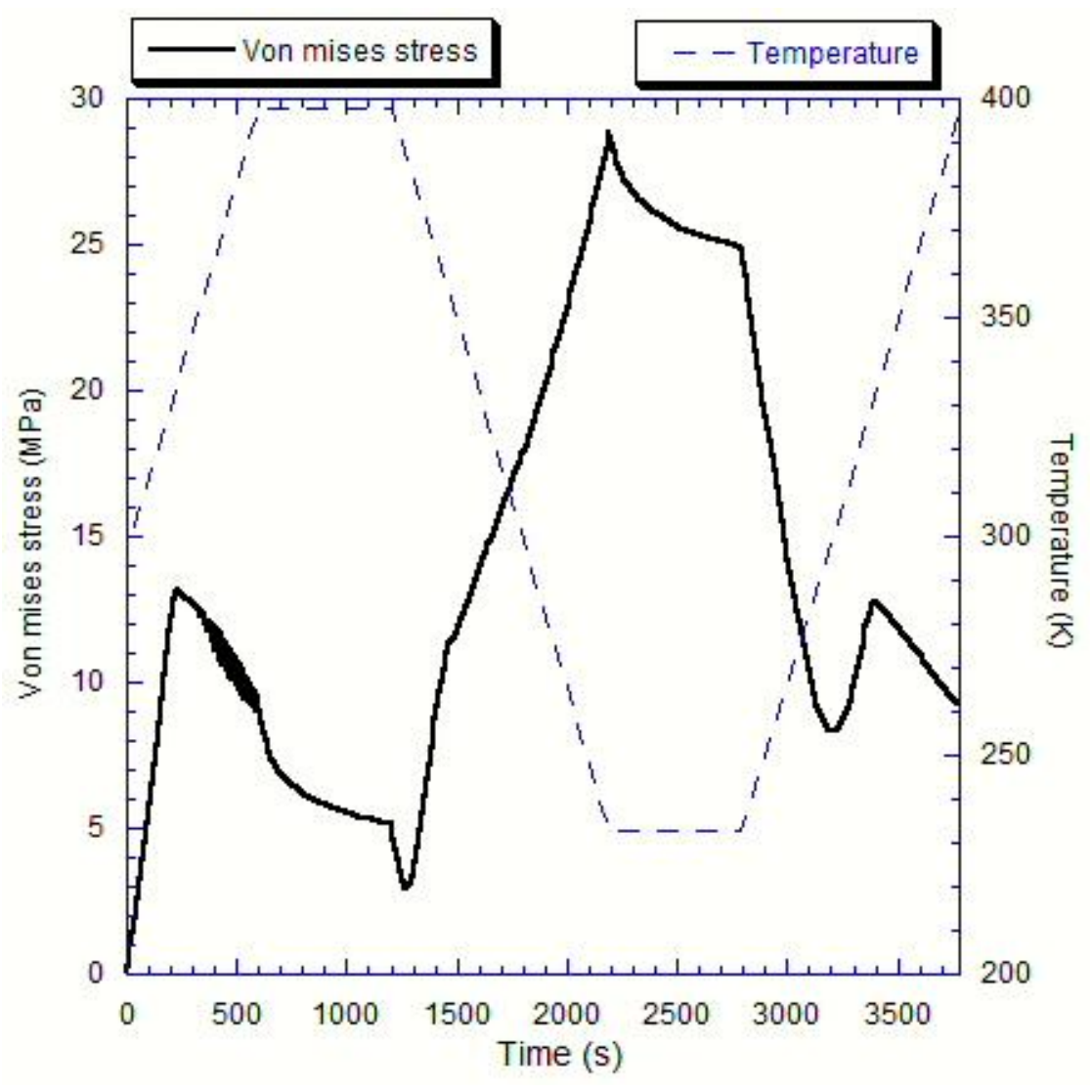

Figure 13 Variation of von Mises stress (Smises) during thermal cycling - .18 mm thickness model 


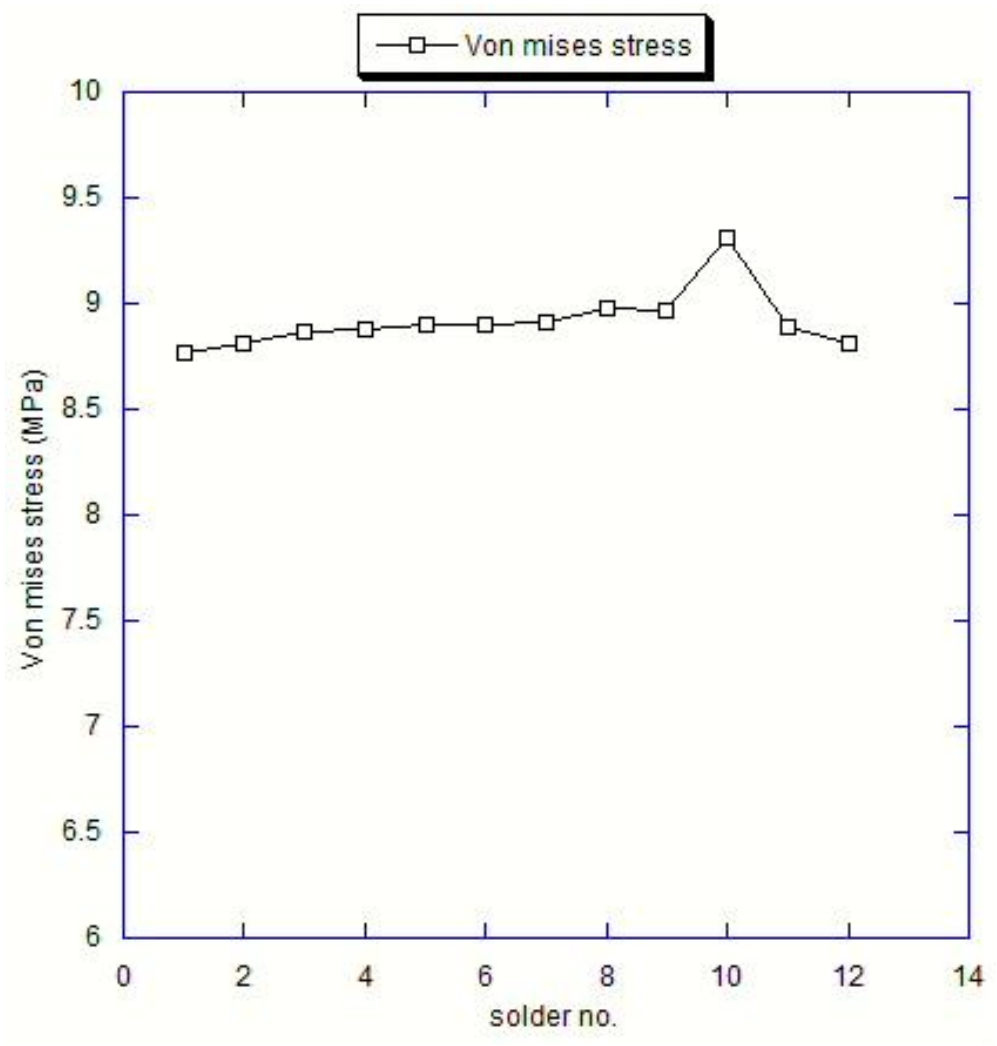

\begin{tabular}{|c|l|}
\hline Solder & \multicolumn{1}{|c|}{ Von mises } \\
no. & stress (MPa) \\
\hline 1 & 8.752 \\
\hline 2 & 8.809 \\
\hline 3 & 8.869 \\
\hline 4 & 8.882 \\
\hline 5 & 8.904 \\
\hline 6 & 8.905 \\
\hline 7 & 8.908 \\
\hline 8 & 8.973 \\
\hline 9 & 8.969 \\
\hline 10 & 9.307 \\
\hline 11 & $\mathbf{8 . 8 8 8}$ \\
\hline 12 & 8.813 \\
\hline
\end{tabular}

Figure 14 Variation of von mises stress diagonal solder model - .18 mm model 


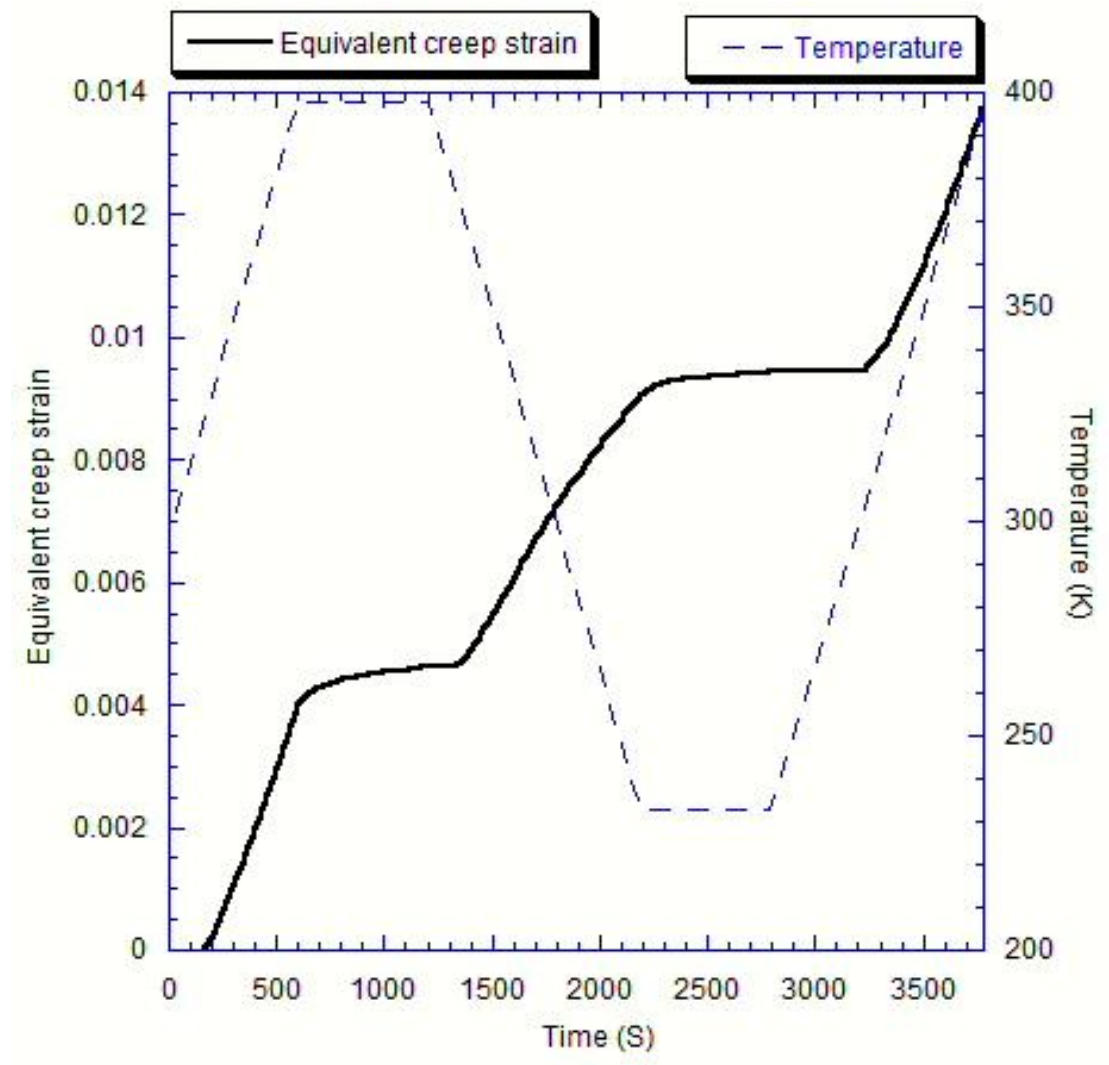

Figure 15 Variation of creep strain (CEEQ) during thermal cycling - .18 mm thickness model 


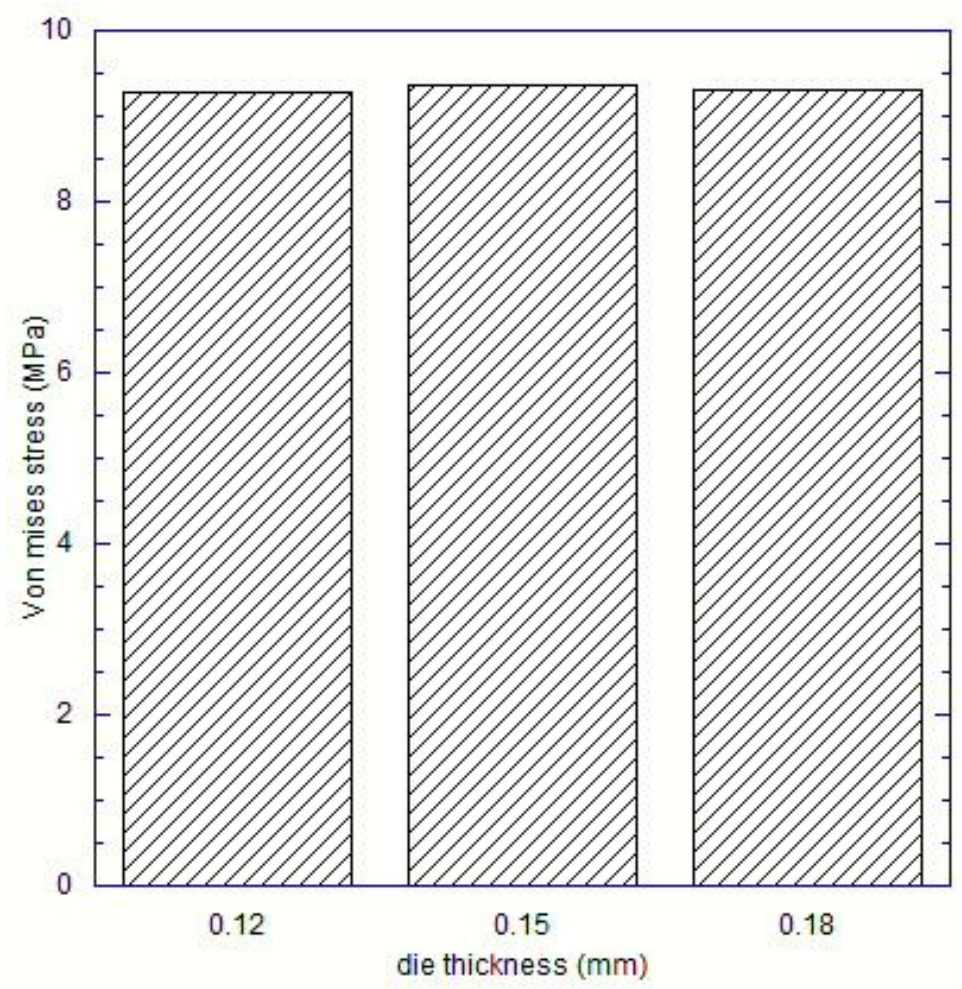

Figure 16 von mises stress comparison - single die with varying thickness

It can be seen in the figure above that the location of maximum von mises stress is still the J10 solder ball but the value increased slightly from the $.12 \mathrm{~mm}$ thickness die to the .15 $\mathrm{mm}$ thickness die but decreased slightly with the $.18 \mathrm{~mm}$ thickness die. An increase is expected with an increase in thickness but since the mesh used is coarse the increasing trend could not be observed. An increase in creep strain was observed with an increase in creep strain as seen in the plot below. 


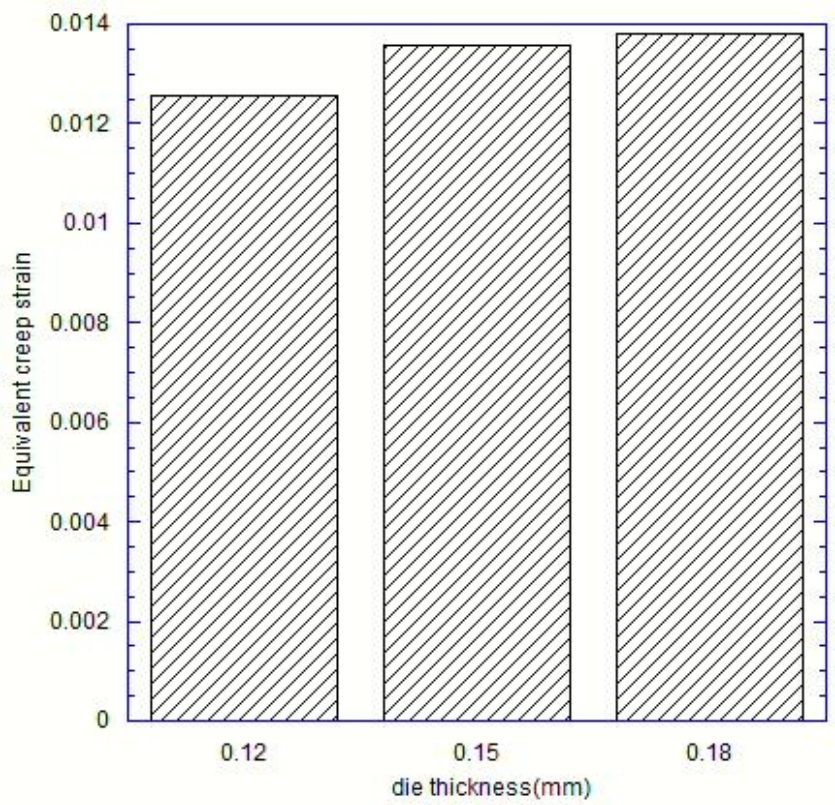

Figure 17 creep strain comparison - single die with varying thickness

\subsection{Results of two dies in the Molding Compound:}

If one packaging has more dies, that will make the system more functional, powerful and smaller, lighter, less expensive. The following analysis was done by adding an additional die in the molding compound of same thickness thereby giving three case namely $0.12 \mathrm{~mm}$, $.15 \mathrm{~mm}$ and $.18 \mathrm{~mm}$. 

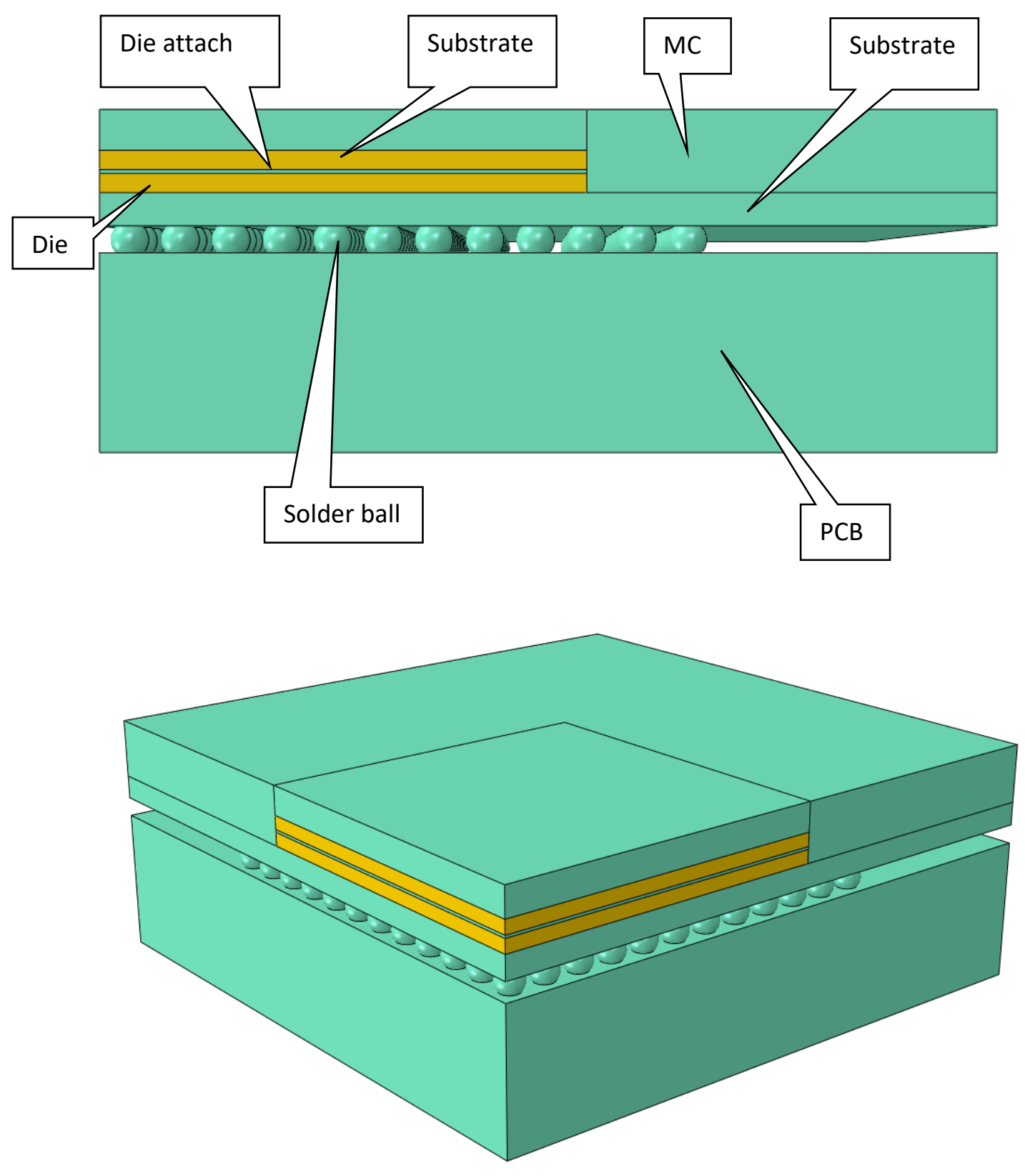

Figure 18 Two dies in molding compound model 


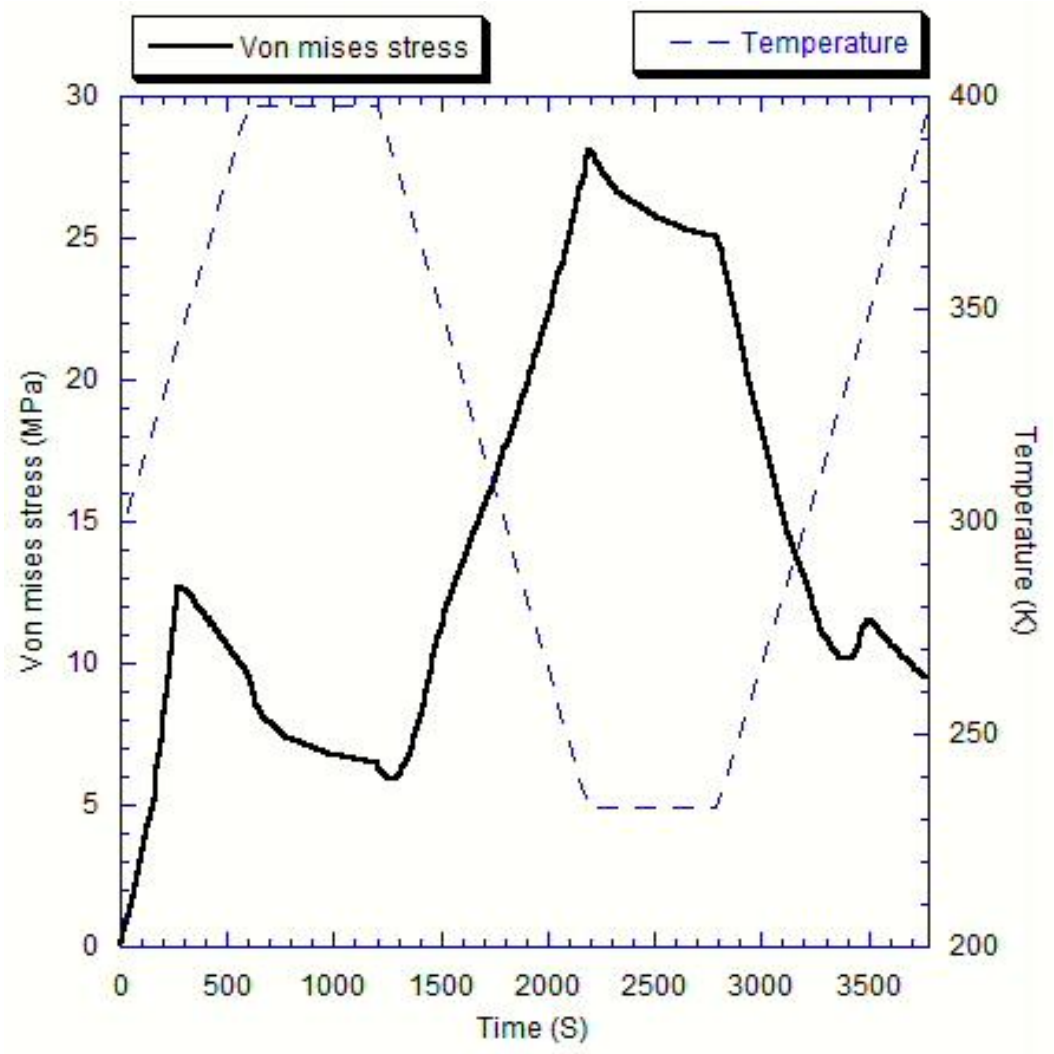

Figure 19 Variation of von Mises stress (Smises) during thermal cycling - $.12 \mathrm{~mm}$ thickness 2 die model 


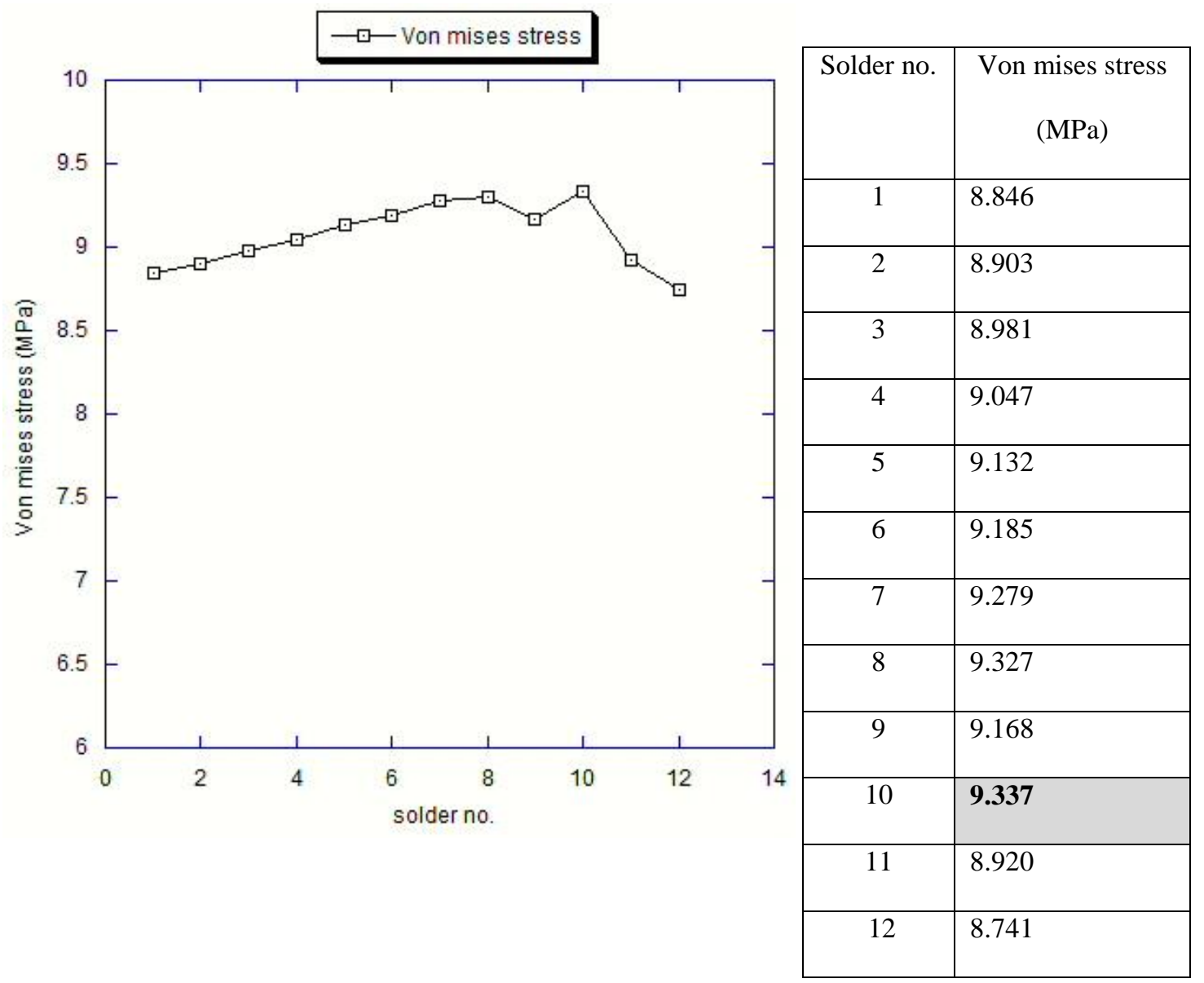

Figure 20 Variation von mises stress in the diagonal solder balls- $.12 \mathrm{~mm}$ thickness 2 die model 


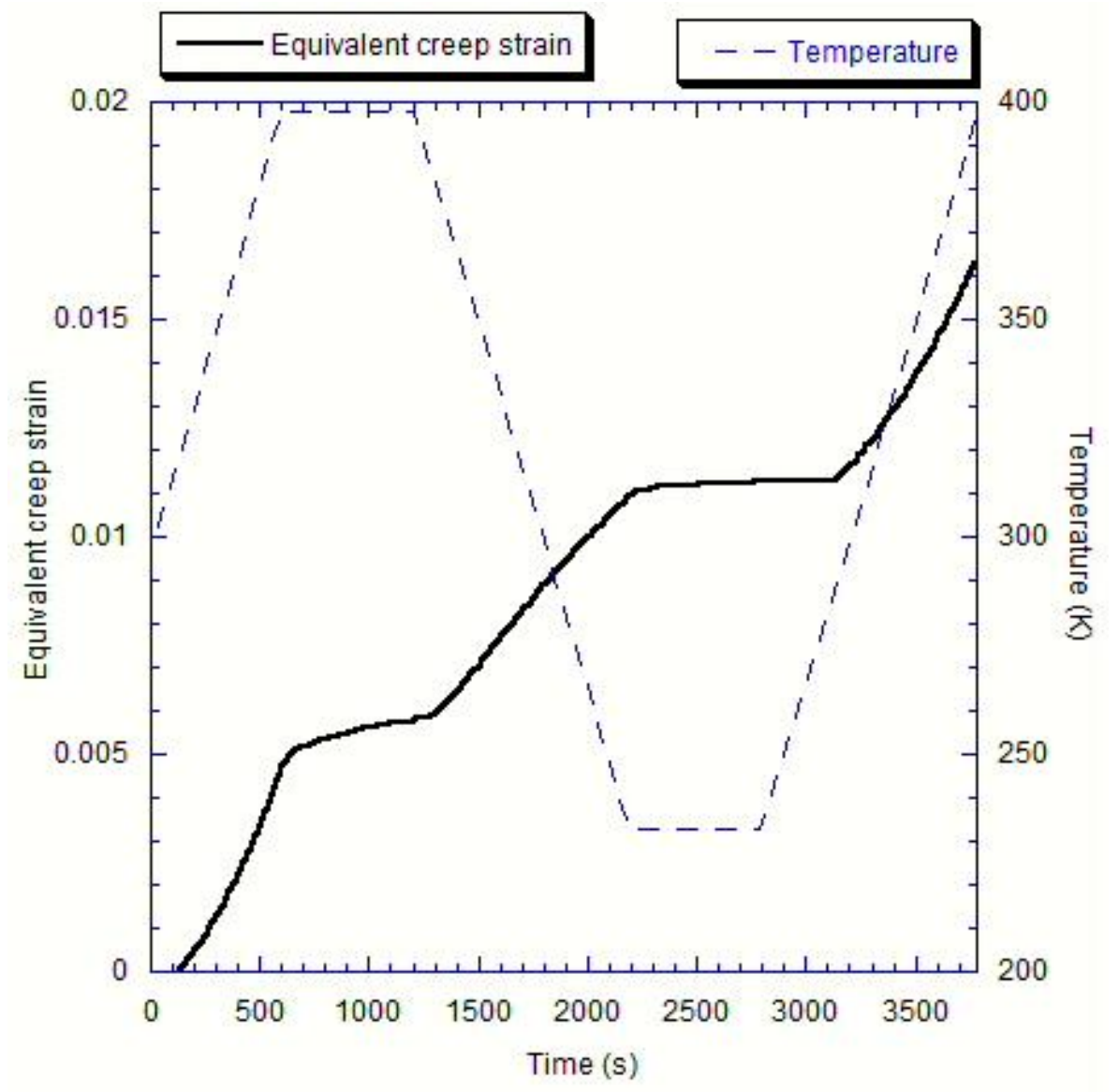

Figure 21 Variation of creep strain (CEEQ) during thermal cycling - .12 mm thickness 2 die model 


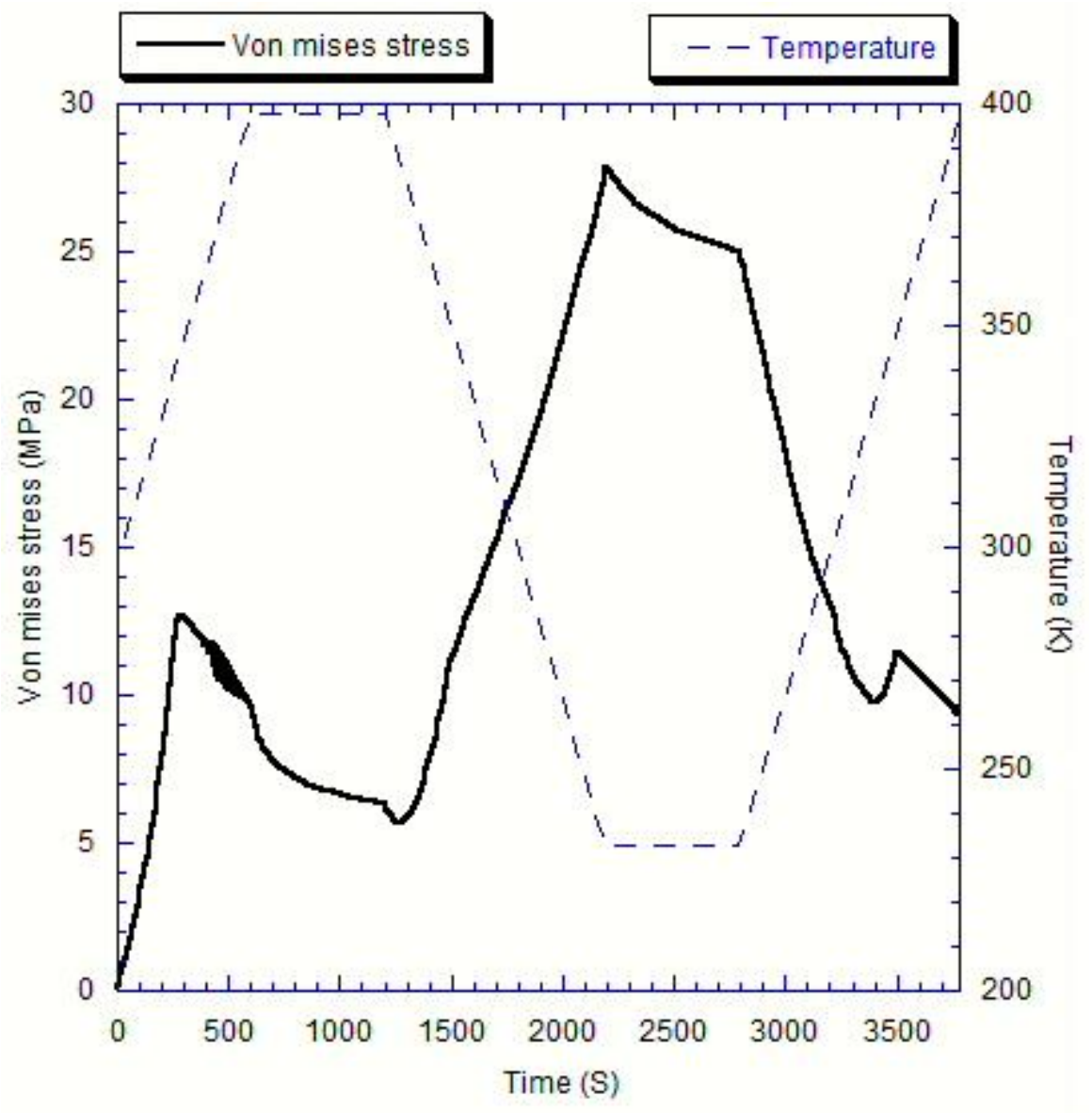

Figure 22 Variation of von Mises stress (Smises) during thermal cycling - .15 mm thickness 2 die model 


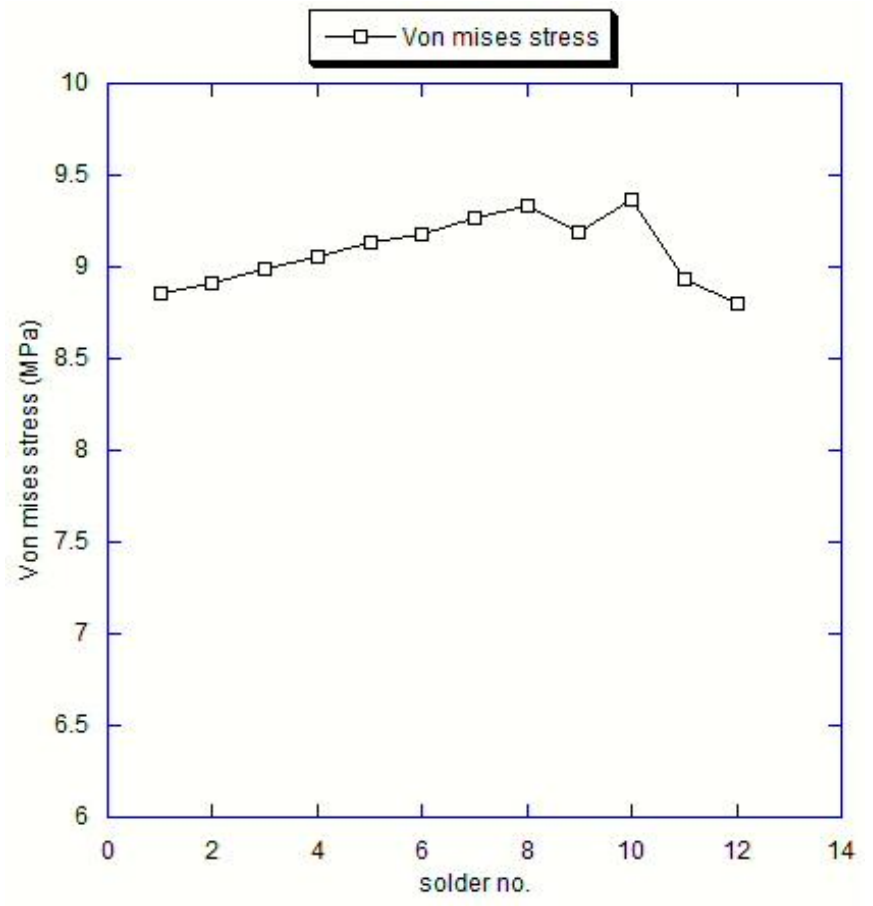

\begin{tabular}{|c|l|}
\hline Solder no. & $\begin{array}{c}\text { Von mises stress } \\
(\mathrm{MPa})\end{array}$ \\
\hline 1 & 8.860 \\
\hline 2 & 8.915 \\
\hline 3 & 8.991 \\
\hline 4 & 9.052 \\
\hline 5 & 9.134 \\
\hline 6 & 9.181 \\
\hline 7 & 9.264 \\
\hline 8 & 9.332 \\
\hline 9 & 9.191 \\
\hline 10 & $\mathbf{9 . 3 7 2}$ \\
\hline 11 & 8.936 \\
\hline 12 & 8.798 \\
\hline
\end{tabular}

Figure 23 Variation of von Mises stress in the diagonal solder balls - .15 mm thickness

2 die model 


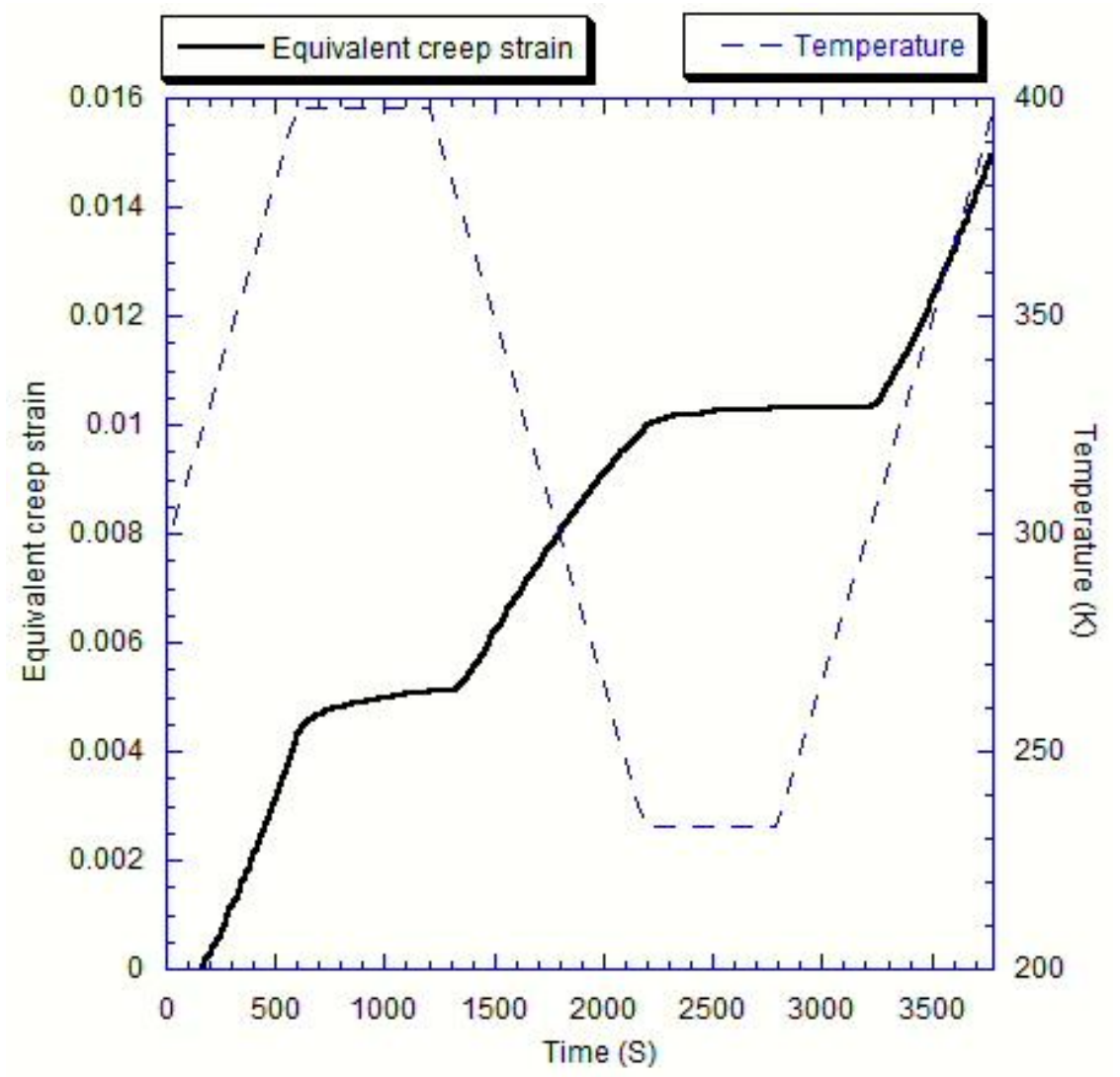

Figure 24 Variation of creep strain (CEEQ) during thermal cycling - .15 mm thickness 2 die model 


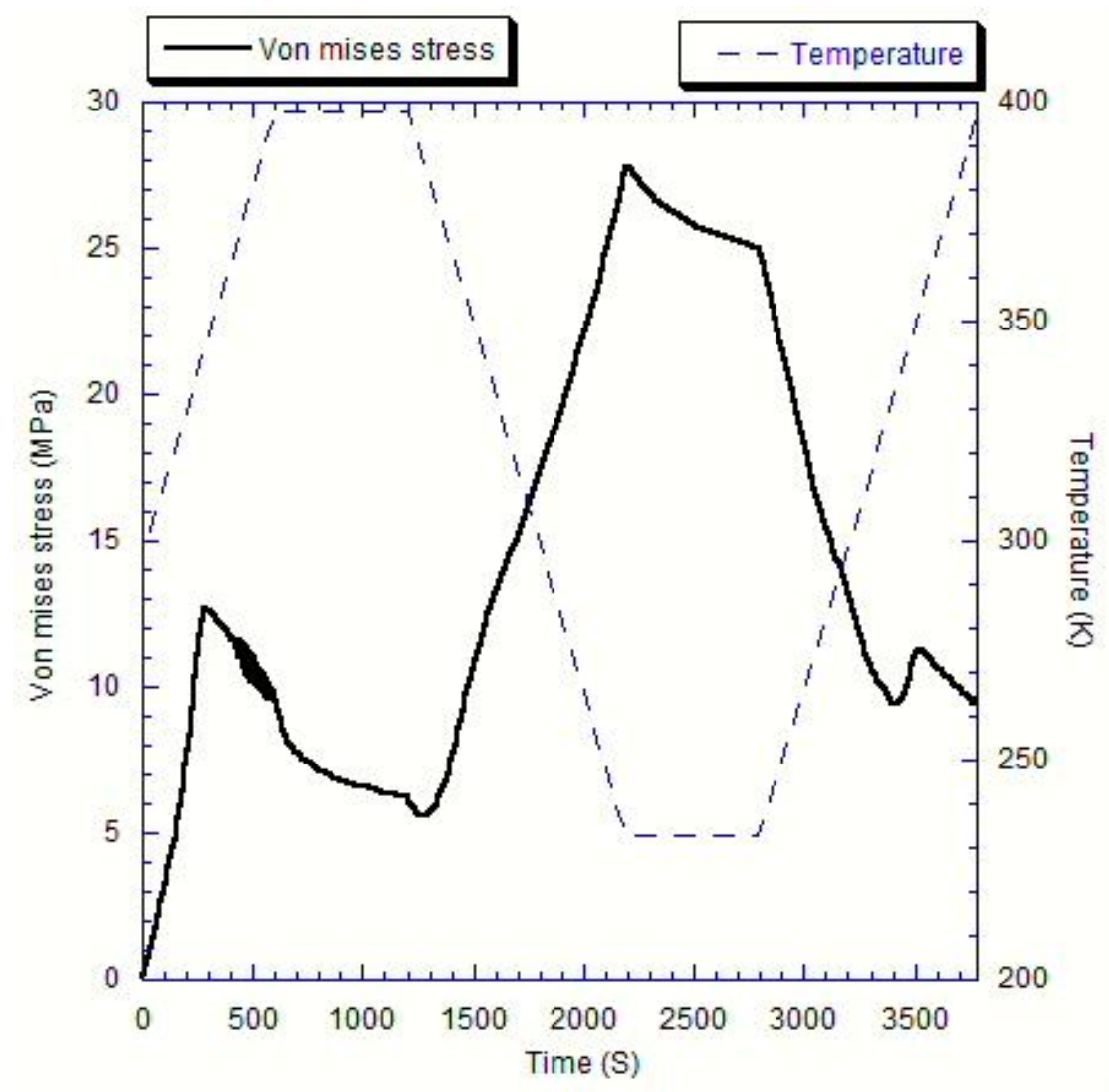

Figure 25 Variation of von Mises stress (Smises) during thermal cycling - .18 mm thickness 2 die model 


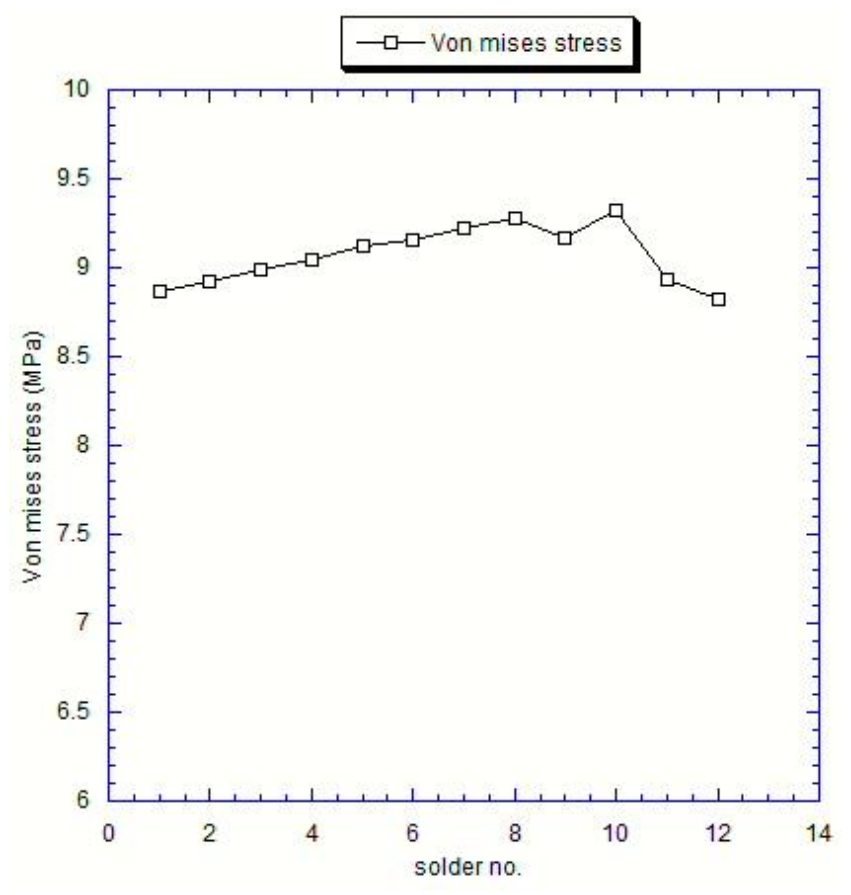

\begin{tabular}{|c|l|}
\hline Solder no. & $\begin{array}{c}\text { Von mises stress } \\
(\mathrm{MPa})\end{array}$ \\
\hline 1 & 8.871 \\
\hline 2 & 8.922 \\
\hline 3 & 8.991 \\
\hline 4 & 9.045 \\
\hline 5 & 9.120 \\
\hline 6 & 9.153 \\
\hline 7 & 9.219 \\
\hline 8 & 9.278 \\
\hline 9 & 9.170 \\
\hline 10 & $\mathbf{9 . 3 2 1}$ \\
\hline 11 & 8.932 \\
\hline 12 & 8.819 \\
\hline & \\
\hline
\end{tabular}

Figure 26 Variation of von Mises stress in the diagonal solder balls - .18 mm thickness 2 die model 


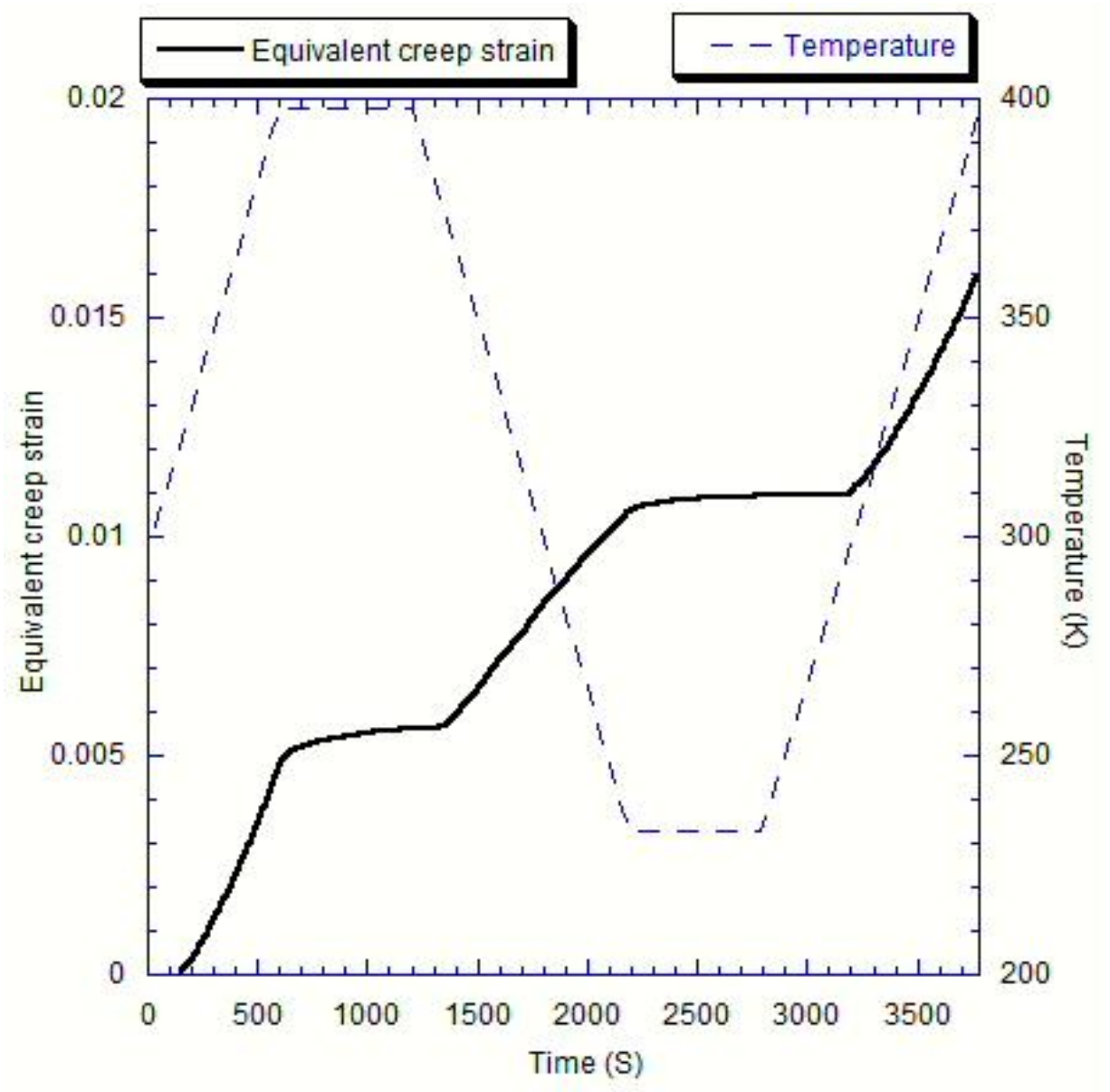

Figure 27 Variation of creep strain (CEEQ) during thermal cycling - .18 mm thickness 2 die model 


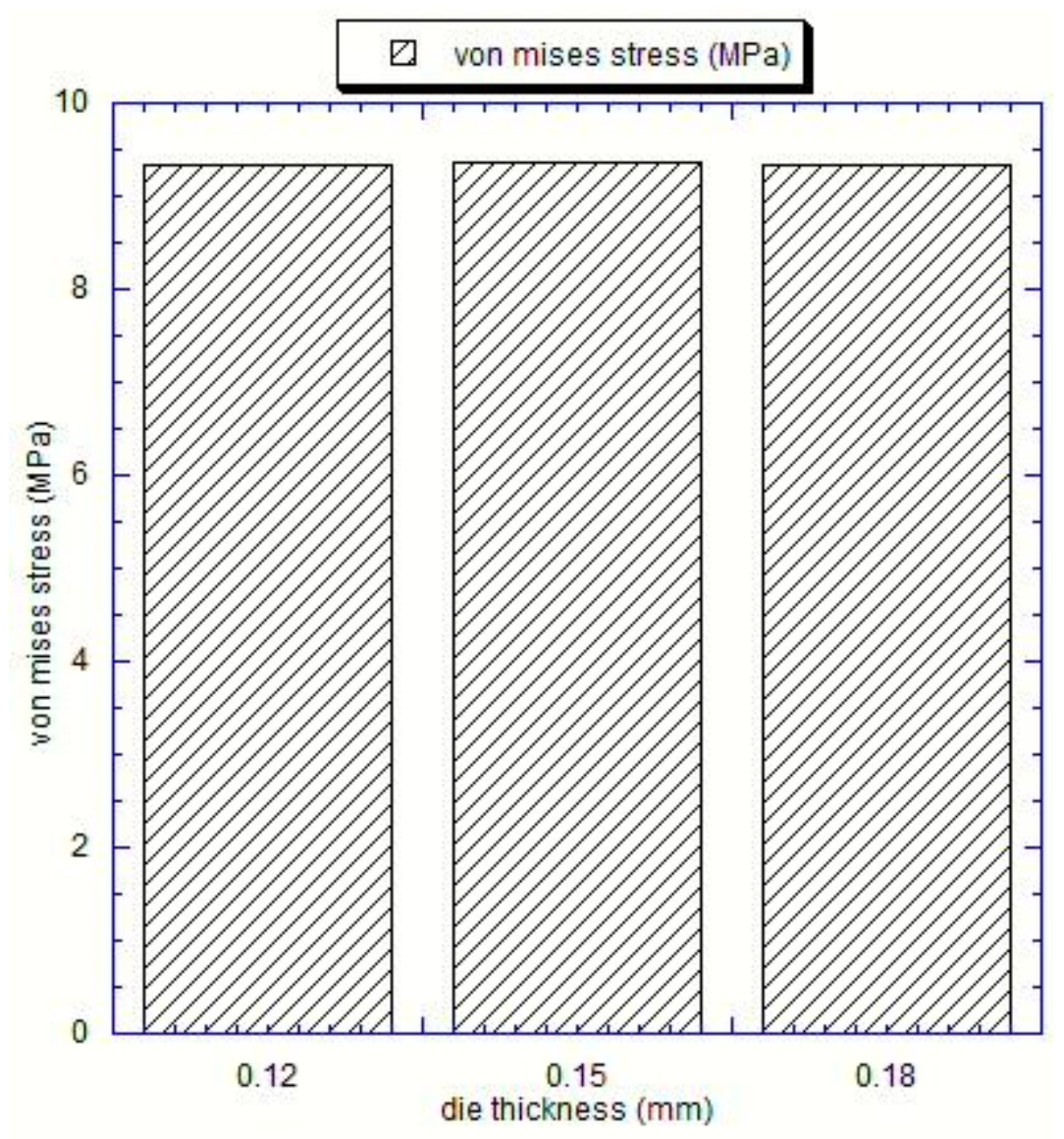

Figure 28 Bar plot comparison of von mises stress for the 2 die model

It can be seen in the figure above that the location of maximum von mises stress is still the $\mathrm{J} 10$ solder ball but the value increased slightly from the $.12 \mathrm{~mm}$ thickness die to the .15 $\mathrm{mm}$ thickness die with an increase of $.37 \%$ but decreased slightly with the $.18 \mathrm{~mm}$ thickness die by about $.17 \%$. The variation observed in not very significant An increase is expected with an increase in thickness but since the mesh used is coarse the increasing trend could not be observed. An increase in creep strain was observed with an increase in creep strain as seen in the plot below with percentage increase of $2.86 \%$ and $2.13 \%$ repectively. 


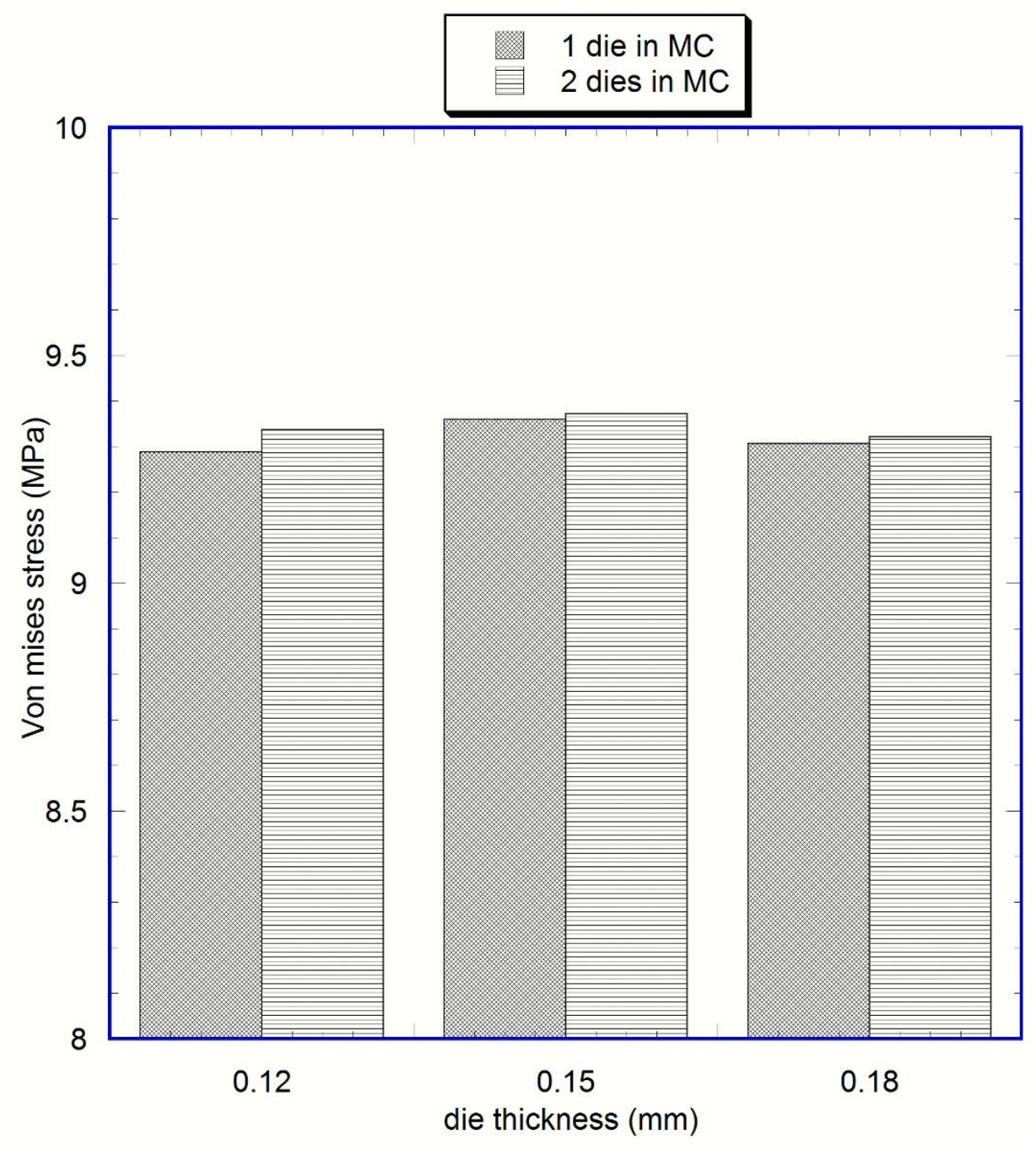

Figure 29 Bar plot comparison of von mises stress for the 1 and 2 die model

As seen in the plot above there is a relative increase in the value of von mises stress between the 1 die and 2 die model, but again as mentioned previously in the case of the $.18 \mathrm{~mm}$ die model the increase in stress is not observed as expected and this can be attributed to the coarseness of the mesh. 


\subsection{Results of one die in molding compound and one die in substrate:}

A die is added in the substrate in addition to the 1 die in the molding compound. The die in the substrate is thinner than the one in the molding compound. The die thickness in MC part is $0.12 \mathrm{~mm}$ and thickness of the die in the substrate layer is varied between $0.05 \mathrm{~mm}$, $0.75 \mathrm{~mm}$ and $0.1 \mathrm{~mm}$.
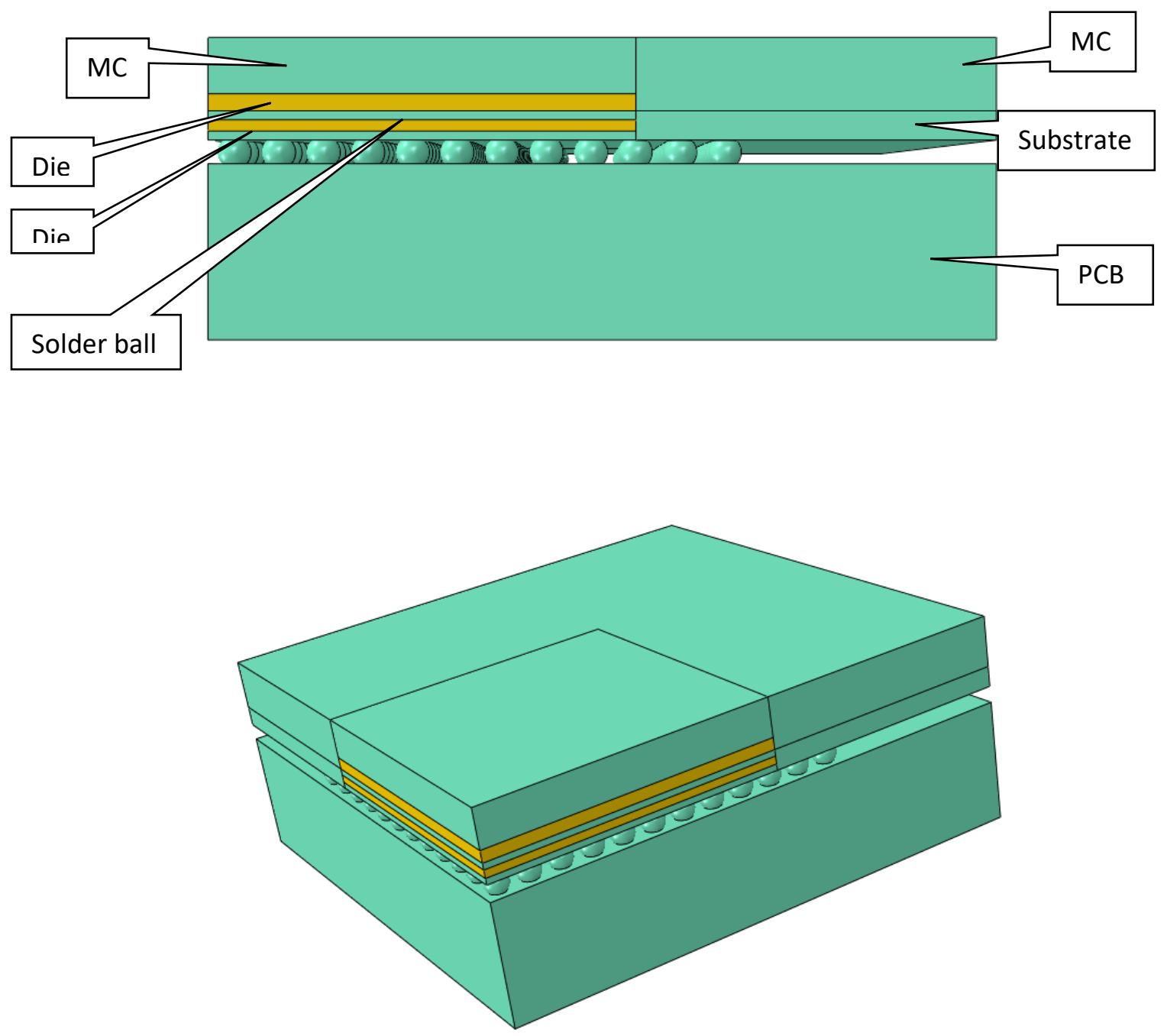

Figure 30 Two die molding compound - one die in MC and one die in substrate 37 


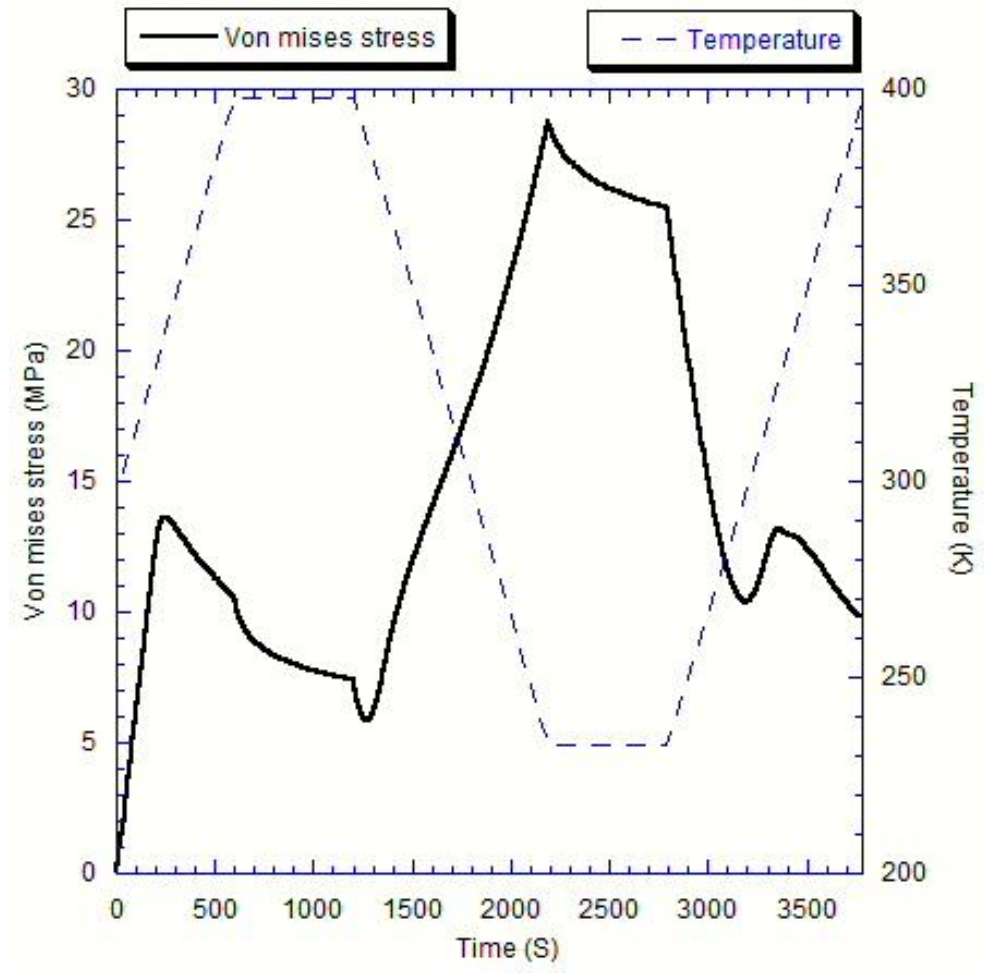

Figure 31 Variation of von Mises stress (Smises) during thermal cycling - .05 mm thickness 2 die model 


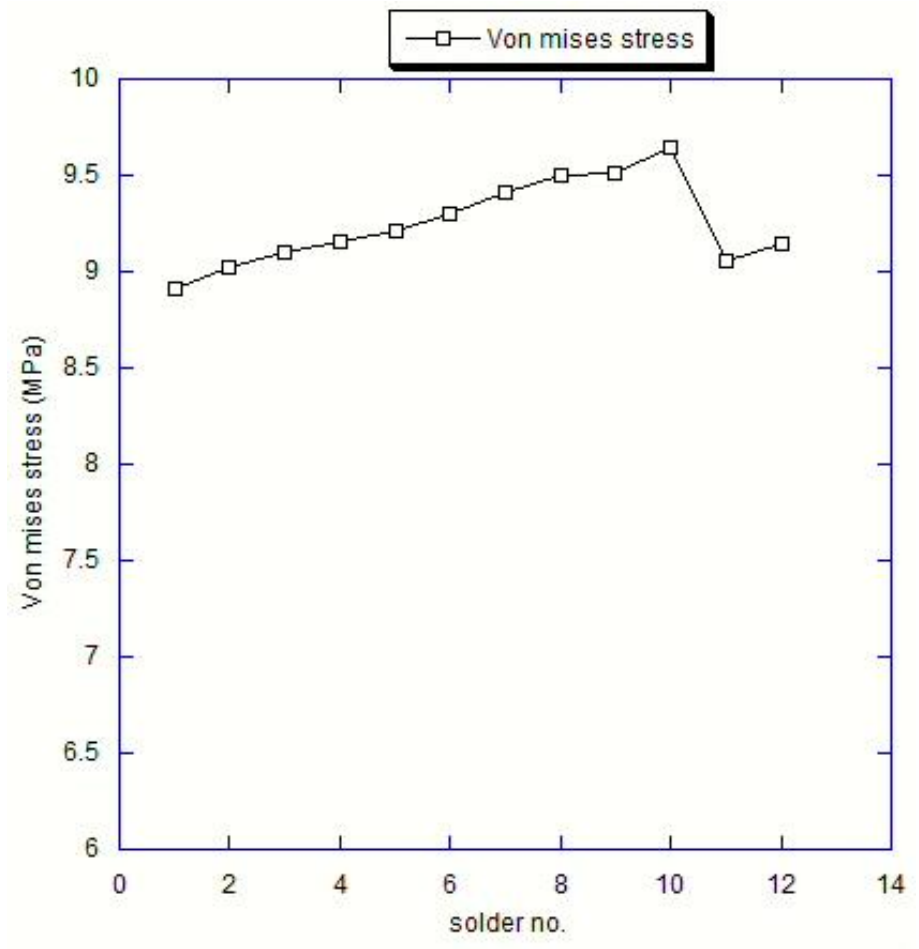

\begin{tabular}{|c|l|}
\hline $\begin{array}{c}\text { Solder } \\
\text { no. }\end{array}$ & \multicolumn{1}{|c|}{ Von mises } \\
\hline 1 & 8.913 \\
\hline 2 & 9.018 \\
\hline 3 & 9.100 \\
\hline 4 & 9.155 \\
\hline 5 & 9.207 \\
\hline 6 & 9.298 \\
\hline 7 & 9.413 \\
\hline 8 & 9.504 \\
\hline 9 & 9.507 \\
\hline 10 & $\mathbf{9 . 6 4 6}$ \\
\hline 11 & 9.054 \\
\hline 12 & 9.147 \\
\hline & \\
\hline
\end{tabular}

Figure 32 Variation of von Mises stress in the diagonal solder balls - .05 mm thickness 2 die model 


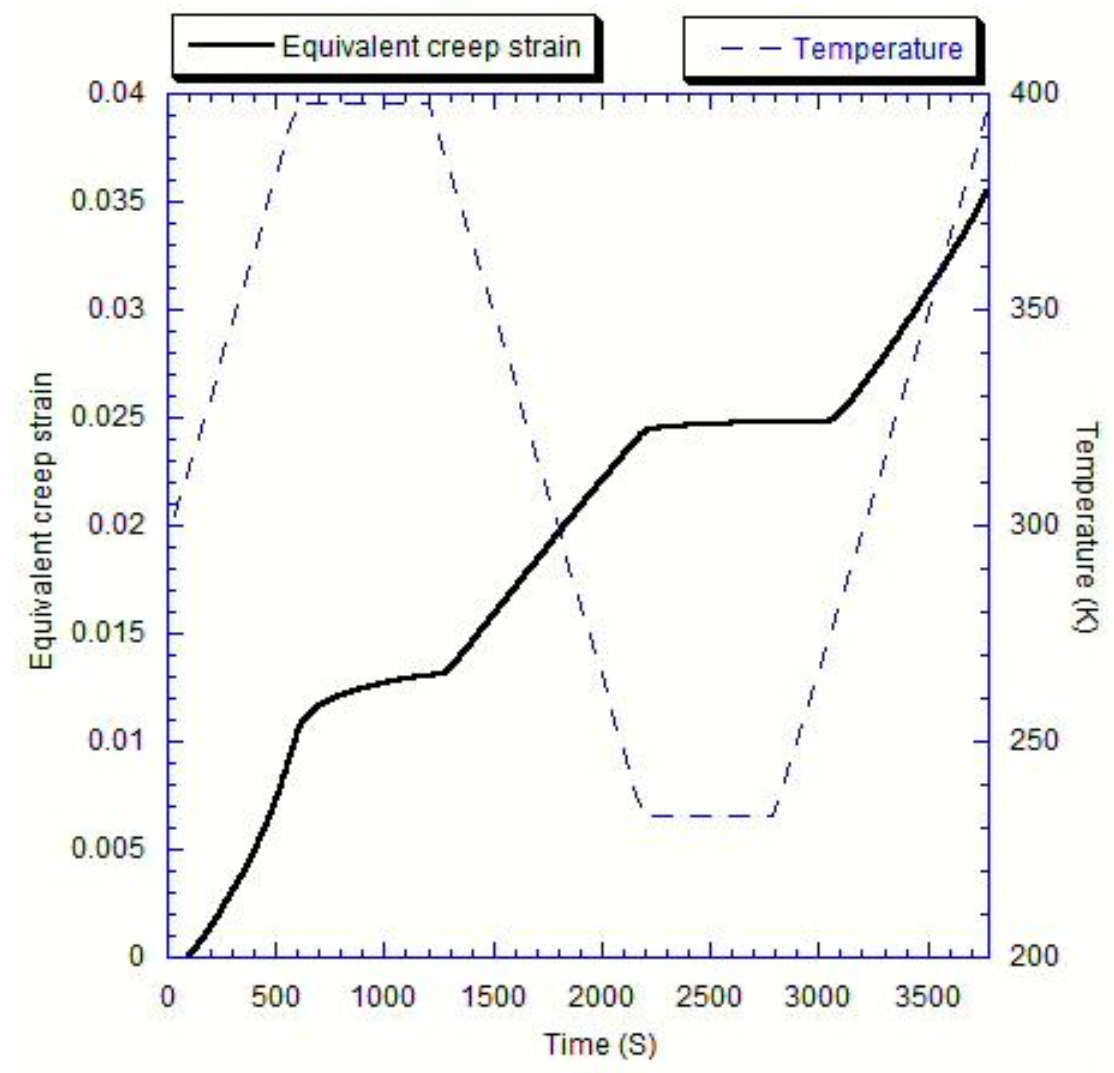

Figure 33 Variation of creep strain (CEEQ) during thermal cycling - .05 mm thickness 2 die model 

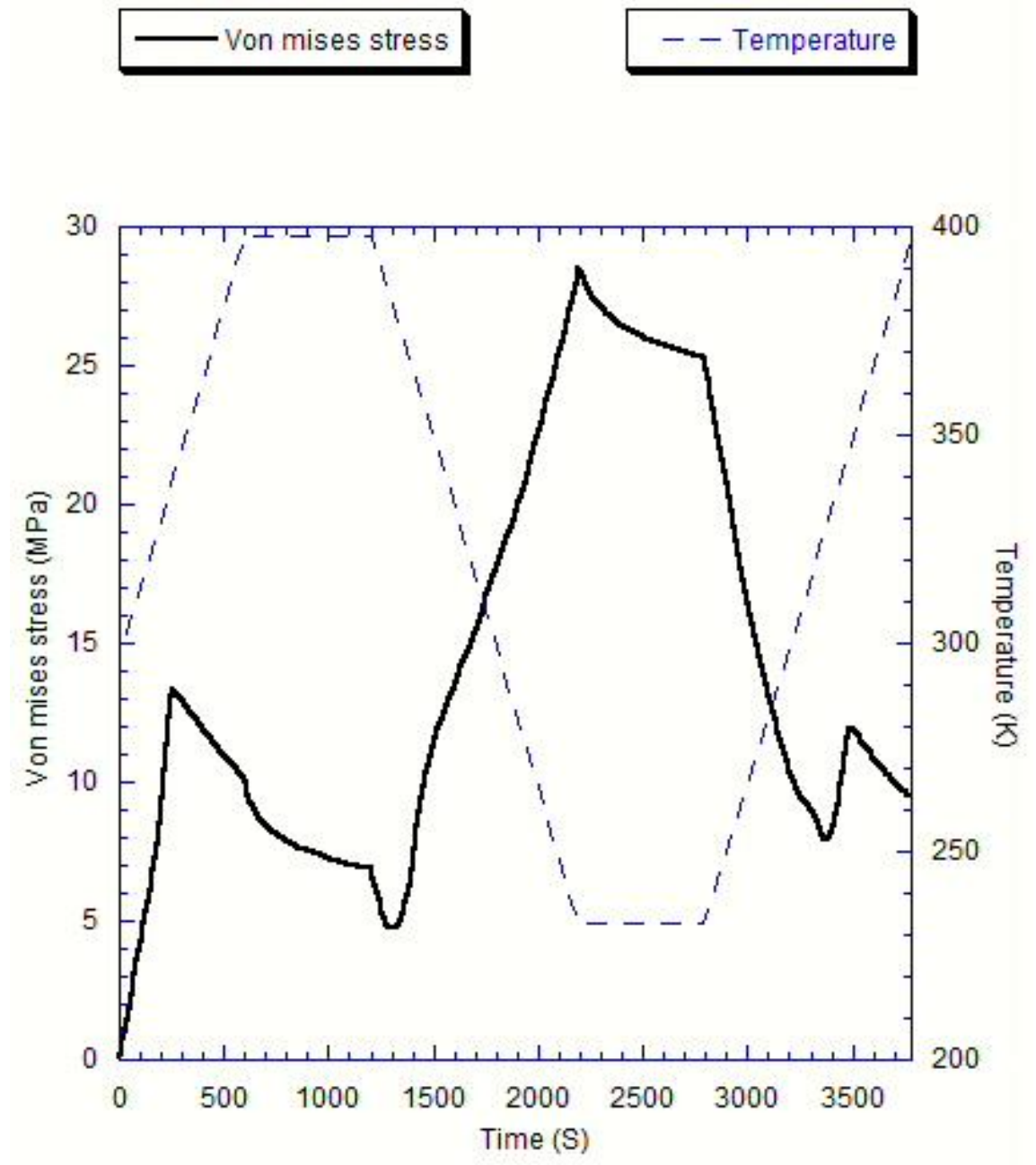

Figure 34 Variation of von Mises stress (Smises) during thermal cycling - $.075 \mathrm{~mm}$ thickness 2 die model 


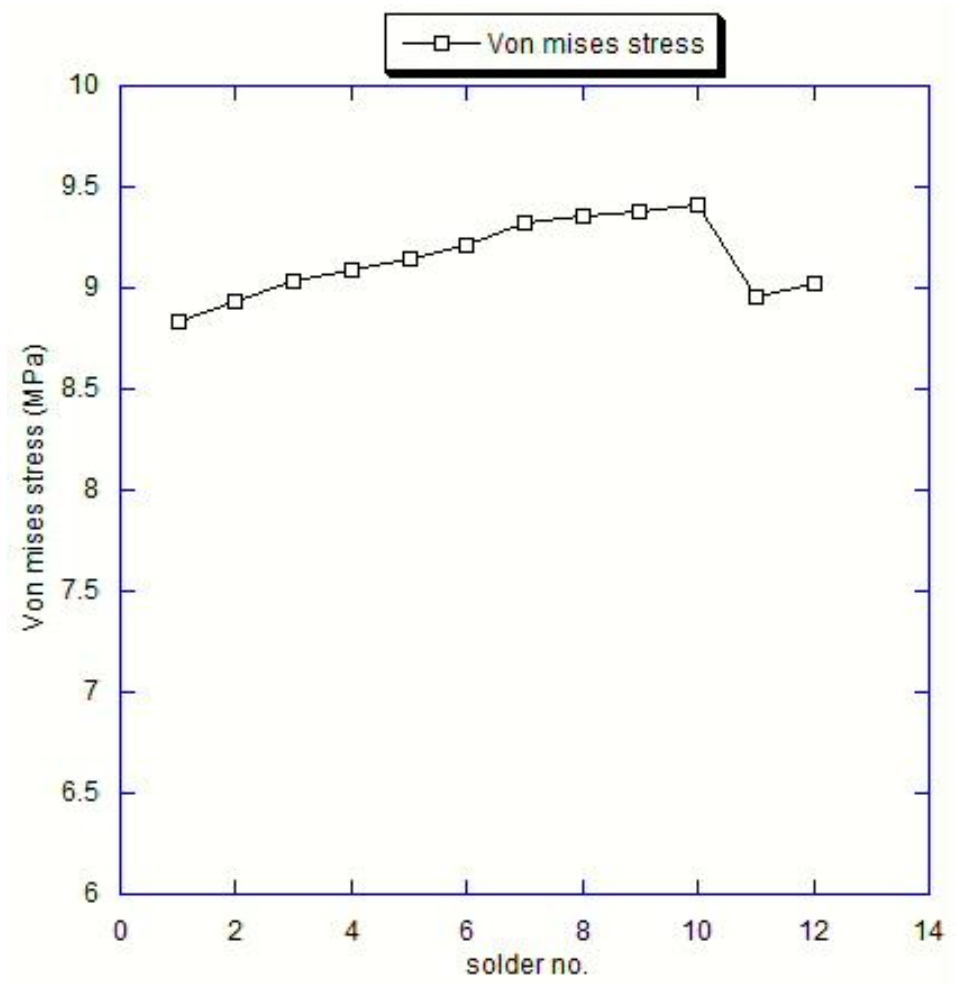

\begin{tabular}{|c|c|}
\hline Solder & Von mises \\
\hline no. & stress $(\mathrm{MPa})$ \\
\hline 1 & 8.839 \\
\hline 2 & 8.935 \\
\hline 3 & 9.031 \\
\hline 4 & 9.088 \\
\hline 5 & 9.146 \\
\hline 6 & 9.213 \\
\hline 7 & 9.325 \\
\hline 8 & 9.353 \\
\hline 9 & 9.375 \\
\hline 10 & 9.488 \\
\hline 11 & 8.955 \\
\hline 12 & 9.019 \\
\hline
\end{tabular}

Figure 35 Variation of von Mises stress in the diagonal solder balls - $.075 \mathrm{~mm}$ thickness 2 die model 


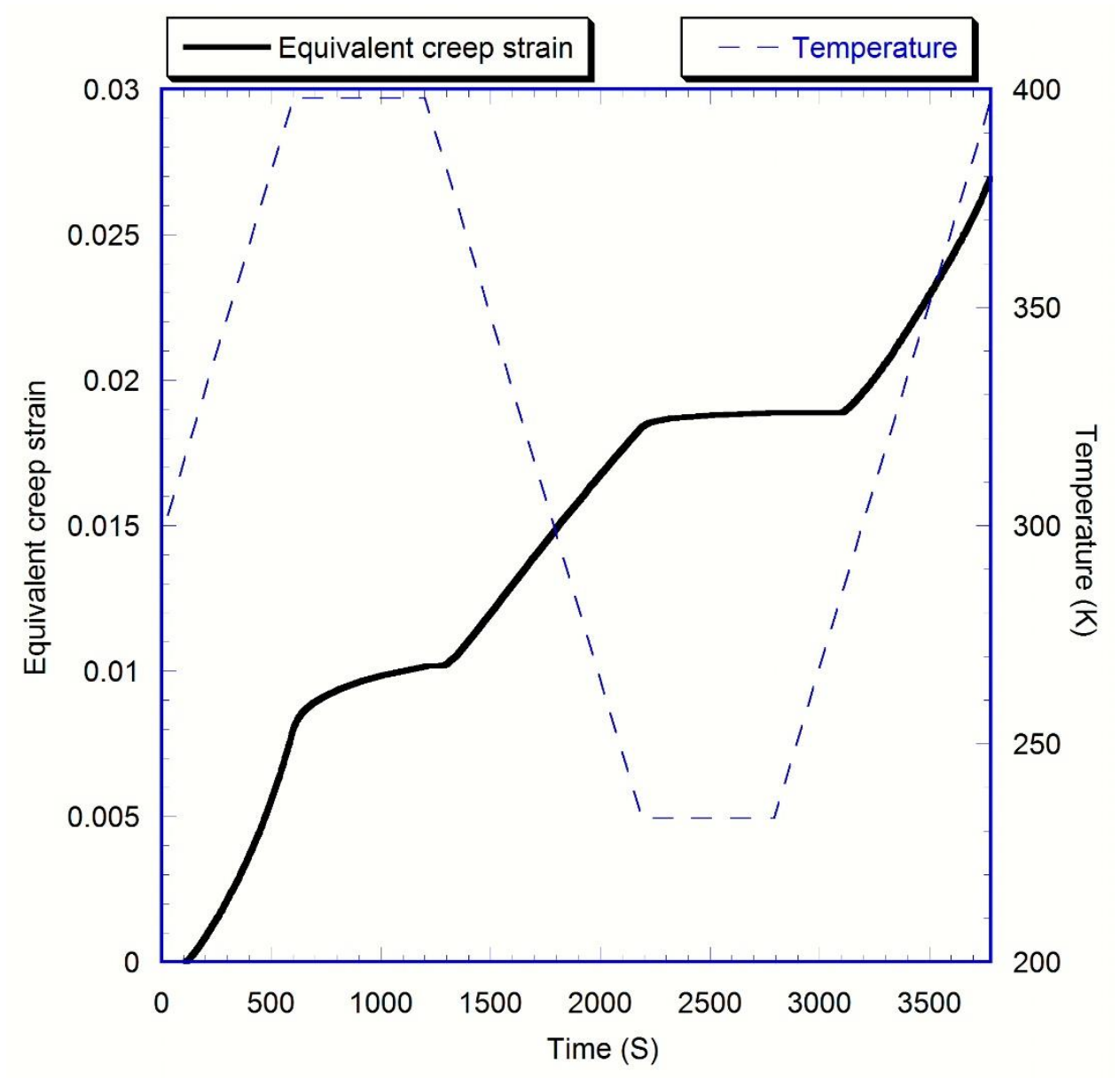

Figure 36 Variation of creep strain (CEEQ) during thermal cycling - .075 mm thickness 2 die model 


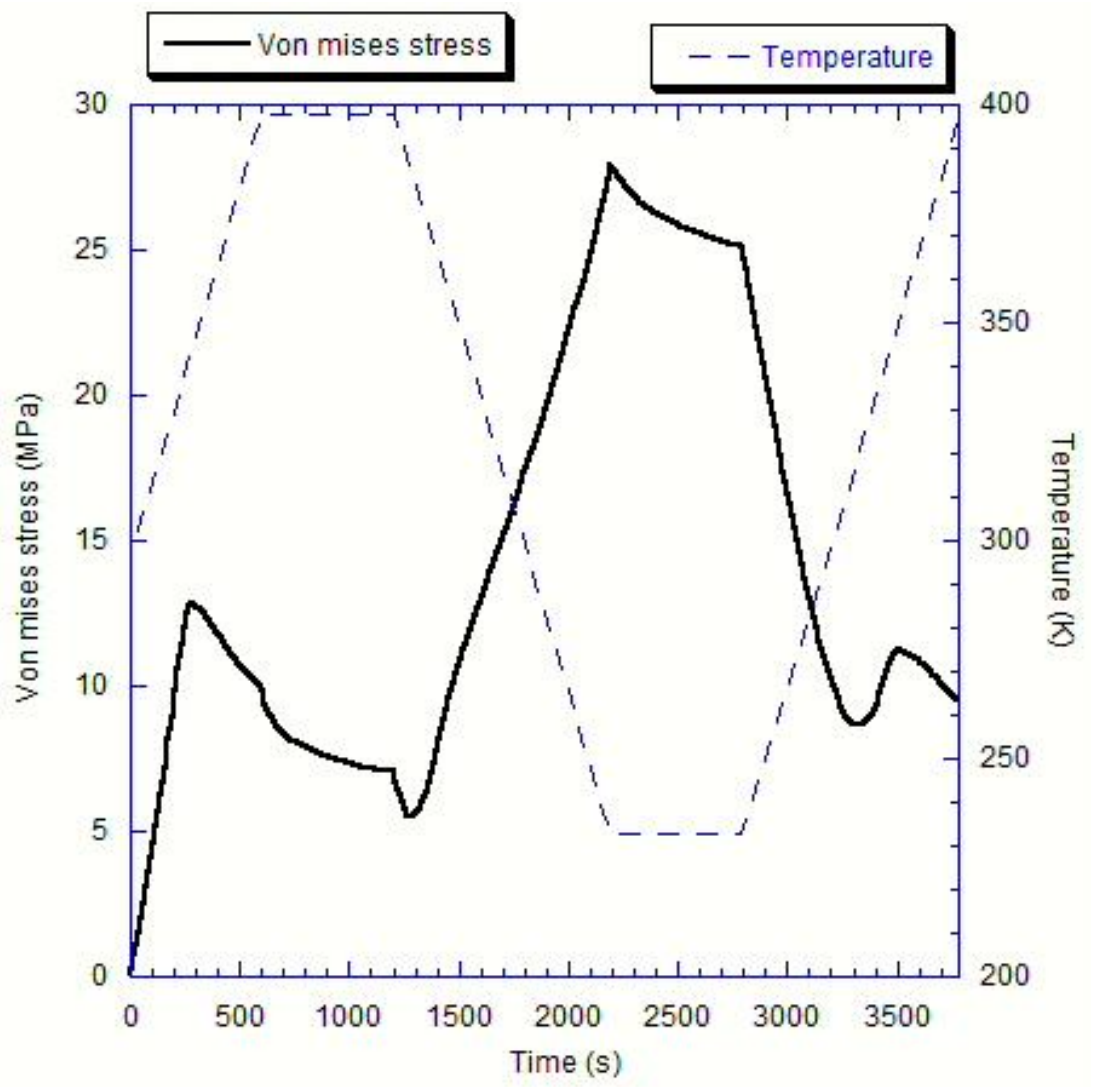

Figure 37 Variation of von Mises stress (Smises) during thermal cycling - .1 mm thickness 2 die model 


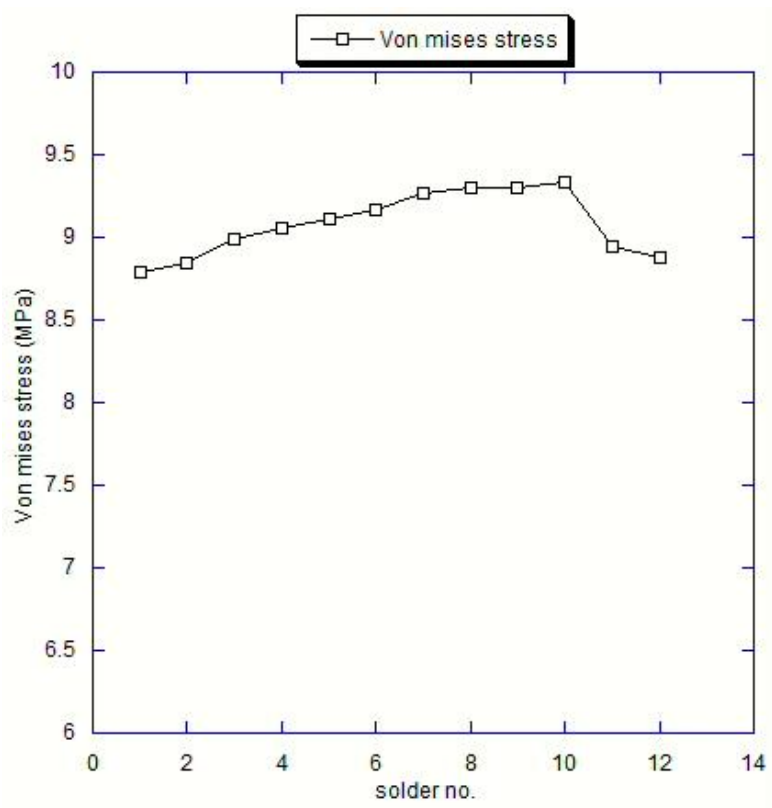

\begin{tabular}{|c|c|}
\hline Solder no. & $\begin{array}{c}\text { Von mises stress } \\
(\mathrm{MPa})\end{array}$ \\
\hline 1 & 8.784 \\
\hline 2 & 8.843 \\
\hline 3 & 8.988 \\
\hline 4 & 9.051 \\
\hline 5 & 9.116 \\
\hline 6 & 9.166 \\
\hline 7 & 9.267 \\
\hline 8 & 9.302 \\
\hline 9 & 9.301 \\
\hline 10 & 9.356 \\
\hline 11 & 9.945 \\
\hline 12 & 8.875 \\
\hline
\end{tabular}

Figure 38 Variation of von Mises stress in the diagonal solder balls - .01 mm thickness 2 die model 

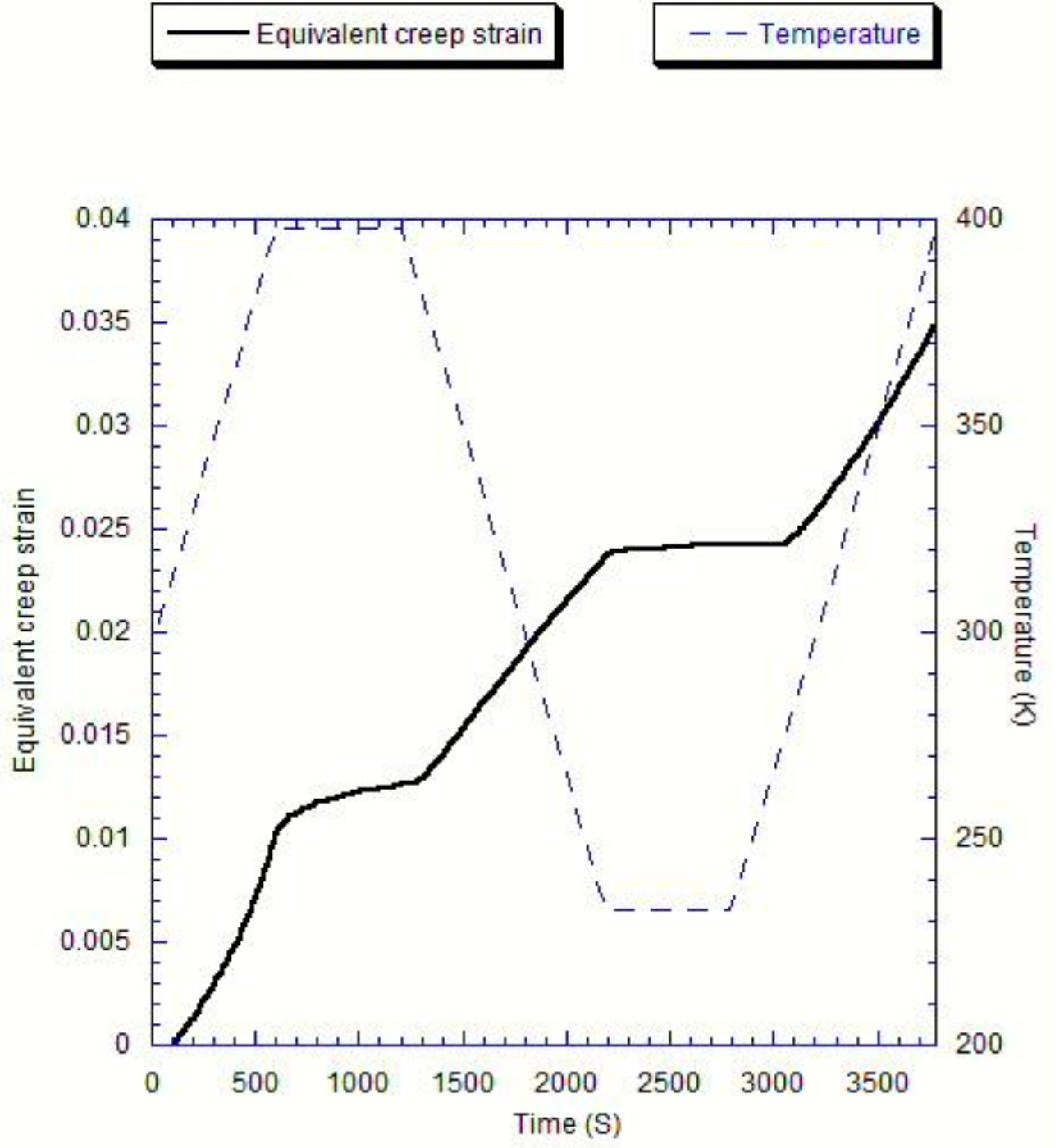

Figure 39 Variation of creep strain (CEEQ) during thermal cycling - .1 mm thickness 2 die model 


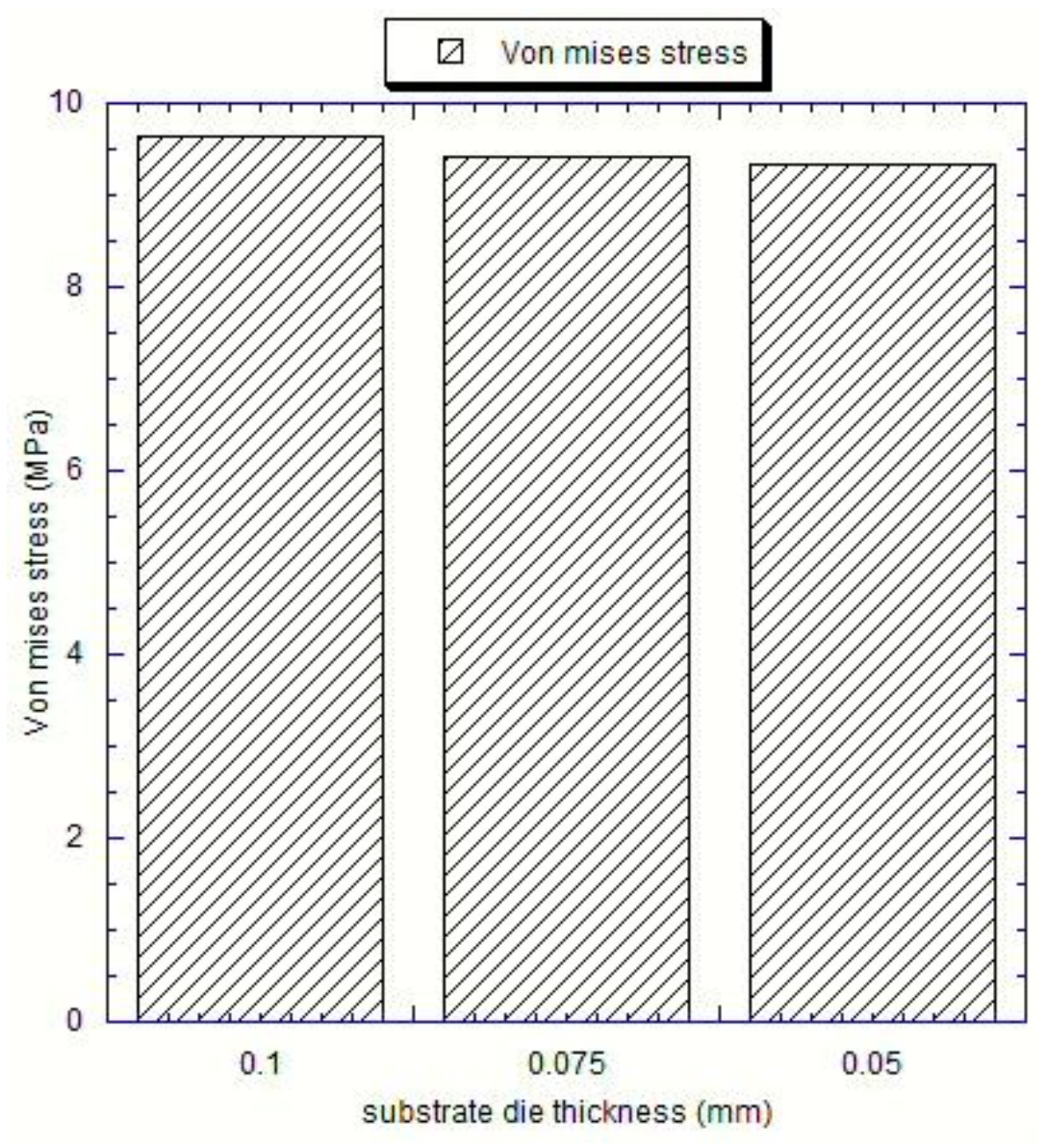

Figure 40 Bar plot comparison of von mises stress for the 2 die (substrate) model

In this case when the second die is added to the substrate instead of the molding compound, the maximum von mises stress is still observed in the J10 solder ball. Also an increase is seen in the stress values with a increase in the substrate die thickness with value of $.82 \%$ and $3.26 \%$ respectively. 


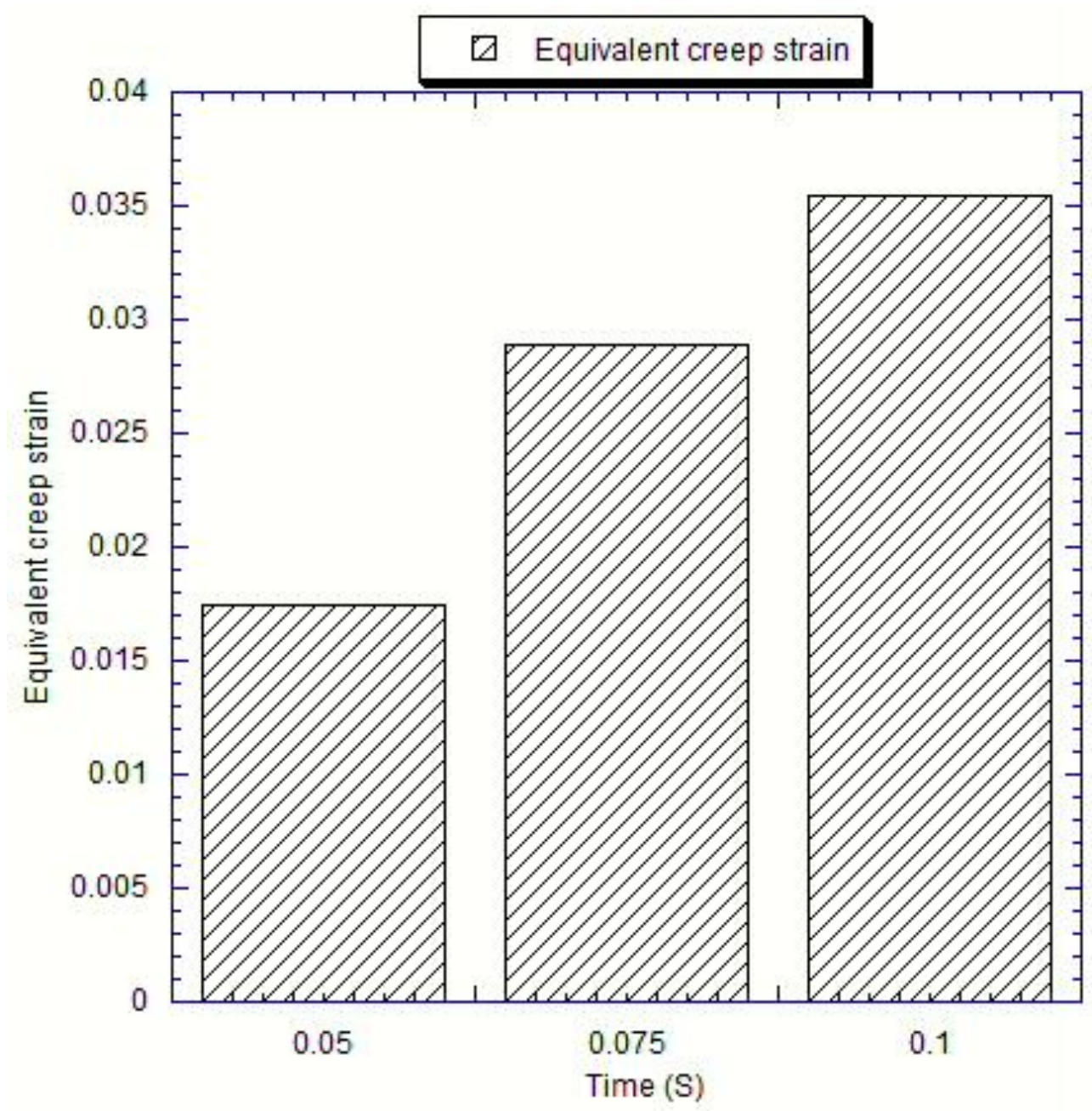

Figure 41 Bar plot comparison of creep strain for the 2 die (substrate) model

The increase in creep strain is more significant as shown above with increase in substrate die thickness with values of $19.65 \%$ and $103.322 \%$ respectively. 


\subsection{Three dies in model:}

We built up a model in which a die is embedded in the substrate layer and two dies in MC part. We will keep the die thickness in MC part is $0.12 \mathrm{~mm}$ and try different thickness die in substrate layer, the thickness will be $0.05 \mathrm{~mm}, 0.75 \mathrm{~mm}$ and $0.1 \mathrm{~mm}$.
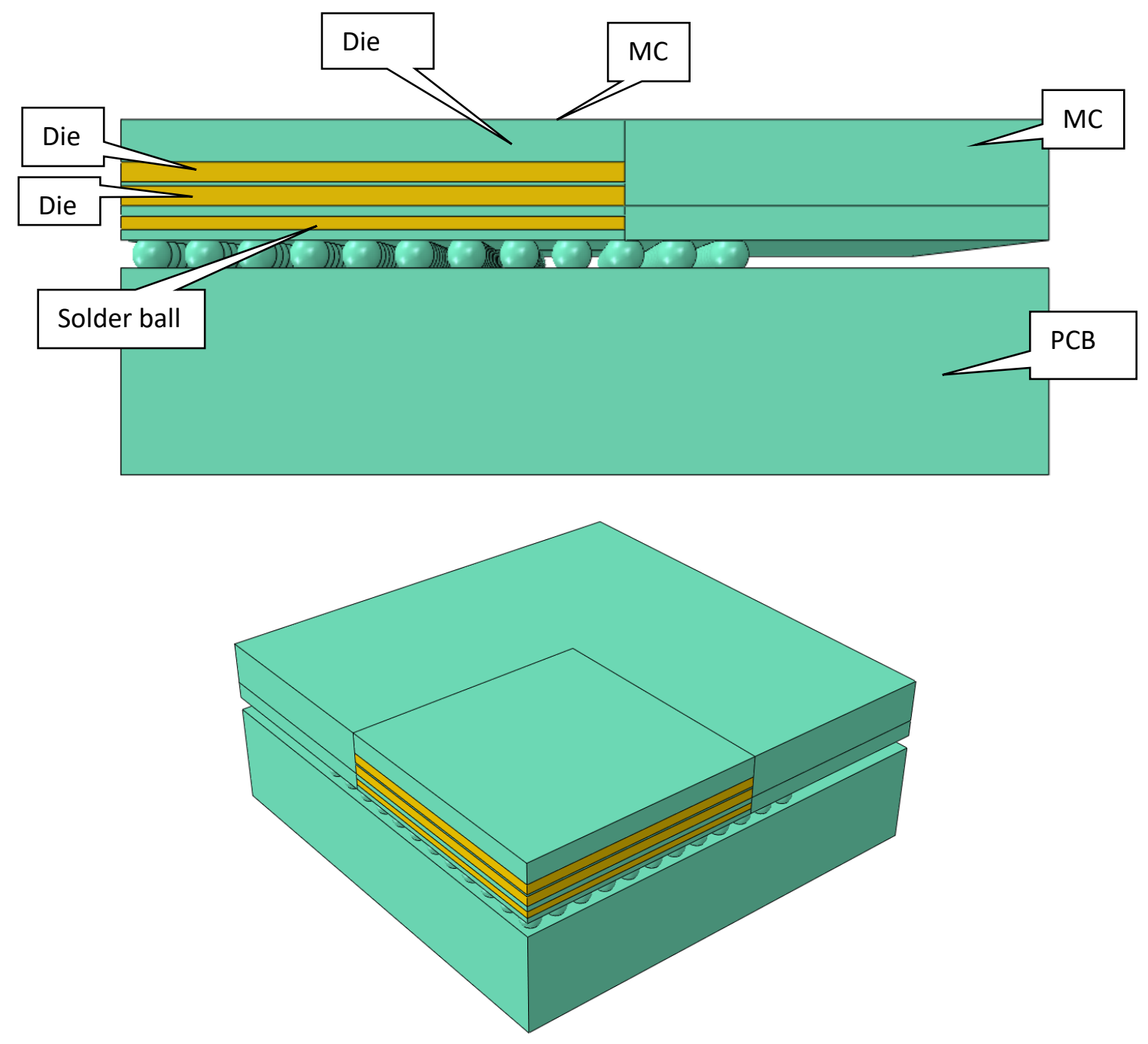

Figure 42 Two dies in molding compound and one die in substrate model 


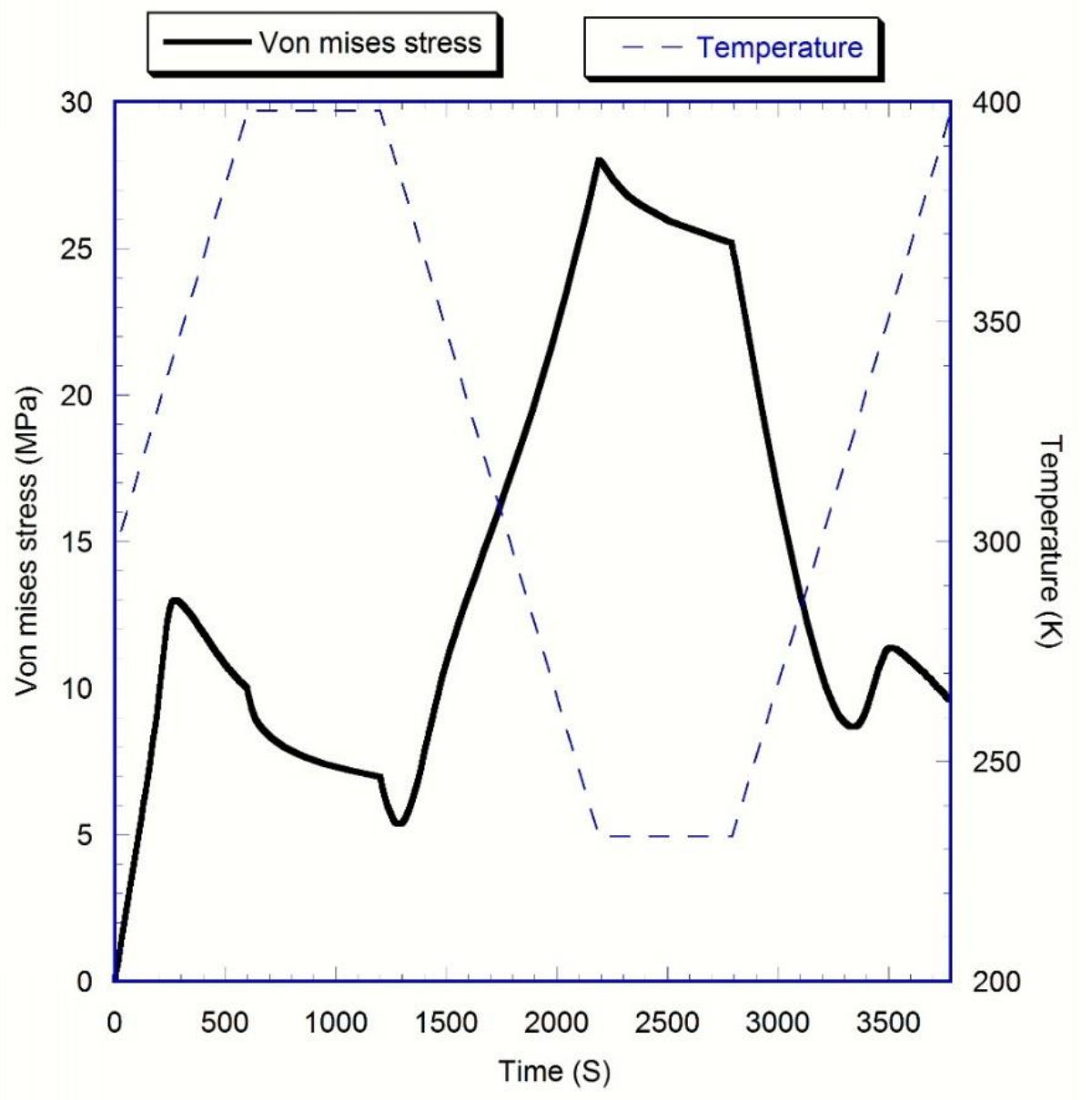

Figure 43 Variation of von Mises stress (Smises) during thermal cycling - .05 mm thickness 3 die model 


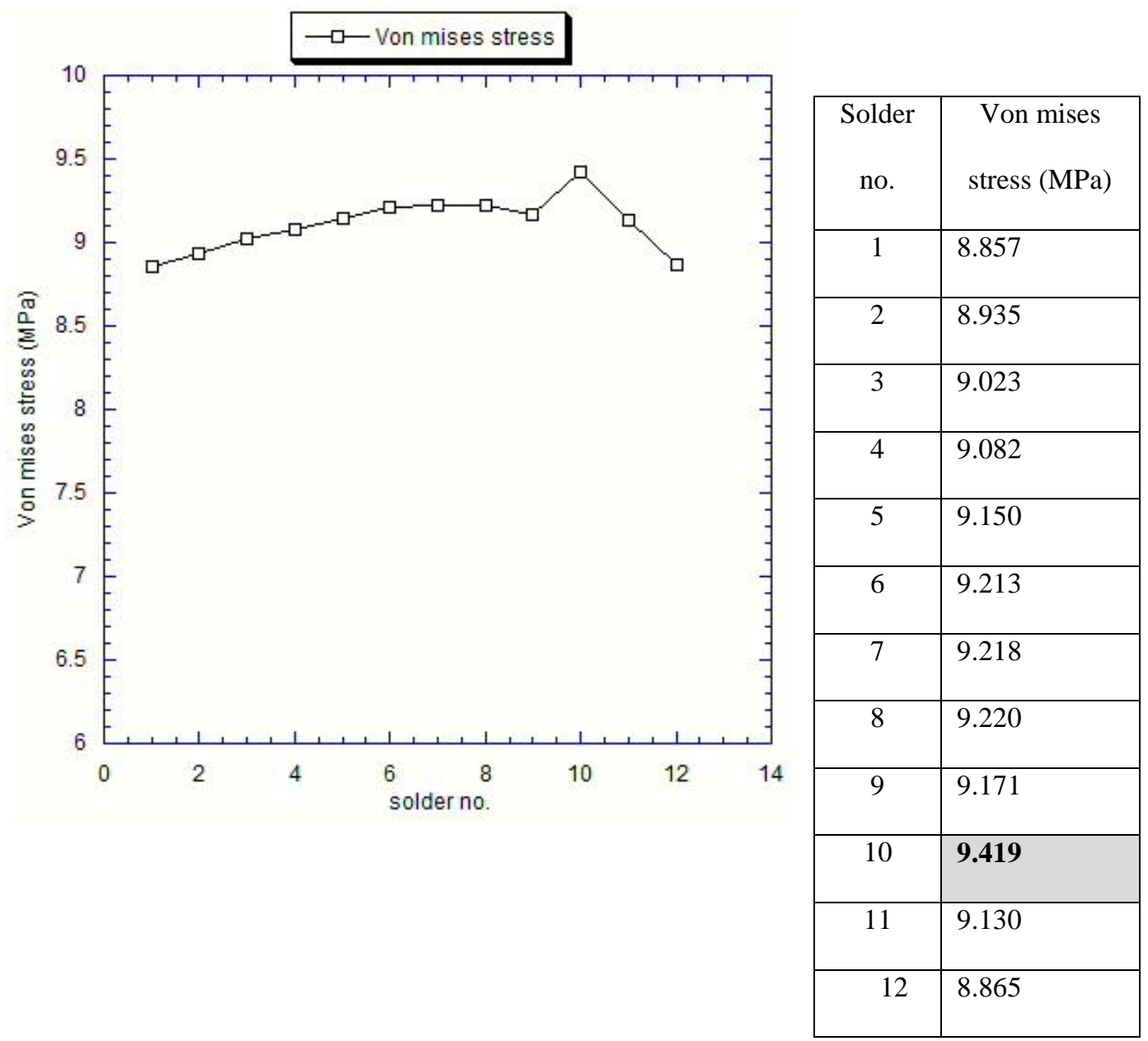

Figure 44 Variation of von Mises stress in the diagonal solder balls - .05 mm thickness 3 die model 


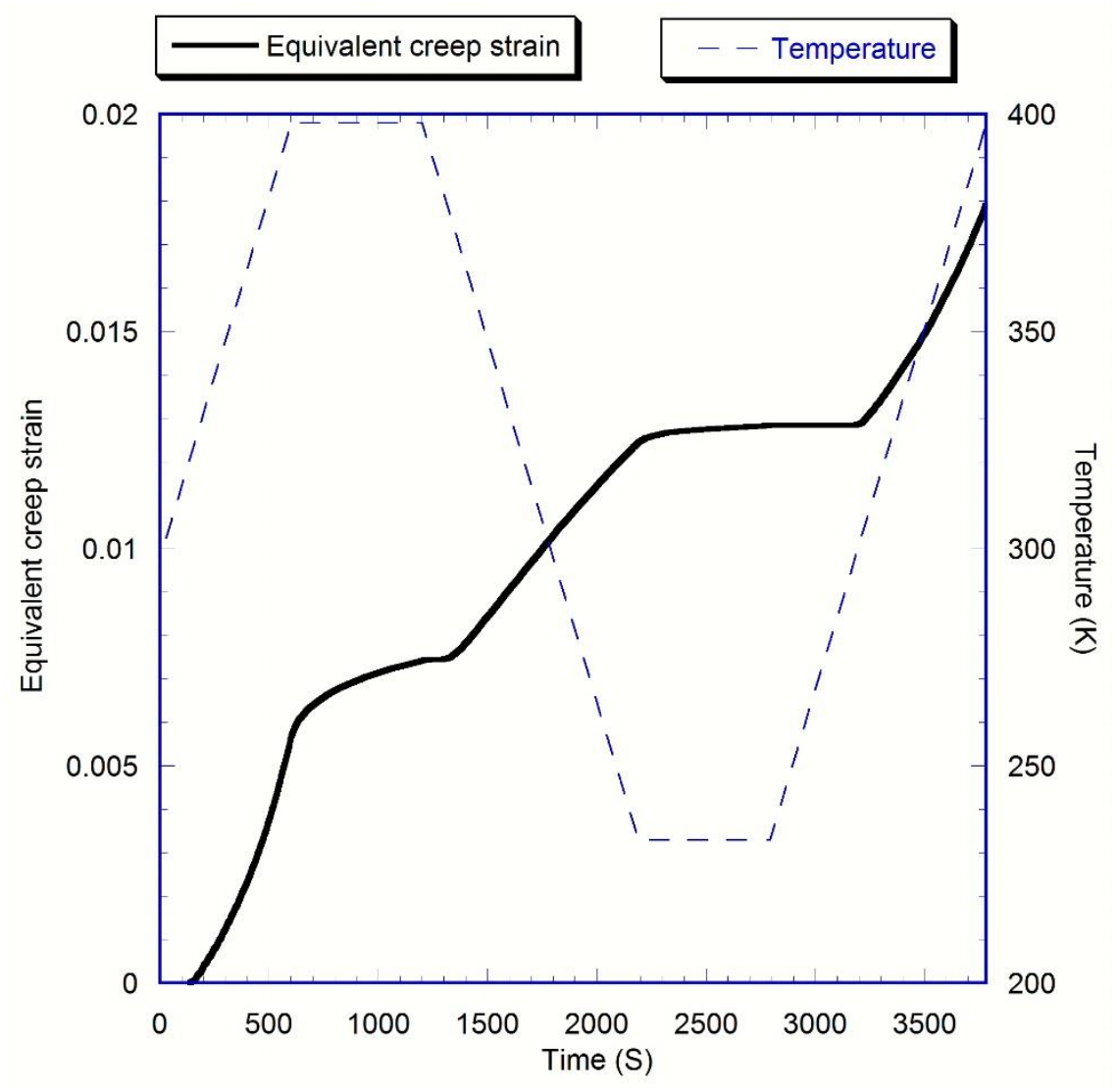

Figure 45 Variation of creep strain (CEEQ) during thermal cycling - .05 mm thickness 3 die model 


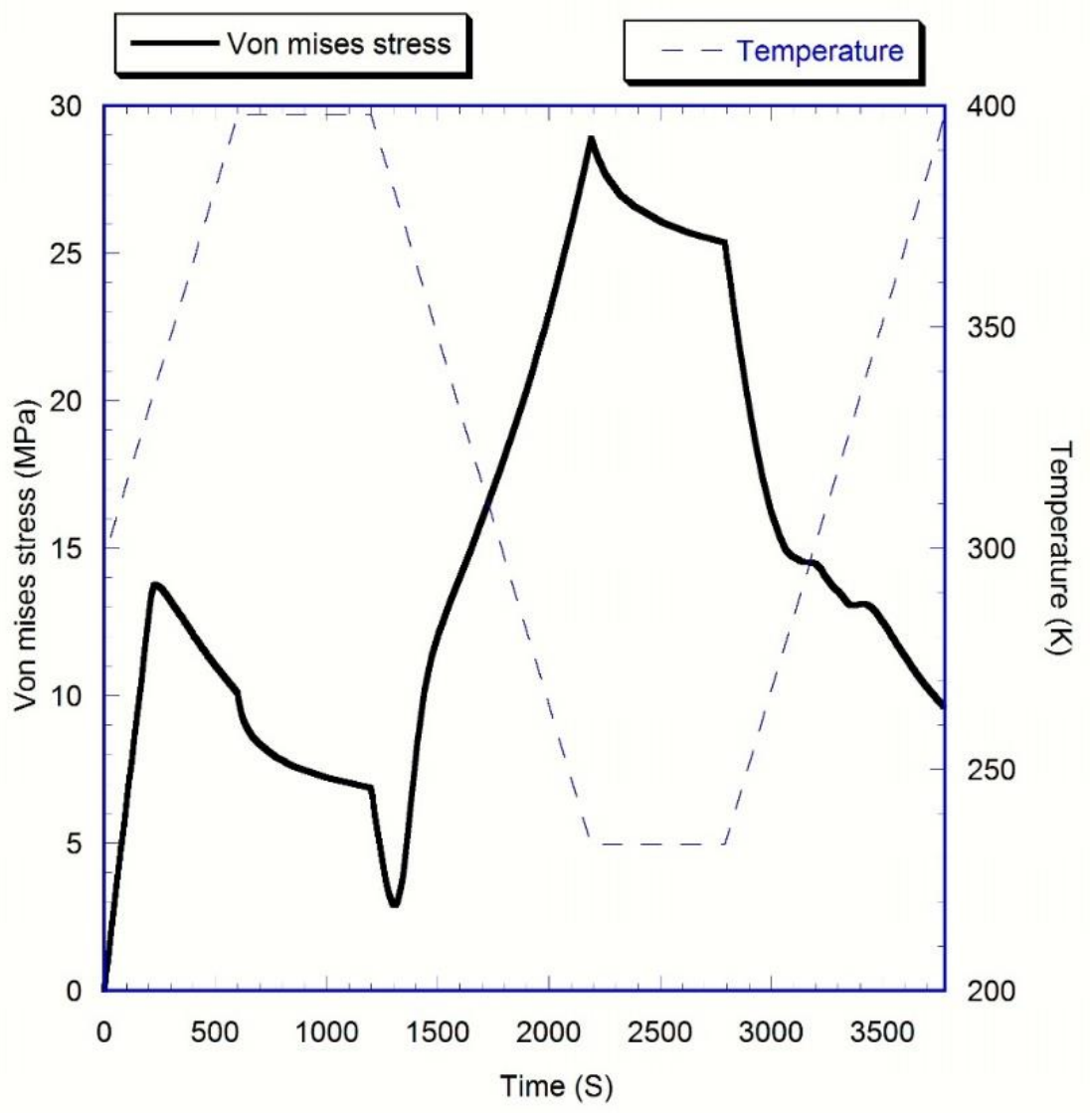

Figure 46 Variation of von Mises stress (Smises) during thermal cycling - $.075 \mathrm{~mm}$ thickness 3 die model 


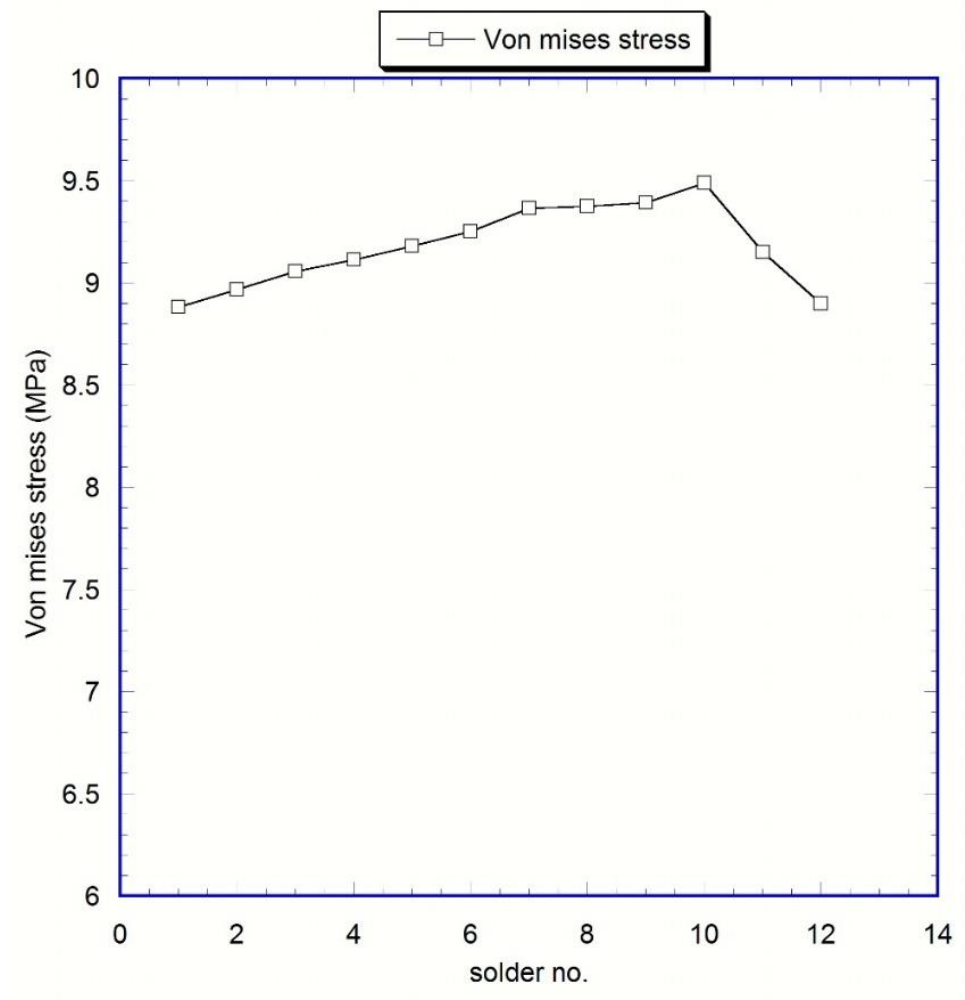

\begin{tabular}{|c|l|}
\hline $\begin{array}{c}\text { Solder } \\
\text { no. }\end{array}$ & \multicolumn{1}{c|}{ Von mises } \\
\hline 1 & 8.882 \\
\hline 2 & 8.9690 \\
\hline 3 & 9.0580 \\
\hline 4 & 9.1150 \\
\hline 5 & 9.1800 \\
\hline 6 & 9.2530 \\
\hline 7 & 9.3670 \\
\hline 8 & 9.3750 \\
\hline 9 & 9.3930 \\
\hline 10 & 9.4880 \\
\hline 11 & 9.1500 \\
\hline 12 & 8.8990 \\
\hline & \\
\hline 10.9
\end{tabular}

Figure 47 Variation of von Mises stress in the diagonal solder balls - .075 mm thickness 2 die model 


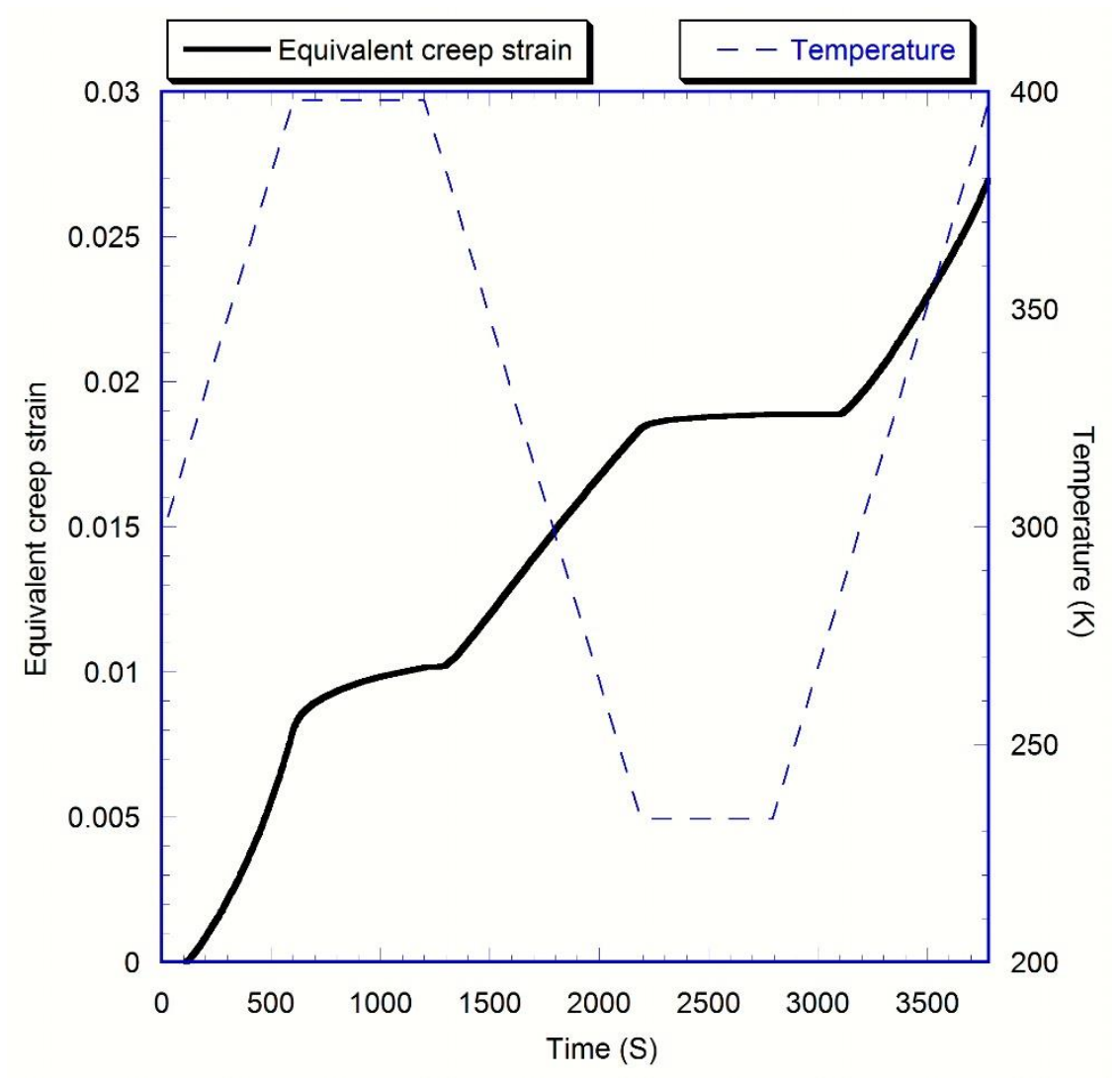

Figure 48 Variation of creep strain (CEEQ) during thermal cycling - .075 mm thickness 3 die model 


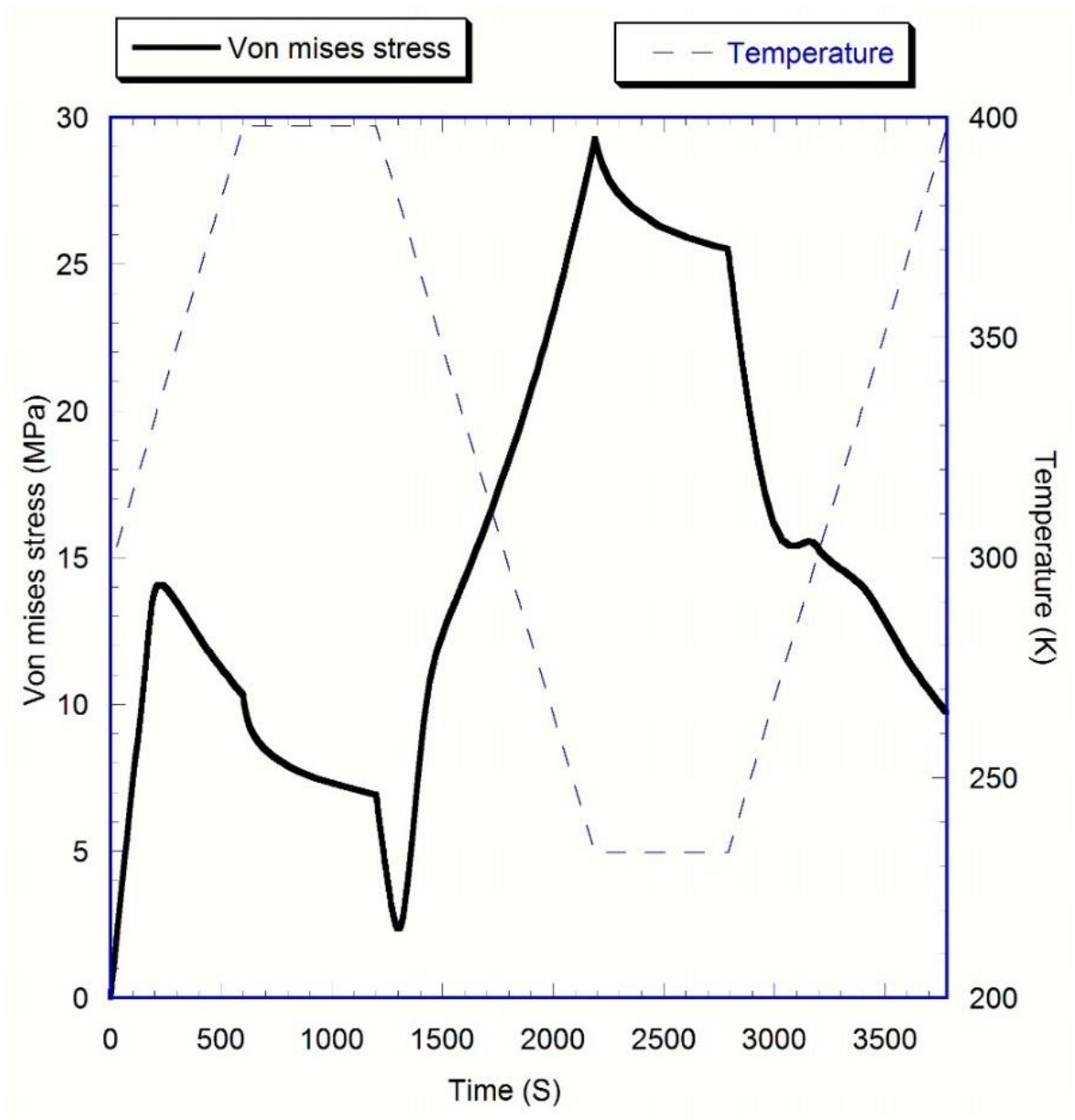

Figure 49 Variation of von Mises stress (Smises) during thermal cycling - .1 mm thickness 3 die model 


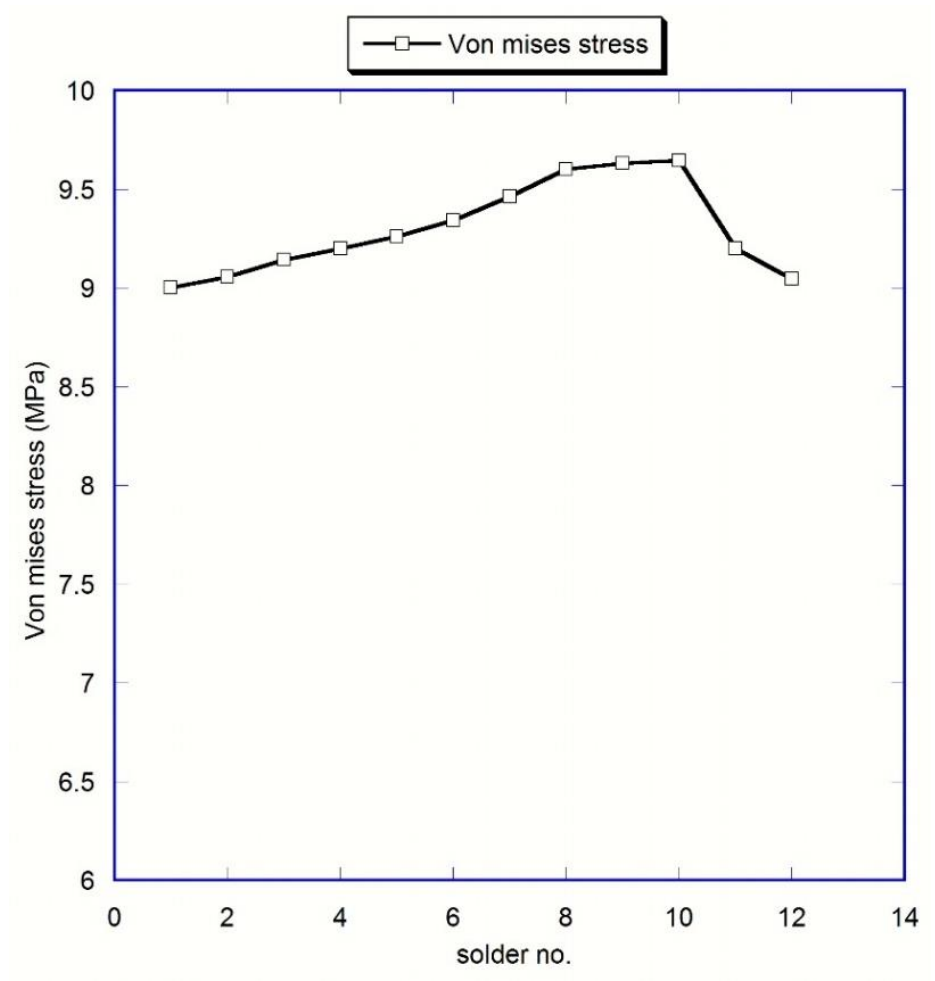

\begin{tabular}{|c|c|}
\hline Solder & Von mises \\
no. & stress \\
(MPa)
\end{tabular}

Figure 50 Variation of von Mises stress in the diagonal solder balls - .1 mm thickness 2 die model 

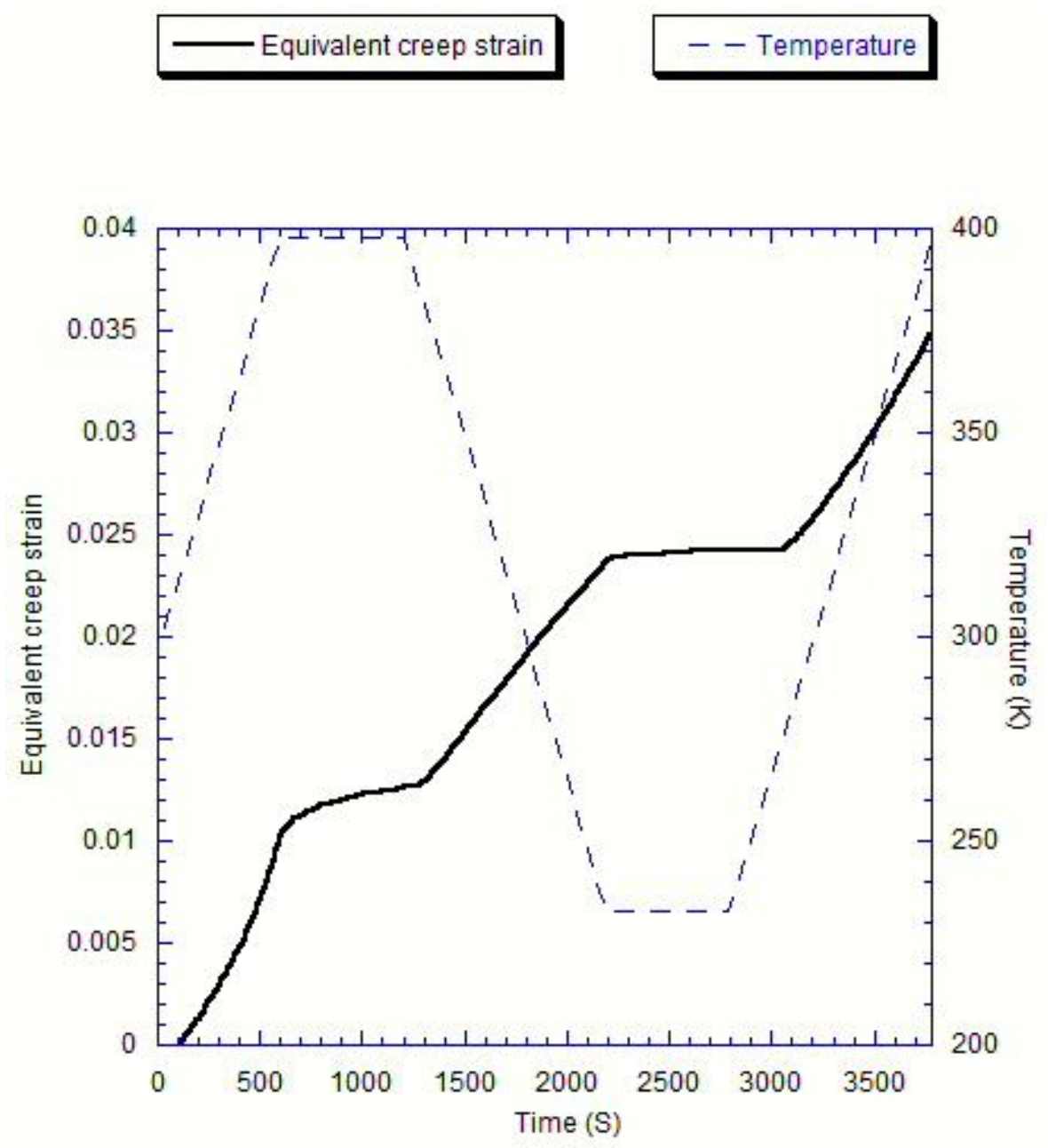

Figure 51 Variation of creep strain (CEEQ) during thermal cycling - $.1 \mathrm{~mm}$ thickness 3 die model 


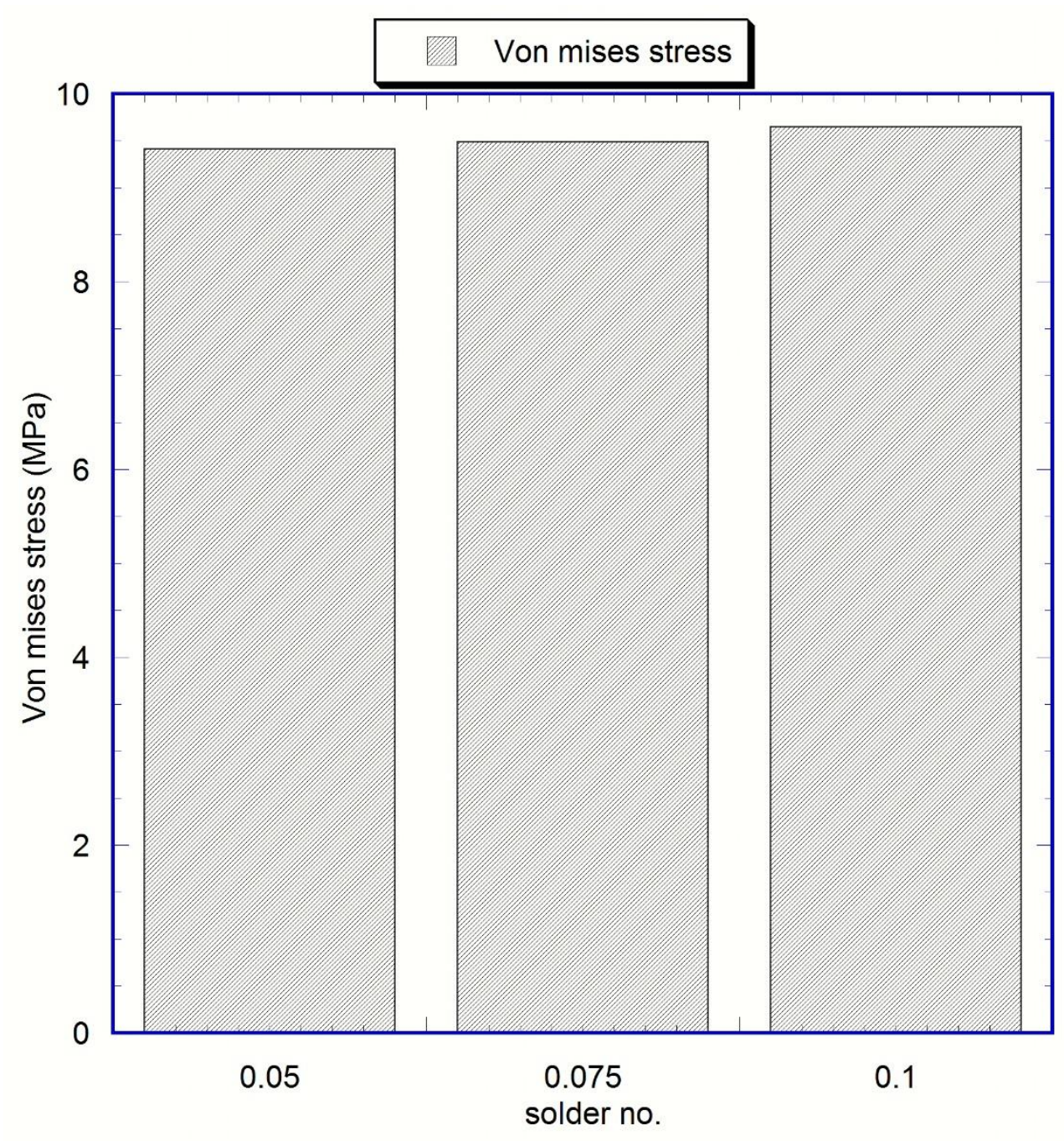

Figure 52 Bar plot comparison of von mises for the 3 die model

In the case of the three die model the maximum von mises stress is again still observed in the J10 solder ball. Also an increase is seen in the stress values with a increase in the substrate die thickness with value of $.73 \%$ and $2.43 \%$ respectively. 


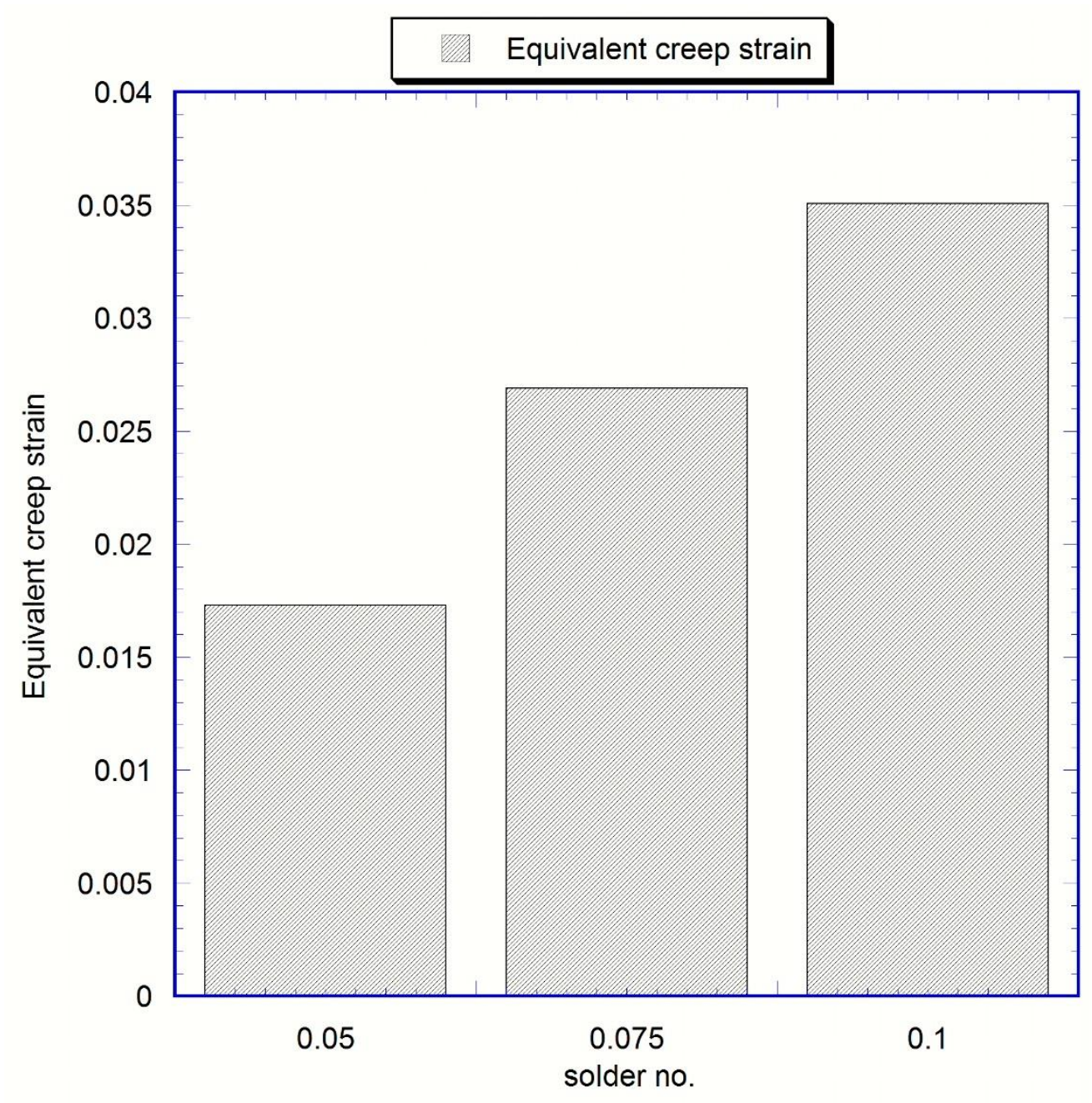

Figure 53 Bar plot comparison of creep strain for the 3 die model

The increase in creep strain is more significant as shown above with increase in substrate die thickness with values of $50.11 \%$ and $95.65 \%$ respectively. 


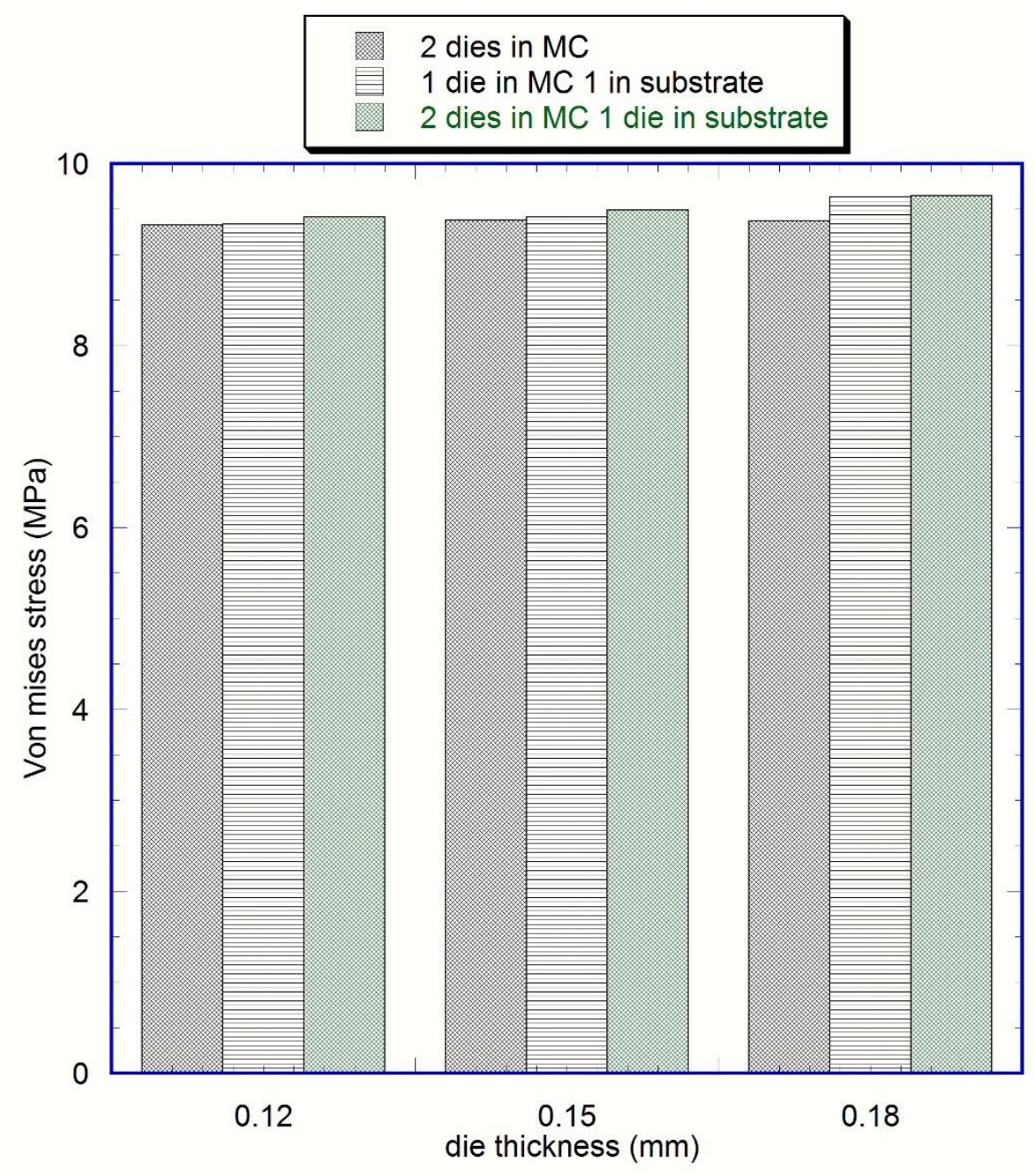

Figure 54 Bar plot comparison of creep strain for the 3 die model

Comparing all results of multiple die models, it can be observed that when the die is in the substrate the max. von mises stress in the solder ball is higher than when the die is in the molding compound part. 


\section{Chapter 5. Conclusions:}

The viscoplastic von mises stress in the eBGA is highly nonlinear and relaxes during dwelling. During the temperature ramp up, the magnitude of stresses decrease due to the reduction of Young's modulus of the solder.

Irrespective of increasing the number of dies the maximum stress and creep strain always lies in the J10th solder ball.

Von mises stress and creep strain increased with increasing die thickness. The increase in von mises stress is very small. This could possibly be because of the coarseness of the mesh used. Embedding more dies in the package resulted in an increase in the von mises stress especially in the J10th solder ball.

Impact of embedding a die in the substrate has a greater significance in increasing the von mises stress and creep strain. This is because when the die is embedded in the substrate, the stress caused by the effect of mismatch of the die between die and substrate is near the solder ball and can be transferred to the solder ball easily. Mesh density affected the result significantly. 


\section{References}

- Mohammad Motalab et.al, Determination of Anand constants for SAC Solders using Stress-Strain or Creep Data, 13th IEEE ITHERM Conference, may 2012

- Liang Zhang et al. Anand constitutive model of lead-free solder joints in 3D IC device, Journal of Physics: Conference Series 738 (2016) 012050.

- Sung Yi Kyungo Kim Dongwan Lee Hongwon Kim Taesung Jung, (2013),"Embedded passive device technology for wirelessmobile devices", Microelectronics International, Vol. 30 Iss 1 pp. 33 - 39

- Da Yu et. Al, Reliability assesmnt of preloaded solder joint under thermal cycling, Journal of Electronic Packaging, december 2012

- Morris, J.W. Jr., Song, H.G. and Hua, F. (2003) 'Creep Resistance of Sn-rich Solder Joints', Proceedings of 53rd Electronic Components and Technology Conference, pp. 54-57.

- Yi, Sung, Luo, G. and Chian, K.S. (2002) 'A Viscoplastic Constitutive Model for 63Sn37Pb Eutectic solders', ASME: Journal of Electronic Packaging, Vol. 124, pp. 91-96.

- Yi, Sung, Daharwal, Paresh D., Lee, Yeong J. and Harknewss, Brain R. (2005) 'Effect of Low-modulus Die Attach Adhesive on Warpage and Damage of BGA', Proceedings of International Symposium on Electronic Materials and Pcakgaging, pp. 162-168. 
- Yi, Sung and Lam, Tatiana M., (2012) "Analysis of warpage and residual stress in plastic ball grid array package after post mold cure", Microelectronics International, Vol. 29 Iss: 3, pp.163 - 171

- Zhang, Q., Dasqupta, A., Nelson, D. and Pallavicini, H. (2005) 'Systematic Study on Thermo-Mechanical Durability of Pb-free Assemblies: Experiments and FE Analysis', ASME: Journal of Electronic Packaging, Vol.127, pp. 415-429, 2005.

- Zhong, C.H. and Yi, S. (1998) 'Effects of Ball Pad Metallurgy and Ball Composition on Solder Ball Integrity of Plastic Ball Grid Array Packages', Proceedings of the 24th International Symposium for Testing and Failure Analysis, pp. 405-409.

- Zhong, C. H. and Yi, Sung, (1999), 'Solder Joint Reliability of Plastic Ball Grid Array Packages', Soldering and Surface Mount Technology, UK, Vol. 11, No. 1, pp.44-48. 